Universidad Nacional de La Plata

Facultad de Humanidades y Ciencias de La Educación

SeCretaria de Posgrado

\title{
Reflexiones sobre la tecnología disciplinar en la práctica deportiva
}

\author{
Prof. Juan Cruz Medina
}

Tesis para optar por el grado de Magister en Deporte

Director: Dr. Ricardo Crisorio (UNLP)

Co-director: Mg. Agustín Lescano (UNLP) 


\section{AGRADECIMIENTOS}

A mi padre, por las lecturas, las devoluciones, las charlas y los préstamos de libros. A mis compañeros (que también son amigos), Fermín Urtasun, Martín Jaime, Rodo Ojeda, por lo que me han enseñado de fútbol y por la paciencia de todos estos años. A Ariel Benavidez, con quien tenemos cientos de horas de charlas sobre el deporte y su enseñanza. A alumnos y padres que son el frontón con el que trabajo a diario en el laboratorio.

A Ricardo Crisorio, quien a esta altura es un amigo y al que agradezco lo que me enseña. A Agustín Lescano, quien me ayudó a dar el primer paso en la vida académica y en esta tesis. A Marcelo Giles y sus teóricos que fueron fuente de consulta para pensar el deporte; a Carolina Escudero que siempre tuvo un espacio de tiempo para mí y a Valeria Emiliozzi por su apoyo constante para que finalice este proceso. A Adrián Casas por hacer las cosas más fáciles. A Eduardo Galak y a Emiliano Gambarotta que me ayudaron sin saberlo y especialmente a Sabrina Carnez y Daiana Melón por su predisposición, dedicación y motivación al momento de sus minuciosas correcciones.

A mis padres por sus consejos y por esa forma de estar siempre; a mis hermanos y amigos que son lo necesario para que todo siga más o menos bien. A Sabri por las correcciones, las charlas, el apoyo, la paciencia y el aguante incondicional, sin ella todo es más difícil y aburrido. 


\section{INDICE}

CAPITULO I: SOBRE LA CIVILIZACIÓN Y LA PRÁCTICA DEPORTIVA.....................16

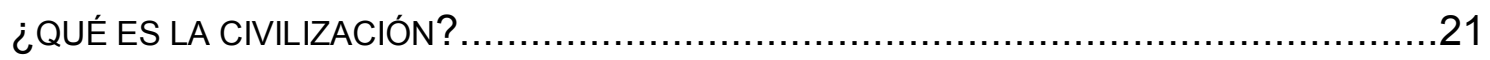

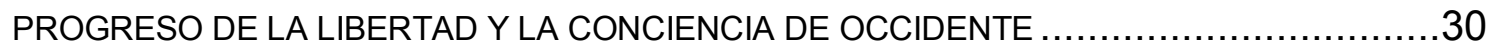

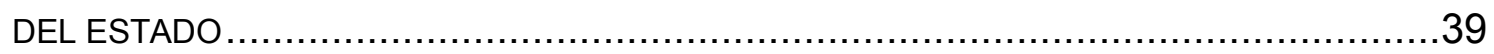

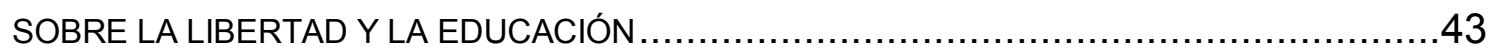

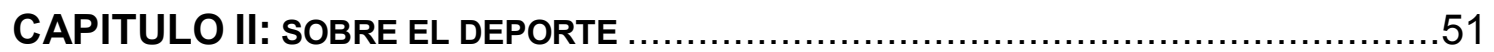

ETIMOLOGÍA. DEFINICIONES A-HISTÓRICAS CONTRA DEFINICIONES HISTÓRICAS..........57

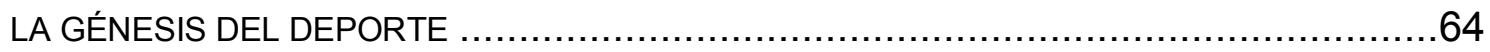

DEL PROCESO CIVILIZADOR EN EL DEPORTE. REGLAS, VIOLENCIA Y TOLERANCIA ........71

EL NUDO ENTRE MIMESIS, REGLAS Y TOLERANCIA A LA VIOLENCIA …....................79

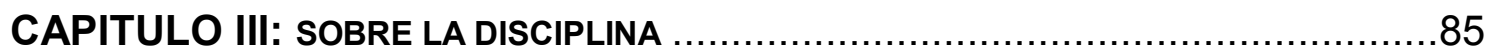

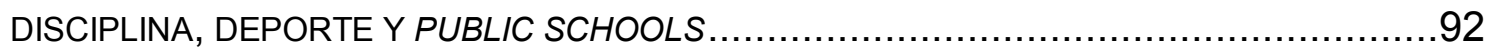

EL DISPOSITIVO DISCIPLINARIO Y LA INSTRUMENTALIZACIÓN DEL CUERPO...............100

EL EJERCICIO Y EL DISCIPLINAMIENTO DE LOS CUERPOS ...................................110

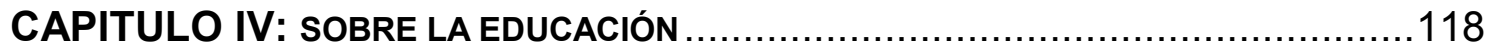

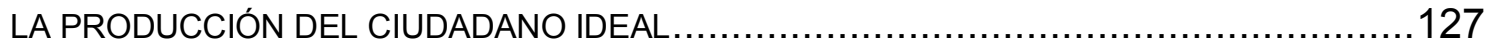

EL OLVIDO (?) DE LO FUNDAMENTAL: EL EQUILIBRIO DE LAS LIBERTADES ...............130

EL DEPORTE: UN CONTENIDO EDUCATIVO (LA DISCIPLINA COMO ACUERDO COLECTIVO)136

LA DISCIPLINA APOYO DEL GESTO EFICAZ: HERRAMIENTA DE REGULACIÓN DE LA TENSIÓN

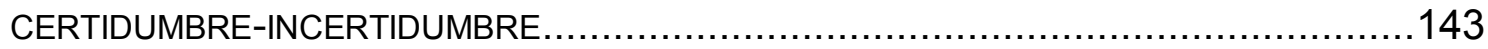

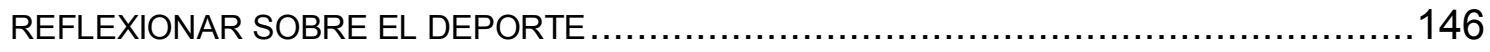

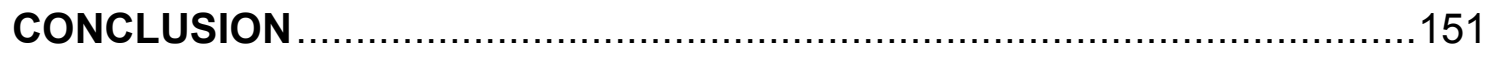

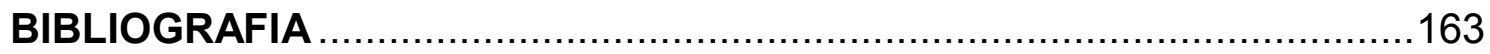




\section{INTRODUCCIÓN}

De todas las prácticas corporales existentes el deporte es una de las más trascendentes en la actualidad y ocupa un lugar significativo a nivel de la educación en nuestro país, en tanto contenido de enseñanza, así como también de mercado, en tanto objeto de consumo. Como en toda práctica hay tensión y ésta no es la excepción. Las lógicas que lo tensionan son tan variadas como dispares: por un lado, la de la educación y, por otro, la del mercado, el consumo y la ganancia. Lógicas que en el deporte actual se muestran inextricablemente relacionadas.

El punto de partida de este trabajo es el análisis de la práctica deportiva entendida en clave educativa, lo que permite preguntarnos y elaborar respuestas sobre qué deporte se enseña y cuál es el deporte que merece ser enseñado y que además invita a incorporar la idea de disciplina como criterio inseparable en el proceso de formación del deportista y en la educación del ciudadano hoy, según el criterio planteado aquí como posibilidad y que guía todo el proceso.

De esta manera, la hipótesis que plantea esta investigación es la siguiente: la disciplina es insoslayable en la práctica deportiva para ser un buen practicante ${ }^{1}$. Hipótesis que sostenemos desde un modo de ser del deporte educativo que merece ser transmitido como alternativa posible para desarrollar su potencial formador, no sólo de deportistas sino también de ciudadanos.

Para ello se realizó un análisis de bibliografía pertinente siguiendo autores como Norbert Elias, por sus relevantes estudios sobre la civilización y el deporte, lo que habilita un análisis de la práctica deportiva como aquí se pretende y reflexiones en torno a la disciplina, concepto trabajado desde Michel Foucault, por la importancia del dispositivo en su obra y también por el efecto simbólico que produce su teoría que permite pensar el deporte como una práctica.

Otro de los autores abordados en este trabajo es Isaías Berlin, por su desarrollo respecto al concepto libertad (y su dimensión positiva y negativa), lo que también

\footnotetext{
${ }^{1}$ Deportista puede asociarse al jugador exclusivamente y aquí se hace referencia a practicante, denominación que incluye a todos los que participan en la práctica deportiva (profesor, alumno, entrenador, espectador, árbitro, dirigente, técnico, periodista, otros).
} 
permite reflexionar sobre la disciplina y sus efectos en la práctica deportiva al pensarla con fines educativos.

Esta investigación incorpora el análisis de un trabajo de observación participante realizado en la Escuela de Fútbol San José de la ciudad de La Plata, durante un período de cinco años (2012 a 2017); una escuela de fútbol mixta para chicos y chicas de 4 a 15 años de edad, con una regularidad de entrenamiento de dos veces por semana. En ésta se elaboraron lecturas de los mecanismos disciplinares en la cotidianidad de la práctica deportiva: se observaron las clases de profesores, sus progresiones y dinámicas de trabajo; a su vez se indagó sobre las propias clases, bajo la observación y crítica de colegas.

La práctica de la enseñanza (del fútbol, para este caso) arrojó interrogantes que fueron los que guían este proceso, manifestándose como indicios de vacancia y ausencia a la hora de enseñar: había algo que escapaba del análisis a la hora de pensar la enseñanza del deporte en clave educativa, ese que se busca enseñar, mediante una conciencia crítica sobre las lógicas que también constituyen al deporte hoy y, en efecto, al practicante.

De la misma manera, se ha tomado como punto de referencia el trabajo realizado por Fabián Amílcar De Marziani (2014) quien investiga en su tesis a las ligas de fútbol infantil platenses y encuentra un correlato entre el deporte que se enseña en los clubes que participan de estas ligas y el fútbol profesional. El autor caracteriza a la disciplina como estructura normativa reguladora de las conductas e identifica que sólo algunos de los entrenadores de fútbol entrevistados le otorgan importancia a las cuestiones disciplinarias. Además plantea que "(...) la idea fundamental, que opera como objetivo, es la de desarrollar futbolistas que logren insertarse en el ámbito adulto, en el deporte de elite, aunque no desestiman la necesidad de lograr metas en el mismo proceso, como el logro de campeonatos. Por tal motivo, la planificación es considerada de la misma forma con la que se piensa el deporte adulto. De alguna manera, la mirada del alto rendimiento es la que controla las prácticas de la enseñanza" (De Marziani; 2014: 48-49).

Amplía y concluye que: "En este contexto, la elección y formación de jugadores juveniles es una actividad que se ha alejado de ese ideal pedagógico y docente 
que debería tener, por ejemplo para Jorge Bernardo $\mathrm{Griffa}^{2}$, y la realidad hoy se encuentra configurada por un jugador al que se lo considera un 'activo' y es el principal ingreso de dinero para los clubes" (De Marziani; 2014: 67).

En este sentido, lo expuesto por De Marziani comprende parte del mismo problema planteado en esta investigación, la cual da un paso más allá sobre el estudio de la disciplina como dimensión de la práctica que es condición necesaria para la acción eficaz, abordaje por demás necesario para quienes trabajamos en procesos formativos y educativos hoy, buscando encontrar en la propia práctica respuestas a problemas que en ellas mismas se producen.

Dicho abordaje también comprende el estudio de clubes de fútbol infantil en la ciudad de La Plata, lo cual aporta un carácter de observación pertinente para este proceso (que se retoma a través de ejemplos citados a lo largo de esta tesis) y se ponen en diálogo con las experiencias propias recogidas en el campo. Dichas experiencias arrojaron evidencias sobre los comportamientos del grupo en cuestión y que enriquecen este trabajo, tales como: los cambios en la puntualidad (un alumnado que pasó de llegar media hora antes en el 2012 a llegar quince minutos tarde durante el 2017); en el orden y la atención (cada año los tiempos de escucha y concentración parecían acortarse, al tiempo que cada ciclo mostraba aumentos en el desorden de la clase, una reducción de los diálogos fundamentales para coordinar el trabajo colectivo); y en la dinámica de trabajo, donde las clases presentaban dificultades para alcanzar la intensidad de ciclos anteriores ${ }^{3}$, entre otras tantas que se irán desprendiendo en la lectura.

En otra investigación anterior, los autores Márquez Guanipa, Díaz Nava y Cazzato Dávila (2007) problematizan cuestiones disciplinares desde las teorías psicológicas restringiendo su campo al ámbito escolar en Venezuela, lo cual centra sus objetivos sobre la relación entre el maestro y el alumno, aportes por

\footnotetext{
${ }^{2}$ Ex futbolista y actual entrenador argentino de fútbol. Luego de su retiro como futbolista continuó su carrera como entrenador de divisiones inferiores. En la actualidad es un referente en los temas de formación de deportistas juveniles.

${ }^{3}$ Con intensidad se hace referencia al modo en que se lleva adelante la clase, siendo más intensa cuando los tiempos entre actividad y actividad se reducen, al tiempo que aumenta la calidad en cada actividad.
} 
demás interesantes a la hora de pensar en la disciplina en contextos escolares (y no en otros).

Los autores plantean que "es importante también señalar el planteamiento de la CECODAP $^{4}$ (2003), cuyos integrantes conciben la disciplina como el dominio de sí mismo para ajustar la conducta a las exigencias del trabajo o estudio, contribuyendo a la convivencia de la vida escolar. Igualmente señalan que las normas son importantes al inicio de toda acción que se emprenda, ya que las reglas de juego deben ser claras desde el comienzo, por tal razón, el reglamento de convivencia escolar, como ellos le llaman, es una herramienta normativa y pedagógica que tiene como propósito regular el funcionamiento, organización y convivencia de la vida escolar. Por tanto, se puede afirmar que la disciplina no sólo implica el conjunto de normas y la aplicación de sanciones cuando la regla es transgredida sino que es importante considerarla además como parte del mundo de la persona, un hábito en donde cada individuo logra su autodominio para actuar libre y responsablemente sin perjudicar al otro. De esta manera, se vincula los elementos del ambiente escolar con el ser de cada persona. Así, se contribuye desde la escuela a formar ciudadanos para vivir en armonía y democracia" (Márquez Guanipa, Díaz Nava y Cazzato Dávila, 2007: 129).

Estos aportes dan cuenta de la importancia de pensar en la disciplina como condición necesaria para la práctica en términos de un deporte educativo y permite retomarlos para ejemplificar desde el punto de vista de nuestro rol como formadores en este contexto.

Esta tesis propone un estudio a la vez diacrónico y sincrónico que procura separar lo que es propio del deporte y lo que no lo es. La pregunta en torno a qué es el deporte para la Educación Corporal ${ }^{5}$ no supone una verdad a revelarse sino una

\footnotetext{
${ }^{4}$ Organización venezolana que trabaja en la promoción y defensa de los derechos humanos de la niñez y adolescencia desde 1984, haciendo especial énfasis en la construcción de una convivencia sin violencia a través de la participación ciudadana de los niños, niñas y adolescentes, familias, centros educativos y sociedad. Disponible en http://cecodap.org.ve/cecodap.

${ }^{5}$ Esta emerge "(...) como fruto de un programa de investigación que desplazó progresivamente su territorio tradicional y sus métodos e intenta (...) etnologizar la mirada que dirigimos sobre nuestras propias prácticas y sobre nuestros propios conocimientos; captar el modo en que son delimitados los ámbitos que la Educación Física procura dominar o investigar, la forma mediante la cual el saber científico se utiliza en ella, el proceso de formación de sus objetos de conocimiento y de creación de sus conceptos; esforzarse por restituir en el interior de nuestra sociedad el proceso
} 
teoría que produce su objeto; esto es una decisión epistemológica cuyos efectos se corresponden mejor con el carácter dinámico de la realidad, que es precisamente lo que habilita la problematización del asunto en los sentidos aquí tratados.

Este posicionamiento contribuye a evidenciar con mayor claridad y precisión qué es deporte y qué no; habilita reflexiones sobre el inconsciente de una práctica que a veces se muestra completa, cerrada y necesaria. El obstáculo es epistemológico: poco hay para hacer si se cree que la cosa es.

Este trabajo recoge la investigación de autores que problematizan conceptos tales como: disciplina, deporte, educación y libertad, lo que permite desentramar la problemática que gira en torno a la enseñanza de los deportes en la actualidad y que persiguen los siguientes interrogantes: ¿Qué deporte se enseña?, ¿cuáles son las lógicas que atraviesan al deporte hoy?, ¿es la disciplina una condición necesaria para la formación del buen practicante?, ¿qué se necesita para ser un buen deportista?, ¿cómo se forma a un buen deportista?

Se realizó un análisis de artículos periodísticos especializados donde se observaron aspectos del deporte que permiten su reflexión (conferencias de prensa y entrevistas televisivas a entrenadores, jugadores, ex jugadores, directores técnicos y profesores en Educación Física) y que dejan entrever la necesaria consideración de criterios disciplinares para el buen desempeño en la práctica.

En el mismo sentido se realizó un análisis de textos y documentos de personalidades referentes en el tema (lo que otorga la palabra de variadas voces a lo largo del tiempo), complementado por la observación participante que da carácter de laboratorio a este punto de vista.

En un mundo globalizado el proceso de mediatización de la cultura da como resultado la denominada cultura digital, un proceso en el que los medios de comunicación se integran a las cotidianeidades y en cuyo seno los medios de

mediante el cual la Educación Física se constituyó como saber, entendiendo a éste como la suma de sus conocimientos efectivos, el espacio de las cosas a conocer, los instrumentos materiales o teóricos que lo perpetúan; empeñarse en el análisis de sus condiciones de existencia, de sus leyes de funcionamiento y de sus reglas de transformación (cf. Giles et al.: 2002-2003)" (Crisorio, 2014). 
comunicación masivos (diarios, revistas, radio, televisión, Internet) cumplen un rol preponderante en la formación de sentido. Resulta de interés analizar el impacto que éstos tienen en la práctica deportiva y, más aún, en la formación del deportista y la educación del ciudadano. Asentadas en una larga tradición de culturas mediáticas, las cuales, según María Cristina Mata (2010: 5) “(...) son aquellas en las que se da un nuevo modo en el diseño de las interacciones, una nueva forma de estructuración de las prácticas sociales, marcadas por la existencia de los medios (...)".

Ante este escenario, la competencia y la espectacularidad se consideran aspectos que le son propios a la práctica deportiva hoy, la reconstruyen y la envuelven, por eso se hace necesario construir y deconstruir estas tramas, indagar sobre la enseñanza y el rol de los educadores para entender qué deporte se enseña y cuál es el deporte que merece ser enseñado en pos de encontrar en la propia práctica las herramientas para una mejor formación en los procesos de educación actual. Mientras estas lógicas operan y constituyen al deporte ( $\mathrm{y}$ le dan forma), el individualismo se presenta como una característica que le es propia, donde la construcción de nuevos sentidos tiene lugar mediante la observación de comportamientos que se legitiman, tal es el caso de valoraciones sobre resultados y no en términos de procesos: se apunta al mejor jugador, al jugador de la fecha, al goleador, al más ganador y se deja en un segundo plano cuestiones que hacen al funcionamiento del equipo (por ejemplo, que un jugador consiga hacer los goles se muestra como un logro personal y no como la culminación de un trabajo colectivo).

Este tipo de comportamientos (trasladados al discurso mediático, compartidos socialmente) son puntos de observación que se desprenden, en parte, de la experiencia recogida en el campo donde, por ejemplo, se manifestó repetidamente una intención de parte de los alumnos por ocupar puestos de juego en posiciones delanteras (nadie o muy pocos quieren desempeñar el rol de defensores o arquero/a), por mencionar algunos.

Para Elias (1992), las sociedades modernas funcionan con base en redes de interdependencia complejas donde los roles se han especificado de tal modo que 
el individuo funciona entre y dependiendo en mayor o menor medida de otros, hecho que en la práctica deportiva se observa, por ejemplo, en cómo se organizan los roles en el juego y también en lo que lo rodea (espectadores, técnicos, preparadores físicos, dirigentes, profesores, alumnos, jugadores, otros).

Siguiendo esta línea, también constituyen un punto de observación los comportamientos de los espectadores en la práctica deportiva, entendidos como formadores y multiplicadores del sentido. Frases como: ¡Cortalo cortalo!, ¡rompele las piernas!, ¡no te puede pasar ese burro!, jdale que no sabe!, ¡no puede ser que te pase una nena!, se escucharon repetidas veces en las inmediaciones del público local y visitante.

Se ha problematizado aquí sobre cuáles son esos criterios que constituyen las valoraciones del buen juego y que, en la medida en que olvidan lo colectivo, lo empobrecen, así como también los criterios con los que se valora. No se trata de hacer un análisis del discurso ni analizar el carácter pregnante de los medios masivos de comunicación y el rol de los líderes de opinión, sino que indagar sobre estos aspectos como contexto del problema deja un camino claro para desentramar los interrogantes planteados que se irán respondiendo a lo largo de este recorrido.

La investigación da cuenta de un desplazamiento que se ha dado al concepto de deporte actual, de objeto de enseñanza a objeto de consumo ${ }^{6}$ y se plantea una serie de problemas que fueron agrupados en núcleos, a su vez vinculados entre sí, en/mediante las siguientes preguntas:

1) Respecto al equilibrio de tensiones (libertad positiva y negativa) que implica el buen funcionamiento colectivo: ¿qué pasa con las prácticas que suponen la civilización para su funcionamiento?, ¿qué sucede con los acuerdos colectivos en el paroxismo de las libertades individuales?

\footnotetext{
${ }^{6}$ Entendemos por consumo a toda una categoría de análisis que implica "el conjunto de procesos socioculturales en que se realizan la apropiación y los usos de los productos. Esta caracterización ayuda a ver los actos a través de los cuales consumimos como algo más que ejercicios de gustos, antojos y compras irreflexivas, según suponen los juicios moralistas, o actitudes individuales, tal como suelen explorarse en encuestas de mercado" (García Canclini, 1995).
} 
2) En una sociedad donde la producción y circulación de información se acelera y los tiempos de reflexión se acortan: ¿qué se sabe sobre el deporte?, ¿es el deporte un contenido educativo?, ¿la Educación Física hace del deporte un contenido educativo o supone que lo es? Si se considera al deporte como una práctica: ¿qué es ser un buen deportista?

3) Pensar el deporte en clave educativa y su enseñanza en la actualidad (donde se manifiesta un avance del individualismo en tanto característica de época) invita a analizar las dimensiones de la práctica deportiva para encontrar en ella respuestas y a la vez más preguntas sobre qué deporte se enseña y qué deporte debería ser enseñado para la educación del buen deportista y ciudadano. Se plantean preguntas que guían este núcleo en referencia a la disciplina como una de las dimensiones que lo conforman y que es aquí el objeto de estudio: entonces, ¿qué es la disciplina?, ¿hay relación entre la disciplina y el deporte?, si la hubiera, ¿cuál sería?, ¿el deporte se estructura con técnicas disciplinares?, ¿puede haber deporte sin disciplina?, ¿la disciplina es una condición necesaria para el buen practicante?, ¿la enseñanza de la disciplina en la práctica deportiva resignifica al deporte y lo reivindica como medio para la educación y la transformación?, ¿se debe ser disciplinado para enseñar, aprender, jugar un deporte o ser espectador?, ¿cuánta indisciplina tolera un equipo para no perder el carácter de equipo?

4) El vínculo entre civilización, práctica deportiva y disciplina se piensa como una unidad de análisis que habilita reflexionar sobre la enseñanza de los deportes en tanto práctica que permite la formación específica del deportista y la educación del ciudadano. Los interrogantes aquí planteados son los siguientes: ¿qué formas adquiere la práctica deportiva?, ¿qué implica formar y educar a un deportista?, ¿cómo se forma y educa a un deportista?, ¿cómo se alcanza un juego mejor?, ¿se forman deportistas o se espera encontrarlos?, ¿son las prácticas y por ende las sociedades caóticas?, ¿hay enseñanza en el caos?, ¿es el caos la contraparte de la disciplina?, ¿qué deportista se forma?, ¿cuál es la causa de un buen deportista? 
Este trabajo analiza y reflexiona sobre estos núcleos. Los capítulos que componen esta tesis son atravesados por cuatro ideas que se ponen en juego a lo largo de todo el escrito: progreso ${ }^{7}$, libertad, política y educación.

El primer capítulo, "Sobre la civilización y la práctica deportiva", se aboca al proceso de la civilización y elabora la tensión existente entre libertad y coacción, lo que permite mostrar el vínculo entre la disciplina y la práctica deportiva, siendo la primera la que habilita, coacción mediante, la libertad en la práctica, mostrando cómo la sujeción a determinadas cadenas libera de otras más pesadas.

La articulación entre dos dimensiones de la libertad, la positiva y la negativa (Berlín, 1998), marca el momento en que el progreso se entiende como la conciencia de la libertad principalmente en el plano político (Bobbio, 1998). Este pasaje supuso la conformación del aparato estatal y el fortalecimiento en los derechos del ciudadano que acrecentó y legitimó la libertad negativa (o individual), en función del fortalecimiento de la libertad positiva (o colectiva). El respeto por los acuerdos colectivos, que tiene al Estado como garante, permitió incrementar las cadenas de interdependencia en la sociedad (Elias, 1994: 452-453), al tiempo que los modos en estas relaciones se pacificaban producto del mismo movimiento.

En este marco contextual, emerge una primera forma de deporte entendido como una práctica corporal conformada por lógicas novedosas respecto de otras prácticas de la Edad Media, así lo muestra Elías al analizar algunos ejemplos como la caza de zorros ${ }^{8}$. En éste, el reglamento (al ser más preciso y al haber agregado prohibiciones) dota de dificultad la forma de alcanzar el objetivo de cazar al zorro, consiguiendo correr el interés de la práctica en un doble sentido: por un

\footnotetext{
${ }^{7}$ Igualar la idea de civilización a la de progreso sería caer en un error. El proceso civilizatorio tal como lo trata Norbert Elias (1994) y como es entendido en esta tesis, muestra oscilaciones progresivas y regresivas. Precisamente por presentar estas oscilaciones es que reflexionar sobre la idea de progreso permite dar un paso más en la precisión del concepto.

8 "Se encontrará en este volumen un breve estudio sobre uno de los pasatiempos que adquirieron las características de deporte durante el siglo XVIII entre las clases hacendadas de Inglaterra: la caza de zorros. Considerada entonces como un deporte, mostraba ya muy claramente algunas de las características estructurales que distinguían los pasatiempos conocidos como deportes de otros pasatiempos anteriores carentes de tales características. En la forma en que surgió por entonces, la caza de zorros era en Inglaterra una modalidad de caza altamente regulada y en estrecha relación con un determinado código de pautas sociales de conducta. La caza puede gustarnos o no pero, independientemente de esto, la caza de zorros nos presenta un vívido retrato de una de las primeras fases del desarrollo del deporte y puede, por ello, ayudarnos a entender mejor la génesis y las características de los deportes en general" (Elias en Elias y Dunning, 1992: 37).
} 
lado pacificándola, según los estándares de la época, ya que no es el cazador quien mata al zorro, menos aún para comerlo, sino los perros; por el otro, desplazando el placer de la matanza y el resultado final que supone alcanzar al zorro (o cualquier otro animal que se cruce) por el del proceso arduo para alcanzarlo (sin eliminar en el camino ningún otro animal).

Otro ejemplo de esta novedad puede apreciarse en el Boxeo, escribe Elias (1992: 169):

[Entre los griegos] la modalidad pancration de lucha, estaba mucho menos circunscrito por reglas y dependía, por tanto, de la fuerza física, de la pasión y la resistencia de la lucha espontánea, en mucho mayor grado que el boxeo deportivo. No se distinguían diferentes clases de boxeadores. No se intentaba, por tanto, emparejar a los participantes según su peso, ni en éste ni en ningún tipo de competición. La única distinción que se hacía era entre hombres y muchachos. Los boxeadores no sólo peleaban con los puños. Como en casi todas las modalidades del boxeo, las piernas formaban parte de la lucha.

En los juegos medievales (como en la vida) los índices de violencia disminuyeron y la tolerancia a la observación de ciertos niveles de violencia se redujo de tal forma que las relaciones entre las personas se vieron notablemente transformadas en la práctica deportiva pero también en la vida en general.

Siguiendo las ideas de Elias, se observa cómo con educación y disciplina se modifican las relaciones entre las personas, de modos bárbaros y violentos a finos y educados al tiempo que se somete a estas personas a un régimen disciplinar que los habilita para funcionar en sociedad. Las redes de interdependencia que hacen a la vida cotidiana se complejizan al ritmo de los niveles de seguridad en las relaciones entre las personas. Esta seguridad la brinda el Estado gracias a su monopolio sobre la violencia y la educación que forma al ciudadano.

Este marco contextual permite dar lugar a la visión más actual sobre el tema que aquí compete, el deporte y su enseñanza en la actualidad y que habilita a pensar 
la disciplina como condición necesaria en procesos de formación, con fines transformadores que son el resultados del juego de tensiones entre ambas dimensiones de la libertad: positiva (colectiva) y negativa (individual).

El segundo capítulo, "Sobre el deporte", responde a la pregunta: ¿Qué es y qué puede ser el deporte? Para ello, muestra cómo éste emerge con características precisas que se relacionan directamente con la disciplina: disminución de la violencia y de la necesidad, en el momento en que se producian transformaciones profundas en la sociedad que fueron condición de posibilidad.

El proceso de la civilización muestra cambios a nivel de las reglas del juego social que hayan su correlato en el juego deportivo, los modos refinados, educados, civilizados se combinan con técnicas disciplinares que tienden a la pacificación de las relaciones sociales. Este proceso estructura las relaciones en diferentes prácticas, entre ellas la deportiva, con una clara tendencia a la pacificación de las conductas y el control sobre las emociones con base en mecanismos disciplinarios.

En función de esto se construyeron dos series conceptuales que precisan lo que se entiende aquí por deporte, restringiendo los usos que del concepto se hacen. La primera, cuyos términos son de uso común en el campo de la Educación Física, constituida por tres contenidos: juego, deporte y gimnasia. Ésta permite distinguir prácticas corporales diferentes en clave educativa. La segunda serie: mimesis, tolerancia a la violencia y reglas; que permite fisonomizar la práctica deportiva y pensarla como una manifestación de época que responde a niveles de violencia tolerados en un momento preciso, es decir la mimesis como característica insoslayable al deporte en tanto batalla en un marco que estructura y limita la violencia, encuentra en la regla la herramienta que le permite alcanzar los niveles tolerados por una sociedad en un momento determinado de la historia. Esta serie permite reflexionar acerca de cómo la práctica deportiva requiere una disciplina que admita un descontrol controlado por parte de todos aquellos que participen, siendo el objetivo elevar la tensión del juego aumentando el peligro y la agresividad pero en un punto lo suficientemente preciso para generar y sostener el interés sin provocar consecuencias reales, como lesiones graves 0 , incluso, la 
muerte, como ocurría en los juegos medievales, por ejemplo. Esto en un nivel relativamente variable en función de los niveles de tolerancia que la sociedad admite en un momento y lugar determinados.

El tercer capítulo, "Sobre la disciplina", desarrolla el dispositivo disciplinario. Describe, por un lado, las operaciones y técnicas del dispositivo y como éstas pueden observarse en la práctica deportiva, así como en toda institución moderna con características que muestran su novedad respecto a la disciplina de otros momentos históricos ${ }^{9}$, en función del grado de detalle, el objeto de control y el modo ininterrumpido de la coerción.

La distribución de los cuerpos en el espacio, el empleo del tiempo y las articulaciones cuerpo-gesto y cuerpo-objeto son los objetivos del dispositivo y los regula con diferentes técnicas. La observación de estas técnicas en la práctica deportiva cobra relevancia para su enseñanza y coadyuvan a la constitución del deporte en clave educativa, cuando se articula con las dimensiones de la libertad, ya que si se consigue que estas tensiones se equilibren puede pensarse en una disciplina positiva que no por coaccionar cae en la dominación ni en la disminución de las fuerzas políticas, sino todo lo contrario, es decir, se constituye como acuerdo colectivo y en este movimiento fortalece las libertades individuales.

El cuarto capítulo, "Sobre la educación", profundiza las reflexiones sobre el deporte en el campo de la educación actual y el impacto que las conclusiones parciales de los capítulos precedentes tienen en el deporte: ¿es la disciplina necesaria en la formación del deportista y la educación del ciudadano?

En momentos formativos y educativos, ¿qué objetivo tiene la disciplina?, ¿se puede enseñar a hacer uso de la disciplina?, ¿puede un practicante hacer uso de la disciplina?, ¿es posible enseñar estas técnicas?, ¿su enseñanza supone mejoras en la práctica?, ¿su dominio supone mejores practicantes?, ¿cuánta libertad tolera la disciplina?, ¿cuánta disciplina tolera la libertad?

Es desde un enfoque histórico y político que esta tesis habilita a pensar y a hacer del deporte un contenido educativo, arrojando evidencias que permiten hacer

\footnotetext{
9 "La historia de la disciplina se extiende hasta los comienzos del cristianismo y la Antigüedad; los monasterios son ejemplo de ello" (Castro, 2011:103).
} 
preguntas y hacer uso de ellas para pensar en la microfísica de los funcionamientos de la práctica deportiva y los efectos que tiene y podría tener en los procesos de enseñanza y viceversa, anclados en un caso de laboratorio concreto que permite un mejor análisis.

Pensar el deporte como práctica invita a considerarlo en su compleja totalidad, no solo como deporte espectáculo, escolar o federado, sino en todas estas manifestaciones. Esto admite un análisis en clave educativa que habilita la reflexión sobre su trasmisión, no pensando en el contexto de actuación, sino en el objeto de enseñanza. Esta interpretación permite pensar que el deporte educativo se hace en el pensamiento del objeto.

En este sentido, esta tesis propone reflexiones sobre la tecnología disciplinar en la práctica deportiva mostrando una línea de análisis que hace de ella un contenido educativo, elaborando herramientas para su enseñanza tales como la disciplina, independientemente del ámbito en el que ésta se desarrolle, sea en la educación formal o en la no formal. 


\section{CAPITULO I: SOBRE LA CIVILIZACIÓN Y LA PRÁCTICA DEPORTIVA}

Si se piensa que la civilización existe desde la aparición de los primeros hombres se plantearía un trabajo extenso e impreciso. Por ello, este trabajo restringe el concepto a un origen más cercano y preciso que lo expresa en términos de proceso y que muestra un cambio trascendental en la forma de pensar el mundo hoy.

Se entiende al proceso civilizatorio como el momento en que el hombre se posiciona de un modo distinto frente al mundo $\mathrm{y}$, si bien existieron otros cambios significativos, éste presenta un punto de inflexión trascendental en el abordaje de la práctica deportiva, ya que es en este proceso donde el deporte emerge en toda su novedad (y no sólo entendido como la historia de la humanidad en términos evolutivos).

A lo largo de los años, el concepto civilización ha sido asociado a la idea de progreso. Sin embargo, se entiende aquí que tal proceso no presenta una única dirección, sino oscilaciones progresivas-regresivas en momentos diferentes e incluso en los mismos momentos, las cuales (observadas a largo plazo) muestran una clara tendencia hacia la pacificación de las conductas y el control de las emociones (Elias, 1994), condiciones necesarias para la emergencia de las prácticas deportivas (ya que sin autocontrol y conductas educadas no es posible cumplir las demandas de esta práctica).

Por esto la importancia de reflexionar sobre las ideas y actitudes que recorren el proceso civilizatorio y que permiten elaborar articulaciones posibles con la práctica deportiva hoy, su propia práctica y las de su enseñanza.

Se problematiza entonces cómo libertad, progreso, política y educación son ideas tensionadas por una actitud propia de la modernidad, adquiriendo una homogeneidad que se cristaliza en este complejo proceso civilizatorio y cómo éstas pueden encontrarse en la práctica deportiva.

Para dar sentido se debe establecer el paradigma desde donde se piensa al concepto de actitud en los tiempos modernos:

Con "actitud" quiero decir un modo de relación con y frente a la actualidad; una elección voluntaria que algunos hacen; en suma, 
una manera de pensar y de sentir, una manera, también, de actuar y de conducirse que marca una relación de pertenencia y, simultáneamente, se presenta a sí misma como una tarea (Foucault, 1994: 4).

Es importante analizar entonces los modos que presentan las relaciones con las cosas, los otros y consigo mismo en términos de libertad, progreso, política y educación, en la práctica deportiva.

Las condiciones de posibilidad resultan significativas para pensar este proceso que muestra su concreción en los modos y las formas que traman las relaciones que las personas sostienen con las cosas, los otros y consigo mismas, continúa Foucault (1994: 5):

(...) para Baudelaire la modernidad no es simplemente una forma de relación con el presente; es, también, un modo de relación que hay que establecer consigo mismo. La actitud voluntaria de modernidad está ligada a un ascetismo indispensable. Ser moderno no es aceptarse a sí mismo tal como se es en el flujo de momentos que pasan; es tomarse a sí mismo como objeto de una elaboración ardua y compleja (...)

El ascetismo indispensable pone en juego tanto la libertad de elaborarse a sí mismo como la libertad en términos colectivos, muestran la tensión entre el gobierno de sí por sí y el gobierno de los otros sobre uno. En otros términos, entre las técnicas de sí, la disciplina de los cuerpos y la regulación de la población (Foucault, 1996).

Éstas son algunas condiciones que posibilitan y hacen al proceso de la civilización, el cual en su dinámica muestra efectos que son causas de otros: hay efectos de verdad que producen nuevas verdades, por lo que, cambios en los modos de relacionarse entre las personas pueden afectar la producción científica, o bien modos de relación con las cosas pueden cambiar la relación con el saber. 
Es así que las instituciones se hacen eco de estas transformaciones, a la vez que sufren los efectos y alteran tanto su protagonismo como su funcionamiento. Por ejemplo, en este proceso, la Iglesia cede terreno al Estado en el campo de la educación y éste la pone al servicio de la formación del ciudadano al mismo tiempo que expande la disciplina al funcionamiento esencial de toda institución ${ }^{10} y$ de toda la sociedad.

En el funcionamiento de las instituciones tiene lugar un sistema de coerciones externas que no sólo se sostienen, sino que consiguen que muchos de estos mandatos se interioricen. La red de instituciones estatales cristaliza ideas y actitudes que muestran, por un lado, una mecánica disciplinaria que (técnica mediante) produce al individuo moderno, el cual, en la medida en que interioriza las coacciones externas se responsabiliza de su docilidad; mientras que, por el otro, muestra una regulación que normatiza la multiplicidad.

Dos niveles que responden a dos libertades relacionadas pero diferenciables: la libertad negativa a nivel de la vida privada, ese ámbito en el que la autoridad es uno mismo y la libertad positiva como un espacio de la vida pública donde la autoridad es del Estado. Tal como plantea Foucault, al retomar la idea de Baudelaire: "Esta modernidad no 'libera al hombre en su propio ser', lo obliga a la tarea de realizarse a sí mismo" (1994: 5).

No existe un límite claro y mucho menos fijo entre estas dos dimensiones de la libertad. El proceso civilizatorio supone la interiorización de controles que se originan en el exterior ${ }^{11}$ y lo que puede ser atribuible a la libertad positiva, puede también serlo a la libertad negativa. Por ejemplo, un alumno puede quedarse sentado sin hablar por la normativa acordada y, así y todo, en algún punto decidir hacerlo; o bien, en pleno partido, un jugador defensor pasa al ataque (deja su lugar porque considera que el sistema de juego y la situación así lo requieren) y

\footnotetext{
${ }^{10}$ Como se observa en el capítulo III, "Sobre la disciplina", no es que ésta aparece en este proceso, sino que lo novedoso es la intensidad, la minuciosidad y el modo en el que se manifiesta. 11 Interno-externo no hace tanto referencia a un espacio como a una relación, siendo interna la relación que se puede establecer consigo mismo y externas las relaciones con los otros y las cosas/instituciones.
} 
también toma la decisión de hacerlo, o no. La libertad positiva se relaciona con una dimensión colectiva y tiene que ver con ese espacio que garantiza la seguridad en función de la previsibilidad en los comportamientos, en la posibilidad de anticipación que estructura los modos que adoptan las relaciones cotidianas.

La libertad negativa se vincula a la relación con uno mismo y también afecta las relaciones con los otros. Estas cuestiones abarcan desde el respeto por los acuerdos del juego propiamente dicho (el reglamento), hasta los referentes al sistema, aceptados por el colectivo respecto al modo de alcanzar el objetivo (graficadas, por ejemplo, en la puntualidad y hora de llegada a la clase o al entrenamiento, donde la impuntualidad trastoca la dinámica del trabajo colectivo).

Pensar en dos dimisiones de la libertad permite analizar las condiciones de posibilidad del proceso que tiene lugar en el siglo XVIII y analizar el contexto actual. Independientemente del marco institucional en la que ésta se lleve a cabo - y en la que se supone una relación de autoridad-, ¿cómo se ponen en juego estas dimensiones de la libertad en la enseñanza del deporte? Berlín (1998) ofrece una posible respuesta al plantear que: "(...) las cuestiones quién manda y en qué ámbito mando yo, no pueden considerarse completamente distintas" (pág. $50)$.

Si bien las categorías libertad positiva y libertad negativa refieren, en su estado puro, a cosas diferentes, en el uso de su función (que es la interpretación de la realidad) se unifican en una misma cosa con matices y gradualidades. Esto favorece las interpretaciones que se hacen y se corresponden mejor con el universo fenoménico.

La libertad se pone en juego de diversas maneras y en múltiples sentidos. Las prácticas, que suponen relaciones complejas, muestran en estos tiempos de civilización el progreso de la libertad a merced de coacciones y coerciones, lo que muestra las oscilaciones progresivas-regresivas ya mencionadas.

La libertad de hacer lo que se quiere sin reparar en el colectivo reduce su libertad y la del individuo también. Por ejemplo, si varios llegan tarde el entrenamiento o 
clase no puede comenzar y, si lo hace, es difícil que lo planificado pueda llevarse adelante, al menos con la eficacia que se le suponía. La misma lectura puede hacerse en el juego propiamente dicho: si las decisiones individuales no respetan el sistema impuesto por la lógica del juego y solo se encuentran excepciones. ¿Qué sucede?

Se problematiza el concepto civilización y práctica deportiva atravesados por cuatro grandes núcleos que se articulan en la vida en general: libertad, progreso, política y educación.

Se encuentra en este proceso histórico y en las ideas que lo atraviesan las condiciones de posibilidad que sostienen el funcionamiento institucional y del juego social en el que emerge la práctica deportiva. Éste es el punto de inicio de las reflexiones respecto a la enseñanza en la actualidad. No se trata de encontrar una suerte de continuidad entre los distintos momentos históricos, sino la posibilidad de problematizar el estado de la cuestión en nuestros días.

Para ello da cuenta de un sistema complejo de relaciones que se dan en un momento particular de la historia, a través del diseño de una red conceptual que habilita la reflexión en el presente, planteados como interrogantes y problemas de una manera que muestra el desplazamiento desde un programa de investigación científica; pensar la Educación Física y la enseñanza acorde con las ideas y los modos que estructuran las relaciones de la vida en sociedad.

Los apartados del presente desarrollo, al igual que los capítulos siguientes, no siguen un orden necesario; los núcleos problemáticos de los que da cuenta se muestran simultáneos.

Se ponen en tensión aquí las vinculaciones entre estos núcleos (libertad, progreso, política y educación) que en el proceso de la civilización aparentan un sentido hacia el progreso (de la ignorancia campesina a la ilustración citadina, de la barbarie a la política, del despotismo al liberalismo). Mientras que en la práctica deportiva se cristalizan en el control de las emociones, el Fair Play, la caballerosidad, la igualdad de oportunidades y el respeto por las reglas. 


\section{¿QUÉ ES LA CIVILIZACIÓN?}

"En general, civilización se usa hoy para designar un estado o condición consumados de vida social organizada" (Williams, 2003: 59), así como también a un ser, a una conducta civilizada, o a un proceso; el acto de civilizar también significa y se lo ha entendido como un proceso en el cual algo adquiere características civilizadas. Según las acepciones de la Real Academia Española (RAE), civilización significa:

1. f. Conjunto de costumbres, saberes y artes propios de una sociedad humana.

2. f. Estadio de progreso material, social, cultural y político propio de las sociedades más avanzadas.

\section{3. f. Acción y efecto de civilizar.}

Estas acepciones muestran los sentidos que se construyen en torno al concepto, por ello es pertinente pensar que el estado de civilización supone un proceso de civilización y viceversa. Podría arriesgarse una potencial línea concluyente de este trabajo: un proceso de civilización supone el arribo a un punto más civilizado.

En cuanto al término, su sentido no siempre fue el mismo. La palabra civilizado se emparenta con civil, cuya etimología refiere a los habitantes de la ciudad "civil del latín civilis, de o perteneciente a los ciudadanos, de civis, ciudadano en latín (...) Así, civil se usó en inglés desde el siglo XIV, y en el siglo XVI había adquirido los sentidos ampliados de ordenado y educado" (Williams, 2003: 59).

Si el proceso de la civilización implica la adquisición de un mayor grado de orden y refinamiento, se supone consigo un proceso de educación, como lo sugiere el rastreo hecho por Williams, que garantice la adquisición de estas características particulares por parte de los habitantes de la ciudad.

En consonancia con lo expresado se encuentra en Gallino (1995: 140):

Para los latinos civilitas era la sociedad de los ciudadanos, es decir, de los habitantes de las ciudades, y a partir de este 
origen el término vino a significar la condición social y cultural más desarrollada o privilegiada respecto de la condición de naturaleza que prevalece en el campo (...) El término civilisation se difundió en Francia y en Inglaterra en la segunda mitad del siglo XVIII para designar el refinamiento de las maneras, la nobleza de las costumbres y del espíritu, con una contraposición implícita a todo lo que es primitivo, selvático o rudo. $^{12}$

En estos términos, la civilización implica un cambio que va de la rusticidad del campo al orden de la ciudad. En una escala gradual, se puede pensar como el pasaje a un estado de menor incertidumbre y con mayores restricciones a los comportamientos salvajes, lo que comienza a mostrar una distancia con los comportamientos apreciables durante la Edad Media (más avanzada la lectura podrá retomarse esta idea de cómo esta distancia puede observarse entre los juegos medievales con grandes masas de gente, en espacios con dimensiones extraordinarias y reglas poco definidas y los deportes modernos con un número de jugadores determinado, en un campo de juego controlable y reglas mucho más precisas). Escribe Williams (2003: 60):

(...) el nuevo sentido de civilización, del $\$ 18$, es una combinación específica de las ideas de un proceso y una condición consumada. (...) Lo sustenta el espíritu general de la Ilustración, con su énfasis en el autodesarrollo humano secular y progresivo. Civilización expresaba este sentido de proceso histórico, pero también celebraba el sentido asociado de modernidad: una condición consumada de refinamiento y orden (...) A fines del S18, la asociación de civilización con el refinamiento de los modales era normal tanto en inglés como en francés.

\footnotetext{
${ }^{12}$ Características que aquí se destacan por ser las de la práctica deportiva en su estado inicial.
} 
Entonces civilización sugeriría cierto estado social que muestra su consumación en el refinamiento de las maneras, la nobleza de las costumbres, el orden y la educación, al tiempo que en su dimensión procesual implica el aumento de las coacciones sobre las emociones y el control sobre las costumbres que dan forma a la vida en la ciudad y a las relaciones entre los hombres. Así la civilización supone la

(...) tendencia a aumentar el control sobre todo lo que provenga de la animalidad, de modo de volverlo menos visible o de recluirlo a la intimidad: la desnudez se muestra menos, se disimulan los olores corporales, las funciones corporales tienden a ejercerse en lugares específicos y aislados, no se escupe más sobre el suelo, sino en una escupidera; no se suenan más las narices con las mangas, sino con un pañuelo; no se come más con los dedos, sino con un tenedor (Heinich, 1999: 11-12).

Estos nuevos modos muestran una actitud diferente frente a la vida en sociedad y son acompañados por cambios en la sensibilidad que invisten de un signo negativo las conductas violentas, rústicas o salvajes.

Este movimiento se produce entre dos polaridades: la libertad y la coacción. Esta tensión muestra, por un lado, la libertad en una dimensión individual respecto al control sobre la impulsividad emotiva gracias al autogobierno y, por el otro, la libertad en su dimensión colectiva en términos de respeto por los acuerdos previos. En este sentido es que el deporte se elabora con este nuevo orden de significados donde lo distintivo pasa por la libertad que permite el control de las emociones y los niveles de violencia que se restringen mediante reglas y controles.

En este juego, la articulación entre libertad y coacción supone en las instituciones (y por ende en el deporte que empieza a institucionalizarse) la instrumentación por parte del Estado del dispositivo disciplinario. Tanto las instituciones como la práctica deportiva toman por objeto el cuerpo en su forma represiva, represión que 
adiestra y que -en el mismo funcionamiento de los engranajes- produce la individualidad de cuerpos civilizados.

El dispositivo disciplinario (mediante sus técnicas: por ejemplo las sanciones, la selección y la exclusión) moldea el cuerpo y los comportamientos, fabrica una entidad que favorece la previsibilidad de éstos y sujeta al cuerpo a un ideal de hombre que la civilización supone y pretende. Es la figura novedosa del individuo que se produce mediante la mecánica disciplinaria, que trastoca las ideas que sostienen la vida pública y la vida privada, el interior y el exterior.

Resulta interesante reflexionar en torno a la intimidad del individuo a la que se recluyen los impulsos violentos o rústicos y desplazar este interior del cuerpo al interior de la casa o a la vida privada. Observar en ese desplazamiento las tensiones que se manifiestan entre dos dimensiones de gobierno: la del sí mismo, en la que el individuo responde a los mandatos interiorizados y la pública, que se desdobla: en ella se respetan los acuerdos de convivencia y, al mismo tiempo, se cuestionan para su transformación en busca de progresos en la libertad.

El proceso de la civilización encuentra su razón de ser en esta división de espacios, ya que se constituye en las ciudades en las que las relaciones entre las personas se diversifican, intensifican y estabilizan al tiempo que se legitima y se restringe el uso de la violencia física. Por otro lado, la vida privada se muestra como el espacio en el que el individuo manda y, en la vida pública, alguien a quien se le delega el poder de mandar (manda y es libre de hacer dentro de los límites de lo permitido, establecido y aceptado por el colectivo, lo que muestra la libertad en su dimensión negativa y positiva).

La distinción entre estas dos dimensiones resulta significativa. Explica Berlín (1998: 51)

(...) esta diferencia se acentuó en la medida en que la idea del yo se escindió metafísicamente en un yo que era, por una parte, un yo superior e ideal, destinado a regir al yo -o naturaleza- que era por otra parte, el yo inferior, empírico y psicológico (...) cuya 
influencia ha sido enorme en el lenguaje, en el pensamiento y en la conducta; sea como sea, el yo superior se identificó debidamente con instituciones, iglesias, naciones, razas, estados, clases, culturas, partidos, y entidades más vagas, tales como voluntad general, el bien común (...). ${ }^{13}$

La diferenciación de espacios que ya se podía apreciar en las polis de la antigua Grecia, por ejemplo, también puede apreciarse durante el siglo XVIII en Inglaterra, pero con un giro en su sentido moderno, la vida pública en aquellos Estados hacía referencia a la vida política en la cual determinadas actividades específicas eran valoradas.

El nacimiento de las ciudades-estado significó que el hombre recibía además de su vida privada, una especie de segunda vida, su bios politikos (...) De todas las actividades necesarias y presentes en las comunidades humanas, solo dos se consideraron políticas y aptas para constituir, lo que Aristóteles llamó bios politikos, es decir, la acción (praxis) y el discurso (lexis) (Arendt, 2010: 39).

Lo que se esperaba entonces de un ciudadano en la esfera pública de Grecia distaba mucho de lo que se esperaba de un ciudadano de los Estados-Nación de la modernidad. Es necesario agregar un punto de referencia, en este caso un punto con cierta dimensión espacial, ya que la vida pública tiene -en este momento histórico- dos esferas diferenciables: la pública-política y la públicasocial.

En este punto cobra sentido la pregunta: ¿en qué esfera se espera qué cosa del ciudadano? Lo que muestra esta nueva diferenciación es que el espacio público

\footnotetext{
${ }^{13} \mathrm{El}$ autor hace referencia a las críticas respecto al uso que hace del término, con las cuales se podría, incluso, estar de acuerdo. Fue retomado aquí para plantear la siguiente hipótesis: en nombre de la libertad, en este sentido positivo, o de las libertades que admite este yo superior, se han visto coacciones sobre algunos derechos individuales. La libertad negativa muestra su exceso en la actualidad impidiendo el buen funcionamiento de aquellas prácticas que requieren acuerdos colectivos, es decir, ciertos niveles de libertad positiva.
} 
ya no se encuentra únicamente vinculado a la vida política, sino además a la vida social, pudiendo conservarse la necesidad de acción y discurso en la esfera pública-política, pero no en la vida pública-social. Respecto a la vida política y la vida pública escribe Arendt (2010: 51)

Es decisivo que la sociedad, en todos sus niveles, excluya la posibilidad de acción, como anteriormente lo fue de la esfera familiar. En su lugar, la sociedad espera de cada uno de sus miembros una cierta clase de conducta, mediante la imposición de innumerables y variadas normas, todas las cuales tienden a normalizar a sus miembros, a hacerlos actuar, a excluir la acción espontanea o el logro sobresaliente.

En Elias (1994) se encuentra representado el proceso civilizatorio como trayectos que nunca se presentan con un sentido único, en retrospectiva y considerando lapsos prolongados de tiempo, muestra en las coacciones que tienden a configurar la vida en sociedad una clara tendencia hacia la pacificación de las conductas y el control de las emociones. Escribe el autor (Elías, 1994: 225):

El proceso civilizatorio jamás se da de modo rectilíneo. En principio, podemos deducir una orientación general de los cambios, como hemos hecho aquí; en los casos concretos, vemos que la trayectoria de la civilización presenta las oscilaciones más acentuadas. Son los avances en una $u$ otra dirección. Si observamos el movimiento a lo largo de períodos más amplios, podemos ver con suficiente claridad, cómo las coacciones, que surgían de modo inmediato de la amenaza con las armas, con la fuerza corporal y guerrera, van reduciéndose paulatinamente, al tiempo que se fortalecen las formas de la dependencia y de la vinculación que conducen a una regulación o administración de la vida afectiva bajo la forma de la 
autoeducación, del self control, en una sola palabra, bajo la forma de la autocoacción.

Son estos funcionamientos los que pacifican y estabilizan las relaciones entre los ciudadanos. Se encuentra pertinente una posible vinculación con lo que Foucault (2006) menciona como normación ${ }^{14}$ y que se produce mediante un modo de biopoder ${ }^{15}$, que opera y tiene efectos en todas las esferas, a saber, el dispositivo disciplinario.

Si bien esta tesis hace hincapié sobre uno de los dos modos del biopoder, menciona ambos para dar precisión al uso del concepto normación, ya que Foucault trabaja en profundidad la disciplina en Vigilar y Castigar (1975), momento en el que aún no distinguía normación de normalización, aunque sí lo hará más adelante en Seguridad, territorio, población (1978). Con esta distinción se piensa una diferencia sustancial que permite la articulación con Elias y permite establecer que la normación de la sociedad se lleva a cabo en el proceso de la civilización.

En el transcurso del siglo XVIII y XIX se produce un fenómeno que tiene la mecánica disciplinaria como condición de posibilidad y que la complementa. Si ésta elabora y sujeta el cuerpo individual, este nuevo modo de biopoder trabaja sobre la población. "A diferencia de la disciplina que inviste el cuerpo, la nueva técnica de poder disciplinario se aplica a la vida de los hombres, o mejor, no inviste al hombre-cuerpo, sino al hombre viviente" (Foucault, 1996: 195).

Estos mecanismos de poder (inscritos en la disciplina-biopolítica que encuentran su respaldo y complemento en el campo del saber) producen en su dinámica “(...) el elemento que circulará de lo disciplinario a lo regulador, que se aplicará al

14 Foucault distingue dos formas de normalización: “(...) la que tiene lugar a través de los mecanismos disciplinarios y la que producen los dispositivos de seguridad. (...) La diferencia fundamental entre ambas formas de relacionarse con la norma radica en que, en el caso de las disciplinas, la norma precede a lo normal y lo anormal. Dicho en otros términos, los mecanismos disciplinarios parten de un determinado modelo, establecido en función de los objetivos que se quiere alcanzar" (E. Castro 2011:116).

15 'Si bien Foucault le atribuye un sentido preciso al termino 'biopoder', reconoce que puede asumir dos alcances diferentes. El sentido general hace referencia a las formas de ejercicio del poder que tienen por objeto la vida biológica del hombre. Entendido de esta manera general incluye tanto el poder ejercido sobre los cuerpos de los individuos (las disciplinas, la anátomopolítica) como el poder ejercido sobre la población o la especie (la biopolítica)" (Castro, 2011: 55). 
cuerpo y a la población y permitirá controlar el orden disciplinario del cuerpo y los hechos aleatorios de la multiplicidad, será la norma" (Foucault, 1996: 204).

La disciplina ordena, la biopolítica regula y el Estado hace uso de esos mecanismos represivos al tiempo que reproduce la ideología dominante. Como escribe Foucault (1996) "La biopolítica es la presencia de los aparatos de Estado en la vida de las poblaciones" (pág. 10). De este modo, la modernidad muestra la tensión entre la libertad y la seguridad, esto puede entenderse si se considera que es la seguridad que sostienen estos aparatos y dispositivos la que permite ciertas prácticas de libertad y procesos de liberación ${ }^{16}$.

En este sentido, un civil es una persona que habita la ciudad, al tiempo que asume el carácter de civilizada en la medida que cuenta con características que la convierten en alguien educado, refinado y ordenado. Una sociedad cualquiera adquiriría el carácter de una sociedad civilizada que se distingue de otra -e incluso de otro momento de ella misma- por el grado de orden, educación y previsibilidad presente en las costumbres que organizan y estructuran las relaciones en los espacios de la vida pública-política, pública-social y hasta de la vida privada. Describe Heinich (1999: 12)

(...) la evolución de los gestos que definen estas "costumbres" es indisociable de la evolución de la sensibilidad (...) Profundamente incorporados y percibidos como naturales, estos sentimientos entrañan la formalización de reglas de conducta, que construyen un consenso sobre los gestos que conviene o no conviene realizar- gestos en sí mismos que contribuyen a su vez a modelar la sensibilidad.

Esta relación indisociable entre la sensibilidad de la sociedad y los gestos es efecto del funcionamiento de las instituciones, lo cual requiere coacciones que no provienen de una institución particular, sino del cuerpo que conforman todas las

\footnotetext{
${ }^{16}$ La diferencia es fundamental. Como se verá, la disciplina existe desde la antigua Grecia. Sin embargo, es claro que hay toda una serie de técnicas de sí, que en la antigüedad contaban con una autonomía que pierden en el momento en que se ven asumidas por diferentes instituciones.
} 
instituciones de la vida pública (incluso los clubes y escuelas deportivas, por eso el locus de observación), lo que termina cristalizando un deber ser. Este cuerpo da forma a una intimidad que se diferencia pero no se desvincula de la vida privada. Esta intimidad supone la dimensión en el que se ejercen las restricciones que el individuo se auto-impone (o cree hacerlo); es decir, un "yo" o un "uno mismo" que encuentra su reflejo en el deber ser que, en el mismo movimiento en que decide acatar esas normas y ser civilizado decide acercarse a ese deber ser del cual ya es previamente reflejo.

No decimos lo que queremos; queremos lo que decimos en un lenguaje que recibimos ya hecho según un contrato sellado en lo que Lacan, en su primera enseñanza, llamaba «Otro». Desde el momento que hablamos, la presencia viva del objeto está proscripta por un orden simbólico que sofoca y corta el continuo de la vida y nos priva de un objeto original que viaja y se pierde en las diferencias del lenguaje (Giorgi y Rodríguez, 2007: 17).

En este sentido, los modos que se encuentran enteramente configurados en los códigos y normas de una institución y que van mucho más allá de la misma, afectan todas las formas y los comportamientos en la vida pública y privada; estas sujeciones, estas coacciones auto-coaccionadas nunca son causa del individuo, sino todo lo contrario, él es su efecto.

El rechazo, el miedo, el pudor, la culpa o la emoción de hacer algo prohibido, en la intimidad de la vida privada o en el fulgor del juego deportivo, muestran hasta qué punto se naturalizan los modos y actitudes de una sociedad. Lo que en la vida cotidiana es el rechazo a la anormalidad, la culpa de no comportarse como es debido, la vergüenza de ser una rareza; en la práctica deportiva va de la falta de caballerosidad y honor, hasta lo no conveniente para el objetivo del juego. Se puede anticipar que el no cumplimiento de las reglas y normas conllevan la imposibilidad de llevar adelante la práctica deportiva. El individuo moderno es libre 
de elegir, pero está sujeto a determinadas elecciones que no pueden romper con la normativa acordada.

\section{PROGRESO DE LA LIBERTAD Y LA CONCIENCIA DE OCCIDENTE}

El refinamiento de las costumbres y la nobleza del espíritu que caracteriza el proceso civilizatorio posee un gran componente aristocrático: la diferencia entre la vida de la ciudad y la del campo, los modos en los gestos, los códigos de conducta que comienzan a reproducirse (por ejemplo sobre el modo de sonarse la nariz o escupir, o bien los modos en la mesa o en el dormitorio, dirigirse a otra persona en público, etc.), son los de un grupo reducido de la población de occidente. No es casual que el deporte moderno haga sus primeras apariciones en Inglaterra y que sus primeros practicantes sean aristócratas. Se comprende entonces por qué "en la reacción romántica contra estas pretensiones de civilización, se acuñaron palabras alternativas que expresaban otras clases de desarrollo humano y otros criterios del bienestar humano, en particular cultura" (Williams, 2003: 60).

En su definición de civilización escribe Gallino (1995: 140): "Un servicio disímil desempeñaba (...) en alemán, el termino Zivilisierung, que acentuaba el sentido de proceso exterior, de adorno externo superpuesto por convención social a algo que era más arraigado, genuino y profundo: la Kultur". Siguiendo esta definición, civilización implica una serie de características como las descritas y, a su vez, pretende imponer la ideología de la aristocracia de occidente, más específicamente de Inglaterra y Francia (aunque implícitamente y en nombre de la ideología occidental).

Si se acepta entonces que las sociedades y los individuos que las integran son civilizados, ordenados y educados, hay que considerar las ideas y actitudes que se ponen en juego en este orden y en esta educación. Analizar el estado civilizado de una sociedad por el grado de ordenamiento y por el refinamiento en sus modales sin conocer las ideas que sostienen el orden, el refinamiento, la 
educación, dejaría entrever al proceso de la civilización más como una evolución de la naturaleza humana que a un movimiento histórico y político.

Distintos autores coinciden en que la sociedad europea se constituye como civilizada en oposición con la de oriente. Escribe Bobbio (1998: 156):

A la pregunta, planteada por Kant, sobre si el género humano está en constante progreso hacia lo mejor, la mayor parte de los filósofos había dado una respuesta afirmativa (...) Sin embargo, al mismo tiempo, el progreso, o el constante movimiento hacia lo mejor, se consideraba como una característica de la historia europea.

Entonces, ¿a qué llamamos progreso?, ¿qué es lo mejor? Continúa Bobbio (1998: 159):

La idea de progreso había nacido en la época moderna, contemporánea al desarrollo de la ciencia y de la técnica, que hasta entonces había parecido, y hasta nuestros días se ha demostrado, irreversible. Sin embargo, solo tuvo su consagración cuando se fue formando la convicción de que el progreso científico era la condición necesaria para el progreso de las costumbres y de las instituciones $y$, por tanto, las naciones científicamente más avanzadas eran también las naciones más civilizadas.

Siguiendo esta línea de pensamiento, el progreso científico puede ser condición para el progreso de las costumbres; y de igual manera, el progreso de las costumbres puede ser condición del progreso científico. La historia de occidente cuenta que:

(...) las civilizaciones no europeas se consideraban estacionarias, porque nunca habían despertado (...) De aquí que se asignase a las naciones europeas más evolucionadas, que se 
consideraban a la cabeza del progreso civilizador, la tarea de introducirlas en el camino que ellas ya habían recorrido (...) (Bobbio, 1998: 156).

Vale la pena recuperar el espíritu de la ilustración -que anuncia Williams (2003) anteriormente- y recordarlo como un proceso de liberación del estado de tutela ${ }^{17}$. En palabras de Foucault (1994: 3) analizando la posición de Kant frente a la salida que propone la Aufklärung:

(...) proceso que nos libera del "estado de tutela". Por "estado de tutela" entiende un cierto estado de nuestra voluntad que nos hace aceptar la autoridad de otros, para nuestra conducción en los dominios donde conviene hacer uso de la razón.

Con estos dominios el autor hace referencia a la esfera pública (pública-política). Cabe la reflexión sobre el no haber despertado, al hacer referencia a que estas civilizaciones no europeas eran pueblos serviles que no cuestionaban el carácter despótico de sus gobiernos, a diferencia de la libertad para participar de los asuntos políticos que caracteriza a los ciudadanos de las naciones modernas. Las naciones europeas se caracterizaron por haberse liberado del estado de tutela.

Cual fuese el criterio en virtud del que se debía juzgar el progreso o decadencia de una nación, podía variar de un autor a otro; pero el criterio dominante fue el de la libertad: la historia humana era progresiva en cuanto historia de la libertad (...) El paso de la humanidad- vaticinado por Marx- del reino de la necesidad al reino de la libertad puede considerarse como una de las expresiones de la confianza del XIX en el progreso, de la que, una vez más, la semilla más importante se encontraba en la filosofía hegeliana de la historia. La historia humana -enseñaba

17 O minoría de edad según la traducción. Escriben Horkheimer y Adorno (1998: 129): "La lustración es, en palabras de Kant, «la salida del hombre de su autoculpable minoría de edad. La minoría de edad significa la incapacidad de servirse de su propio entendimiento sin la guía de otro»". 
en sus Lecciones sobre la filosofía de la historia- es el progreso en la conciencia de la libertad (Bobbio, 1998: 157).

Mientras que Elias (1994: 57) afirma:

(...) no hay nada que no pueda hacerse de forma civilizada y de una forma incivilizada (...) Pero si se trata de comprobar cuál es, en realidad, la función general que cumple el concepto de civilización y cuál es la generalidad que se pretende designar con estas acciones y actitudes humanas al agruparlas bajo el término de civilizadas, llegamos a una conclusión muy simple: este concepto expresa la autoconciencia de Occidente.

Esta autoconciencia ¿se refiere a la libertad? De ser así, ¿libertad en qué términos?, o ¿respecto de qué?

Con el término civilización trata la sociedad occidental de caracterizar aquello que expresa su peculiaridad y de lo que se siente orgullosa: el grado alcanzado por su técnica, sus modales, el desarrollo de sus conocimientos científicos, su concepción del mundo y muchas otras cosas (Elias, 1994: 57).

Tanto Bobbio como Elias describen la particular relación de Occidente y Oriente; en Bobbio (1998: 157-158) la diferencia está marcada por la conciencia de libertad en términos políticos, ya que opone el binomio libertad/progreso con el par despotismo/inmovilismo, haciendo referencia al núcleo de lo que ha llamado "(...) ideología europea, es decir, el conjunto de creencias sobre cuya base se formó la conciencia de Europa en oposición y enfrentamiento con el mundo extraeuropeo"18; mientras que en Elias (1994) la conciencia también hace referencia a la libertad, pero pone el acento en la liberación del Estado bárbaro, rústico, rudo, sea por los avances científicos o fundamentalmente por el control en las emociones de los hombres.

\footnotetext{
${ }^{18}$ Para ganar precisión, vale aclarar que: “(...) señaló Hegel (1770-1831), en los reinos despóticos de Oriente 'uno solo es libre', los Estados despóticos son estacionarios e inmóviles, no sujetos a la ley del progreso indefinido que solamente vale para la Europa civil” (Bobbio, 1992: 31).
} 
Si bien con enfoques distintos, en ambos se puede entrever la clara tendencia del concepto civilización a designar -a la vez que constituir- la conciencia europea en contraposición con el Oriente y, consecuentemente, en sacar al hombre de su estado de sometimiento tanto político como ideológico.

El progreso es la dirección de la técnica y la historia de la libertad. El dominio de la naturaleza, gracias al avance de la técnica, logra que el hombre en el mismo movimiento -siendo él mismo parte de la naturaleza-, acabe por dominarse a sí mismo. La idea de progreso entonces, supone el avance tecnológico y el dominio del hombre sobre la naturaleza y sobre sí mismo. Así es como el Estado, en pos de la liberación política e ideológica, somete a la represión y la coacción de las normas, escribe Hobbes (1999: 89):

(...) fuera del régimen del Estado cada uno conserva su libertad íntegra aunque infructuosa; porque el que gracias a su libertad todo lo hace a su arbitrio, gracias a la libertad de los demás todo lo padece al arbitrio ajeno (...) una vez constituido el Estado, cada ciudadano conserva la libertad que le basta para vivir bien y con tranquilidad, y a los demás se les quita lo justo para que no sean de temer. Fuera del Estado cada uno tiene tanto derecho a todo, que no puede disfrutar de nada, pero en el Estado todos disfrutan con seguridad de un derecho delimitado.

Si el progreso de la libertad puede ir en detrimento de la libertad, se tendría que aceptar su revés lógico, es decir, que la coacción favorezca la libertad. En términos deportivos la libertad de jugar sin temor a perder la vida supone la coacción de la regla, así como a otro nivel las restricciones que propone un sistema de juego admiten la libertad de la creatividad. Mientras que desde otro enfoque la pura libertad supone un juego descontrolado, violento y asistemático, así como la pura creatividad olvida todo emprendimiento colectivo.

Es significativo realizar un breve desarrollo respecto a la idea que subyace a la forma hegeliana: la historia como historia de la libertad, que ayuda a comprender 
mejor la idea de libertad ya enunciada. Es interesante detenerse en esta cita de Bobbio (1993: 134) quien da precisión al asunto definiendo tres direcciones en la lucha por la libertad

Cuando, con las teorías del progreso, apareció por vez primera con particular ímpetu la interpretación de la historia como historia de la libertad, la lucha por la libertad se concibió en esta triple dirección: a) como liberación de la superstición religiosa, en general de toda forma de dogmatismo de las ideas que obstaculiza el avance de la filosofía esclarecedora y de la ciencia liberadora, e impide el libre desarrollo de las opiniones, la ampliación del saber, el conocimiento real de la posición que el hombre tiene en el mundo; b) como liberación de los vínculos de una estructura económica que defiende privilegios históricos hoy en día ya anacrónicos, frena la iniciativa del capitalismo naciente, la libre expansión de nuevos grupos dirigidos a la producción de nuevos bienes, la conquista de nuevos mercados, el desarrollo de nuevas fuerzas productivas; c) como liberación de un sistema político y legislativo concentrado en un restringido círculo de la clase dominante que se trasmite el poder hereditariamente, incontrolado, arbitrario, despótico, concentrado, frente al cual el individuo singular no goza de garantía alguna contra el abuso de poder.

Se identifican en estas direcciones tanto la libertad en términos políticos que menciona antes Bobbio (1993) (tercera dirección) como también la que menciona Elias (1994) (primera dirección), en términos del avance de la técnica. Se observa cómo las tres líneas de lucha por la libertad se corresponden con tres formas o campos de poder: el ideológico, el económico y el político. Del dogmatismo religioso a la ciencia liberadora, del privilegio por tradición a la igualdad política, de la monarquía a la democracia. Respecto a este momento escribe Gramsci (2011: 60-61), 
Se convirtió en uno de los momentos más importantes y más significativos de la vieja y paciente lucha que los hombres mantienen contra la naturaleza y contra una parte de sí mismos para ser cada vez más libres, más dueños de su voluntad y de los medios para alcanzarla. $\mathrm{Y}$ el propósito que los hombres anhelan con su actividad fue estableciéndose cada vez mejor y ya no fue un fin ultraterreno, otra vida, y también fue humanizado, secularizado. (...) Un sepulcro, una ciudad, volvieron a ser simplemente un sepulcro, una ciudad. Los hombres descubrieron que la luz que una vez les pareció que irradiaba del más allá, irradiaba en realidad de su conciencia, de su voluntad, de sus propias obras. (...) No fue tanto que Jerusalén fue liberada como que los hombres fueron liberados por Jerusalén. Porque una libertad fosilizada, materializada, dogmatizada se convierte en esclavitud (...).

Esa transformación se dio en la trama de la vida social, en la cotidianidad de todas las prácticas, pudiéndose observar cómo unas influyen sobre otras, aunque, en una primera instancia, puedan parecer desvinculadas. El progreso de formas científicas de pensamiento a las que se accede, entre otras cosas, gracias al control emotivo de los seres humanos, bien puede ser ejemplo de ello, como escribe Elias (1994: 39):

No es posible desarrollar formas científicas de pensar, ni convertirlas en un bien común, si no se consigue que los hombres se liberen de la seguridad primaria con la que tratan siempre de comprender en un principio, de modo irreflexivo y espontáneo, todo lo experimentado en función de su objetivo y sentido. Considerada desde otro punto de vista, la evolución que llevo a un conocimiento objetivo y a un control creciente sobre los procesos naturales por parte del hombre, también fue una evolución hacia el autocontrol de los seres humanos. 
Corresponde pensar las relaciones que se establecen entre las tres esferas que identifica Bobbio (1998): saber, economía y política, y lo expuesto por Elías sobre los modales y las costumbres, la ciencia y la técnica, la posesión de la fuerza, el trabajo y el comercio, para observar las tensiones existentes entre coacción y libertad, seguridad y control. Se volverá sobre esto al analizar la constitución de los Estados-Nación.

Ante lo expuesto, se establece que civilización hace referencia a un proceso que pone en juego toda una estructura coercitiva que, sujeciones mediante, libera y habilita la conciencia de esta libertad. Estas sujeciones se cristalizan en una serie de coacciones que se imponen al hombre y le permiten pensar de otra manera al mundo, las relaciones con las cosas, los hombres e, incluso, con él mismo.

Hasta aquí se relataron discusiones en torno al uso del concepto civilización. Es necesario comprender que la civilización, en el marco de esta tesis, implica reconocer que individuo y sociedad no son entidades desarticuladas independientes la una de la otra. Pensar los fenómenos que se dan en el ámbito de los hombres implica necesariamente tomar en consideración que no existe un yo independiente, un ego, un individuo autónomo desvinculado de la sociedad.

(...) nadie comprende adecuadamente por sí mismo y sin sus iguales lo que es objetivo en su plena realidad porque se lo muestra y manifiesta siempre en una perspectiva que se ajusta a su posición en el mundo y le es inherente (...) Solamente en la libertad de conversar surge en su objetividad visible desde todos lados el mundo del que se habla (Arendt, 1997: 79).

Es precisamente en esta relación con los otros donde tiene lugar el mundo y la política. Si de proceso de civilización se habla, esta relación inextricable entre individuo y sociedad se observa manifiesta en las condiciones de posibilidad que formaron parte del gran empuje civilizador de occidente, por ejemplo, en la conformación de los Estados-Nación, lo que resulta fundamental, ya que, 
(...) lo importante para nosotros es que entendamos la libertad misma como algo político y no como el fin supremo de los medios políticos y que comprendamos que coacción y violencia eran ciertamente medios para proteger o fundar o ampliar este espacio político pero como tales no eran precisamente políticos ellos mismos (Arendt, 1997: 80).

Si una de las características fundamentales del Estado es el poder de ejercer la violencia legítimamente para, entre otras cosas, generar el espacio político ${ }^{19}$, la relevancia de interpretar el proceso de la civilización como una matriz de pensamiento que permite, parafraseando a Agamben (2004: 12), superar el binomio individuo/sociedad y convertirla en polaridades recorridas por tensiones que impiden poder establecer un límite claro que las separe.

Entender la articulación entre el progreso y la libertad en relación con la política implica poner en tensión la idea misma de libertad y también la de autoridad. La liberación que compromete varios órdenes de poder: política, ideología y economía, pone en juego el gobierno tanto en la vida privada como en la vida pública. Fundamentalmente supone la primacía de lo público y consecuentemente una reinterpretación de la autoridad y su legitimidad. ¿Quién ordena?, ¿por qué se debe obedecer?, ¿hasta dónde se puede ordenar?, ¿hasta qué punto se debe obedecer? Incluso antes de la pregunta por quién ordena, la adecuada sería ¿qué ordena?:

(...) la primacía de lo público significa el aumento de la intervención estatal en la regulación coactiva del comportamiento de los individuos y de los grupos infraestatales, o sea, el camino de la emancipación de la sociedad civil con

\footnotetext{
${ }^{19}$ Espacio político que encuentra su razón de ser en la posibilidad que tienen todos de participar del mismo. Si bien el todos no puede ser más que una ilusión en términos estrictos, la representación (o que nuevos grupos de la comunidad tengan participación), aunque sea indirectamente, cuentan con la posibilidad de hablar, "(...) para la libertad no es necesaria una democracia igualitaria en el sentido moderno sino una esfera restringida, delimitada oligárquica o aristocráticamente, en que al menos unos pocos o los mejores traten los unos con los otros como iguales entre iguales" (Arendt, 1997: 70).
} 
respecto al Estado que fue una de las consecuencias históricas del nacimiento, desarrollo, hegemonía, de la clase burguesa (...) (Bobbio, 2006: 29).

La intervención del Estado es la encargada de formar al ciudadano y, en este sentido, resulta necesario mostrar algunas características esenciales del Estado y su naturaleza.

\section{DEL ESTADO}

La conformación de Estados-Nación fue uno de los sucesos más significativos que supuso el progreso en los diversos órdenes, los cuales cuentan con características que influyen en el proceso civilizador, tanto como éste en ellos.

Un factor determinante de esta dialéctica tiene que ver con un doble monopolio por parte del Estado, por un lado, el de la violencia o de la fuerza y, por el otro, el de la recaudación de impuestos. Según Elias y Dunning (1992: 24),

Los elementos centrales de este proceso civilizador han sido: la formación del Estado, lo que equivale a decir el aumento de la centralización política y administrativa, y la pacificación bajo el control del Estado, proceso del que un componente clave ha sido la monopolización por el Estado del derecho a utilizar la fuerza y a cobrar impuestos; el alargamiento de las cadenas de interdependencia; el cambio hacia la compensación, en la balanza del poder, entre las clases sociales y los demás grupos, es decir, un proceso de 'democratización funcional'; la elaboración y el refinamiento de los modales y normas sociales; el aumento concomitante en la presión social sobre los individuos para que autocontrolen su sexualidad, su agresividad, sus emociones en general (...) (cursivas nuestras).

Este doble monopolio favorece, gracias a la seguridad que sostiene, el acrecentamiento de las redes de interdependencia que no significan otra cosa que 
la diversificación de las funciones de los ciudadanos, lo que además supone un modo particular de relacionarse en los diferentes ámbitos de la vida en la ciudad. En ella se depone cualquier pretensión de hacer valer los propios intereses con la fuerza y el único medio para llegar a una decisión que afecte a todo el pueblo es la discusión (...)" (Bobbio, 1998: 139). Ejemplo de ello es el caso inglés, cuyo parlamento, en tanto que arena de conflicto, muestra claramente el predominio de este medio en la toma de decisiones durante el siglo XVIII. Aun habiendo debates en el parlamento, éstas no quedaban exentas de represalias sangrientas, lo que generaba la inestabilidad propia de las relaciones en un contexto de inseguridad. Sin embargo, fue en este siglo en el que avanzó notablemente el pensamiento político en el que emerge la soberanía popular ${ }^{20}$.

Las tensiones entre el parlamento y los monarcas, en un contexto de enfrentamientos entre católicos y protestantes, se tejían en la disputa, que colocaba a Dios como ser supremo, pero no se decidían respecto a si éste mandaba para el pueblo a través del rey o al rey. Sin intentar resolver el conflicto en estas líneas, la idea de bien común comienza a tener cada vez más relevancia, en un contexto en el que el Rey pasaba de responder a Dios, a responder al pueblo (Morgan, 2006), con la consecuente impunidad que esto suponía.

Las disputas dentro del parlamento inglés dan cuenta de conflictos de clase sobre todo cuando se observa el funcionamiento de la Cámara de los Lores, la Cámara de los Comunes y el Rey. Los Comunes estaban representados en gran medida por la gentry que era un grupo social compuesto por propietarios de tierras rurales que no poseían títulos de nobleza, que comenzaron a tener lugar en el parlamento a partir de la necesidad de los reyes Tudor. Este grupo cumplió un rol fundamental en el desarrollo de los acontecimientos en el ámbito político y muestra de ello es que, a pesar de responder al rey, defendían los intereses de los súbditos, grupo del que ellos mismos formaban parte (Morgan, 2006).

\footnotetext{
${ }^{20}$ Se puede objetar el concepto popular, sin embargo es la tensión entre parlamento y pueblo la que avanza y habilita el funcionamiento democrático, vale nombrarlo siendo que, antes o después, el pueblo posee un poder que ceder. Esto supone la salida de lo salvaje y violento que, adelantamos en el texto, esta salida no es un fin sino un medio, donde se debe trabajar para sostener esta salida.
} 
Estos desplazamientos se cristalizan con sutileza en los debates que tienen lugar en el parlamento, los argumentos utilizados muestran cómo se utilizaba la misma divinidad del Monarca para corregir los defectos del hombre Rey, equivocaciones cuyas causas se encontrarían en quienes obedecían tales órdenes salvando así, la divinidad del Rey ${ }^{21}$.

Ya durante el siglo XVIII el Estado se presenta como el contexto propicio, causa y efecto a la vez, para la materialización del proceso de la civilización. En este marco, el cuerpo queda ceñido a controles estrictos, sujeciones que resultan ser apoyo firme para la elaboración de conductas refinadas, lucha que no se da en términos de eliminación, sino de empoderamiento. Es gracias a estos mecanismos, que dan forma a modos previsibles de comportamiento, que las personas pueden plantear estrategias en las diferentes redes de tensión.

Ahora bien, para comprender cómo se cristaliza este proceso, resulta interesante pensar que:

(...) de la misma manera que no se cambia un mundo cambiando a los hombres (...) tampoco se cambia una organización o una asociación empezando a influir sobre sus miembros. Si se quiere cambiar una institución, una organización, cualquier corporación pública mundana, solo puede renovarse su constitución, sus leyes, sus estatutos y esperar que todo lo demás se dé por sí mismo (Arendt, 1997: $57)$.

\footnotetext{
21 "(...) en 1629, cuando, al inaugurarse las sesiones, un miembro hizo saber que los funcionarios de aduana le habían embargado algunos artículos por negarse a pagar tonelaje y una tasa por cada libra de peso. El parlamento normalmente había votado estos impuestos sobre las importaciones para el monarca por la duración de su reinado, pero se había negado expresamente a votárselos a Carlos, y este lo había convocado para pedir la concesión de otros impuestos. Los miembros del parlamento se dieron cuenta rápidamente de que a menos que los artículos embargados fueran devueltos, la concesión de nuevos impuestos implicaría que el embargo había sido válido y que el rey podía cobrar tonelaje y una tasa por cada libra de peso sin su consentimiento. Si el rey lo hacía, en opinión del Parlamento estaría claramente cometiendo un error, pero el rey no podía cometer errores. Por lo tanto los que debían estar equivocados eran los funcionarios de aduana, por no mencionar al tribunal de hacienda, que había aprobado el embargo" (Morgan, 2006: 29).
} 
Tal proceso se manifiesta principalmente en las instituciones que norman y reglamentan su funcionamiento, ejemplo de ello bien puede ser el parlamento, también el taller, el hospital, la escuela. En sociedades actuales los medios masivos de comunicación y las distintas agencias de transmisión de la cultura (entre ellas los clubes sociales y deportivos, las escuelas de deportes), instituciones que conforman un cuerpo que responde a una ideología dominante que los unifica.

En el contexto inglés del siglo XVIII, parece evidente la presencia en el parlamento de alianzas de clase, como la aristocracia y la gentry. Es aceptable la idea que supone el control de éstas sobre las instituciones y la consecuente expansión de los modos aristocráticos de comportamiento al resto de la sociedad, cambios que, retrayendo lo escrito por Arendt (1997), no se realizan influyendo en los hombres, sino transformando las normas, leyes y estatutos de las instituciones.

Esto deja una reflexión clara respecto a las transformaciones que se dan en este contexto: si bien los cambios en un sentido tienen un carácter positivo, como pueden ser la constitución de un espacio político de funcionamiento democrático, la palabra como medio para la resolución de conflictos, la internalización de coacciones para la pacificación de las relaciones; por otro lado, esta construcción conlleva la normación y la imposición de un modo aristocrático de pensar el mundo en el nombre de Occidente, modo que tiende a la dominación y manipulación de una población productiva en términos económicos y dócil en términos políticos.

A continuación se verá cómo las instituciones recurren a técnicas que se pueden considerar propias del dispositivo disciplinario de la modernidad. Dispositivo que en su funcionamiento muestra cómo "(...) la coerción disciplinaria establece en el cuerpo el vínculo de coacción entre una aptitud aumentada y una dominación acrecentada" (Foucault, 2008c: 160). 


\section{SOBRE LA LIBERTAD Y LA EDUCACIÓN}

La articulación que pone en juego el dispositivo disciplinario entre la aptitud y la dominación muestra una serie de tensiones sobre las que resulta necesario reflexionar en clave de libertad, significativas para analizar el proceso educativo (proceso que al tratarse del deporte no se restringe a la institución escolar sino a todo espacio destinado a la formación de deportistas, como clubes y escuelas deportivas). Principalmente debido a que educar implica una relación de autoridad asimétrica entre el maestro y el alumno, entre el mundo y lo nuevo ${ }^{22}$, y, en esta relación, la idea de libertad se pone en juego en varias dimensiones que van desde la coerción en la normativa para vivir en sociedad, hasta la represión más sutil necesaria para la vida institucional.

La educación implica una relación que pone en tensión la libertad. "La educación dice Fichte- debe actuar inevitablemente de tal manera que reconozcas después las razones de lo que estoy haciendo ahora" (Berlín, 1998: 253). Puede que aquel que esté siendo educado, o bien afectado por la educación, esté de acuerdo o no, sin embargo las razones pueden no ser conocidas por éste en el preciso momento en el que se está educando. Como escribe Berlín (1998: 253) respecto a los deseos de aquel que está en formación:

Si no puedes entender tus propios intereses como ser racional, no se puede esperar de mí que te consulte o me atenga a tus deseos en el proceso de hacerte racional. En último término tengo que obligarte a que te protejas de las viruelas, incluso aunque no quieras.

Estos enunciados, que bien pueden interpretarse como sumamente autoritarios, en algún punto conservan este carácter de la relación asimétrica en el proceso de

\footnotetext{
${ }^{22}$ El término nuevo hace alusión a un sentido cercano al dado por Arendt (1977: 45) para referirse a los recién llegados al mundo, a los recién nacidos, pero encontramos que también puede ser entendido, en clave de proceso civilizatorio, incorporando a la categoría nuevo otros grupos etarios, en este caso mundo no sería explícitamente la tierra, sino la civilización. De hecho, escribe: "Así, el muchacho, sujeto de la educación, presenta para el educador un doble aspecto: es nuevo en un mundo que le es extraño, y está en proceso de formación; es un ser humano nuevo, y un ser humano en proceso de formación".
} 
enseñanza, donde siempre uno debe cumplir el rol de adulto, o mejor aún, el rol de mundo.

El proceso civilizatorio supone la formación del ciudadano y consigo la presentación del mundo a los que recién llegan a él. Los niños ignoran las cuestiones inherentes a la vida en sociedad, lo que autoriza el ejercicio de una relación de autoridad, asimétrica, que los introduzca en ellas, se las enseñe. De lo contrario ellos seguirán siendo incapaces de cuestionar la coacción.

En el contexto actual, los adultos no sólo están autorizados, sino obligados a educar, aún si esto implica el ejercicio de la coacción (en palabras de Berlín, "tengo que obligarte a que te protejas de las viruelas, incluso aunque no quieras"). Quien no es civilizado no cuenta con la capacidad de responder a los requerimientos de la sociedad civil, tampoco con la capacidad para cuestionarla. El educador es la cristalización de la imagen especular que supone el individuo, o su garante. Quien ocupa ese rol es el ideal de ciudadano (aunque no lo sea efectivamente) $y$, al seguirlo y someterse a sus órdenes, se acerca progresivamente a ese ideal,

(...) al obedecer al hombre racional nos obedecemos a nosotros mismos, por supuesto no tal como somos, sumidos en la ignorancia y las pasiones, débiles criaturas afligidas por enfermedades que necesitan alguien que las cure, pupilos que requieren un tutor, sino cómo podríamos ser si fuésemos racionales (...) (Berlín, 1998: 254).

Es este deber ser el que pone en juego la tensión entre coacción y libertad. La educación, que ejerce la coacción y acerca al individuo a ese ideal de hombre, garantiza la libertad. Las tensiones que se dibujan entre la libertad absoluta de los hombres de momentos anteriores y la coacción de la que es objeto en el proceso de la civilización, muestran el juego entre la libertad de hacer lo que se quiere en la sociedad y las restricciones para sostener la sociedad (al menos como se la 
conoce) y la libertad. En este sentido es interesante recuperar lo escrito por Rousseau (1993: 18-19)

Para que el pacto social no sea, pues, una vana fórmula, encierra tácitamente este compromiso, que solo puede dar fuerza a los restantes, y que consiste en que quien se niegue a obedecer a la voluntad general será obligado por todo el cuerpo: lo que no significa sino que se le obligará a ser libre, pues ésta es la condición que garantiza de toda dependencia personal, al entregar a cada ciudadano a la patria; condición ésta que constituye el artificio y el juego de la máquina política, y que hace legítimos los compromisos civiles, los cuales sin ello serian absurdos, tiránicos, y estarían sujetos a los más grandes abusos.

Esta tensión supone la articulación entre dos tipos de libertades: la del individuo, que es libre de hacer lo que quiera hasta el punto en el que la libertad de otro se vea comprometida, y la que es producto del respeto de los acuerdos que tienen lugar en la sociedad. Si bien desde un enfoque teórico diferente, Hobbes (1999: 15) también hace referencia a lo que se denomina acuerdos colectivos:

(...) las sociedades civiles no son meras agrupaciones, sino alianzas, y para conseguirlas son necesarios la lealtad y los pactos. Los niños y los ignorantes desconocen la fuerza de estos, y los que nunca han experimentado los daños de la falta de sociedad, su utilidad. De donde se deduce que aquellos no pueden formar parte de la sociedad porque no comprenden lo que es, y éstos porque, al no saber su provecho, no se preocupan por ella. Está claro, por lo tanto, que todos los hombres, al haber nacido niños, han nacido ineptos para la sociedad, y que muchos, tal vez la mayor parte, permanecen 
ineptos toda su vida, bien por enfermedad del alma, o bien por falta de educación ${ }^{23}$.

Independientemente de lo polémico del enunciado de Hobbes, se plantea una afirmación que se acepta sin mucho esfuerzo: la educación es garante de la formación del ciudadano. En el proceso civilizatorio es este ciudadano, coaccionado en nombre de la libertad, al que se conoce como individuo. El cuerpo institucional participa de esta educación que, en el mismo movimiento que produce al individuo, lo domina. La articulación de la ideología y la represión en los intersticios de los funcionamientos institucionales dan forma al ciudadano ideal, que es producto de las relaciones de poder que lo dividen. Escribe Berlín (1998: 233):

Dos yos pueden estar representados como separados por una distancia aun mayor: puede concebirse al verdadero yo como algo que es más que el individuo (tal como se entiende este término normalmente), como un todo social del que el individuo es un elemento o aspecto: una tribu, una raza, una iglesia, un Estado (...) Esta entidad se identifica entonces como el verdadero yo, que imponiendo su única voluntad colectiva u orgánica a sus recalcitrantes miembros logra la suya propia y, por tanto, una libertad superior para estos miembros.

Puede identificarse en estos yos la libertad en su doble sentido: la negativa que se corresponde con el yo del individuo particular y la positiva que se corresponde con la del colectivo. La primera, que es la libertad de hacer lo que se quiera mientras no sobrepase la libertad del otro, y la segunda, que es la del respeto por los acuerdos para liberar la sociedad.

\footnotetext{
${ }^{23}$ El extracto pertenece al Tratado sobre el ciudadano escrito en Inglaterra en 1646, contexto en el que el mundo occidental, y en particular este país, comienza a emanciparse del pensamiento medieval.
} 
No se pierde libertad por estar encadenado, a veces hay que encadenarse para quedar bajo el peso de cadenas más livianas y es, en este sentido, que se requieren cadenas para liberarse.

El problema que aquí se trasluce es el de la autoridad ¿quién tiene la autoridad para mandar y obligar a ser de tal o cual manera? Y esta autoridad, ¿en qué punto pierde su legitimidad?, ¿cuándo se convierte la autoridad en autoritarismo?

El proceso civilizatorio supone, en muchos aspectos, tensiones al gobierno, tanto de los cuerpos como de las poblaciones. Estas coacciones y controles se interiorizan con el avance del proceso y, en la medida que esta interiorización es más marcada, el yo se divide: por un lado, el que se somete al mandato del deber ser $y$, por el otro, el que decide someterse. Claro al respecto resulta la cita de Berlín (1998: 231)

El sentido positivo de la palabra libertad se deriva del deseo por parte del individuo de ser su propio dueño. Quiero que mi vida y mis decisiones dependan de mí mismo, y no de fuerzas exteriores (...) Quiero ser el instrumento de mí mismo y no de los actos de voluntad de otros hombres (...) Quiero ser sujeto y no objeto (...) quiero ser alguien, no nadie; quiero actuar, decidir, no que decidan por mí (...).

Este es el núcleo, “(...) el problema central de la política: el problema de la obediencia y de la coacción" (Berlín, 1998: 219), conflicto que no se ha resuelto y que parece ser más importante mantener en la problematización.

El proceso civilizatorio -que supone progreso y libertad o bien un progreso de la libertad- no permite suponer a priori la idea de progreso. Como lo hemos descripto anteriormente, el proceso civilizatorio se muestra como un proceso histórico en el que la libertad no aparece como un factor lineal cuyo aumento sea directamente proporcional al progreso, no existe una relación necesaria entre éste y el aumento de las libertades. Y, así como la coacción no implica necesariamente un retroceso en los niveles de libertad, el aumento en las libertades no implica avances. Esta 
tensión, que resulta necesario sostener, es la apuesta. Al respecto, escribe Foucault (1994: 12):

Está indicada por lo que pudiéramos llamar "la paradoja [de las relaciones] de la capacidad y del poder". Sabemos que la gran promesa o la gran esperanza del siglo XVIII, o al menos de una parte de él, estaba centrada en el crecimiento simultáneo y proporcional de la capacidad técnica de actuar sobre las cosas, y de la libertad de los individuos, unos en relación con otros. Por lo demás, se puede ver que a través de toda la historia de las sociedades occidentales (...) la adquisición de capacidades y la lucha por la libertad han constituido elementos permanentes [de esa historia]. Ahora bien, las relaciones entre crecimiento de capacidades y crecimiento de la autonomía no son tan simples como se pudo creer (...) las disciplinas, tanto colectivas como individuales y los procedimientos de normalización ejercidos en nombre del poder del Estado, de las exigencias de la sociedad o de regiones de la población, constituyen algunos ejemplos. La apuesta puede entonces resumirse en la siguiente pregunta: ¿Cómo desconectar el crecimiento de las capacidades y la intensificación de las relaciones de poder?

Desconectar estas dimensiones desprende algunas preguntas: ¿De dónde sale la legitimidad de esta coacción?, ¿quién decide los núcleos de coacción? O lo que es igual, ¿cómo se establecen las formas del deber ser al que toda subjetividad individual apunta?, ¿cuáles son los límites de esta coacción?

Las tensiones entre una libertad negativa y una libertad positiva son claras, 0 mejor dicho, es claro que existe una tensión, sin embargo el juego se complementa con el borde que se forma entre la autoridad y el autoritarismo, entre el totalitarismo y el liberalismo. 
Al reflexionar sobre estas cuestiones en clave educativa, se aprecia cómo el proceso civilizatorio que tiene lugar en la modernidad se muestra como una imposición de la cultura occidental, sin embargo la coyuntura permite sostener la autoridad y la normación en pos de una libertad que, en ese momento histórico, podía suponer la idea de progreso.

Este movimiento plantea un desafío sobre el que se reflexiona: la tensión entre la libertad en su dimensión negativa y la coacción que ejerce el funcionamiento institucional en la actualidad. Ya que bien podría preguntarse si en la medida en que se deja funcionar una libertad plena, no se estaría condenando a la esclavitud. En este sentido, toda autoridad corre el riesgo de ser interpretada como autoritaria, toda coacción como un ataque a las libertades individuales, todo disciplinamiento, dominador y en consecuencia, negativo. Si bien estos enunciados pueden inclinarse hacia la verdad en determinados momentos, esta no es una relación necesaria, sino contingente. $Y$ es precisamente esa contingencia la que se muestra en los usos del dispositivo disciplinario en el campo de la Educación Física, con especial atención a uno de sus contenidos: el deporte.

La civilización es un proceso que comienza en la modernidad y supone la conformación del Estado y de lo necesario para su funcionamiento. En las instituciones se comienza a formar al ciudadano responsable y pacífico, y al individuo dócil y productor. En este proceso, la idea de progreso se relaciona con la conciencia de la libertad y esto, en términos políticos, significa que este ciudadano es sujeto de derechos, y también de obligaciones.

El Estado tiende a reducir sus intervenciones y cede terreno al mercado que, en este avance, también ha ganado terreno en la política y ha sido y es propulsor en la exacerbación de los derechos y el olvido de las obligaciones. La civilización -en tanto que proceso- ni ha culminado ni culminará, ni tampoco tiene una clara dirección hacia el progreso.

Si se entiende al progreso como conciencia de la libertad ( $y$ se pretende ir en su búsqueda), es necesario comprender la libertad como lo político y no como el fin 
de lo político. Esto implica pensar en prácticas de libertad, más que en procesos de liberación (Foucault, 2010). Hoy la libertad negativa protagoniza la escena y en el intento de ejercer su máxima expresión atenta contra sí misma en un movimiento regresivo. Más adelante se conversará sobre ello. 


\section{CAPITULO II: SOBRE EL DEPORTE}

Si aparece algún término en el que pensábamos fijarnos y asegurarnos, oscila y nos abandona; si lo seguimos, escapa a nuestras tomas, se nos desliza y huye con eterna fuga. Para nosotros, nada se detiene. Tal es nuestro estado natural $y$, sin embargo, es el más contrario a nuestra inclinación; ardemos por el deseo de hallar un asiento firme y una última base constante sobre la cual edificar una torre que se eleve al infinito $n$, pero todo nuestro fundamento cruje y la tierra se abre hasta los abismos (Pascal, 2015: 100-101).

Uno de los objetivos de este capítulo es restringir, cuanto sea posible, los usos del término deporte, dotarlo de profundidad y amplitud: profundidad en cuanto a su especificidad y amplitud respecto a la articulación con otros saberes.

Para ello, se analizó lo dicho hasta el momento por algunos referentes de la Educación Física y sociólogos, así como también lo escrito en diccionarios específicos, generales y académicos. Se mostraron las dificultades en el acuerdo respecto a la definición del término deporte del cual se desprenden dos perspectivas para su análisis: una ahistórica y otra histórica.

Esta decisión de ampliar la articulación con otros saberes y restringir el uso del concepto se debe a que el fenómeno deportivo encuentra en sus manifestaciones discursivas y no discursivas tanta diversidad que dificulta la posibilidad de hacer de él un objeto de estudio. Es difícil saber qué es, porque de él se dicen demasiadas cosas.

En este apartado se muestra la imposibilidad lógica de una definición universal y eterna de deporte que, como todo concepto, es contingente. Las teorías fracasan 
en su intento de definir el deporte debido a la imposibilidad epistemológica que supone entender que el objeto está dado, mientras que existen una multiplicidad de fenómenos que no permiten el acceso directo a la cosa (Heisenberg, 1994 ${ }^{24}$ ).

Como afirma Elías (en Elías y Dunning, 1992: 187): "No son pruebas lo que realmente faltan. Es solo que, al buscarlas, no nos damos cuenta de su existencia debido a las ideas preconcebidas reinantes sobre cómo se escribe la historia en general y la de los deportes en particular". Ideas que en su carácter de presupuestos operan como obstáculos epistemológicos (Bachelard, 2000). Sin embargo, hay un camino posible para la construcción del deporte como objeto de estudio, mientras se da cuenta de la teoría y el método como procesos que se retroalimentan y en cuya dialéctica dan forma a un objeto, siendo a la vez afectadas por éste.

En la actualidad, el deporte es algo presente en la vida de cualquier ser humano, sea porque lo practica o lo consume en alguna de sus formas, viéndolo en la televisión o en el estadio, escuchándolo en la radio, leyéndolo en los diarios, en revistas o en libros, sean éstos de literatura o ciencia. En el ambiente académico, desde la medicina en general a la medicina del deporte, de la anatomía y la fisiología a la Educación Física, pasando por la pedagogía, la psicología, la sociología y la filosofía, todos dicen y escuchan algo referido al deporte.

Esta cotidianeidad, su fácil acceso, su poca o mucha importancia, la pasión o la indiferencia que suscita, habilita que toda persona pueda emitir un juicio sobre el deporte. Los sociólogos han encontrado en él un fenómeno digno de ser analizado, los profesores de Educación Física un contenido a transmitir. También lo analizan los deportistas, los periodistas y los espectadores. En definitiva todos, ya sea desde el fanatismo del hincha, la aparente objetividad del periodista, la experiencia del deportista o las preguntas del académico o científico que tienen

\footnotetext{
${ }^{24}$ La referencia a un físico no es casual, si bien se podría mostrar, por diferentes caminos, la imposibilidad de acceder a lo real, parece contundente el hecho de que sean los propios referentes de la física (disciplina que se ocupa del estudio de la naturaleza) los que muestran tal imposibilidad. Lo que permite pensar si ya en el campo de la Física se encuentran con esa imposibilidad, ¿qué se puede esperar de un fenómeno cultural?
} 
algo para contar sobre el deporte. Algunos autores dan cuenta de esta problemática haciendo mención al carácter polisémico del término y a las dificultades para encontrar acuerdo en una definición clara y precisa,

Decir que se trata de un término polisémico es poco, es pansémico. Y como se aplica a todo, acaba por perder su valor diferenciador y acaba por no significar nada. Su sentido se ha desvanecido por abuso de la metáfora (Parlebás, 2001: 106).

Esta amplitud en sus usos y la consecuente pérdida de sentido se evidencian en la indistinción de fenómenos cuya singularidad histórica no se contempla, así se encuentra en el Diccionario Crítico de la Educación Física Académica (Carballo, 2015: 121):

(...) el concepto deporte no es un concepto interpretado o entendido de forma unívoca (Cagigal, 1979), es un concepto equívoco, utilizado a partir de diferentes acepciones y en diferentes formas. Su carácter polisémico es evidente (Mandel, 1984: 89). Esta ambigüedad es la que ha llevado además a considerar al deporte como una práctica realizada indistintamente en oriente o en occidente, tanto en China en el 6000 a.C. (...) como en ese mismo país pero en el 200 d.C.

Los límites de lo deportivo son difusos y una de las mayores dificultades se debe a que el problema tiene dos frentes: una definición que no termina de (ni puede) cerrarse y un conjunto de prácticas que no dejan de tener diferencias.

Ahora bien, si un concepto científico debe ser preciso, y si,

(...) la voz deporte se utiliza, a veces, para referirse a situaciones extremadamente dispares como una partida de ajedrez, un trotecillo por el bosque, cavar un poco en el jardín, dar unas brazadas en el mar, un partido de fútbol, una final olímpica y hasta una animada discusión. (Parlebás, 2001: 106)

La búsqueda de precisión en el concepto hace al interés de la tesis y además se constituye como una obligación implícita del rigor científico. 
La popularidad del término, su presencia abrumadora y la frecuente falta de construcción del mismo como objeto de investigación abonan su carácter evidente $y$, consecuentemente, la imposibilidad de dudar del fenómeno. "Para la población de nuestra época el deporte se constituye como uno de los términos más indudables de nuestra cultura global y un símbolo identificador de nuestra época" (Olivera-Betrán y Torrabadella-Flix, 2015: 2). Este carácter evidente e indudable debe ponerse en duda a fin de que, atravesando y reflexionando esta exposición, la precisión del asunto aumente y dote de rigurosidad el trabajo científico.

Delimitar un terreno relativamente estable de investigación para trabajar con un objeto (también con estabilidad relativa) no es un problema sino una realidad, por ello los límites son flexibles. No se puede producir una estructura fija y eterna porque el modelo perdería toda posibilidad de anticipación y, por lo tanto, indefectiblemente en el mismo momento comenzaría su regresión (Lakatos, 1978). Vale aclarar -y éste es el desafío- que esta flexibilidad de los límites no habilita a decir o a interpretar cualquier cosa, sino que procura ganar precisión y sostener el carácter progresivo de un modelo científico que trabaja con los efectos culturales de una realidad interpretada a través de su teoría.

La exposición permanente de este fenómeno que convoca tiene como efecto una gran dificultad a la hora de hacer una definición precisa porque, después de todo, el deporte no puede ser otra cosa que aquello que las personas entienden por ello, al respecto opina Cagigal (1975: 32):

El pueblo entiende también por deporte gran espectáculo, destacados campeones, poderosas sociedades, empresas económicas, rivalidades populares, etc. El pueblo es el verdadero dictador del lenguaje, $y$, queramos o no, a toda esta compleja y alborotada realidad social de nuestro tiempo le llaman deporte.

Estos usos del término -que la sociedad populariza- adhieren en el imaginario colectivo con la misma velocidad con la que la información circula, principalmente por los procesos de mediatización, facilitados por los medios de comunicación. 
El concepto deporte plantea una situación difícil; tanto más cuanto que es un término empleado corrientemente y cuyo significado parece claro. Sin embargo, se trata de un caso ejemplar de pseudo claridad que encubre una confusión increíble, testimonio del embrollo semántico que acecha constantemente el campo de las prácticas motrices (Parlebás, 2001: 106).

En este sentido y, aunque parezca una contradicción, no es extraño encontrar que el Diccionario de los Deportes (1959: 1235) también manifieste la inexistencia de una definición diciendo: “(...) aunque parezca extraordinario, no se ha establecido todavía la fórmula definitiva, la definición exacta, concisa y precisa; no existe tampoco un acuerdo unánime entre las distintas definiciones aportadas (...)".

Si bien la inexistencia de una definición de deporte en el Diccionario de los deportes es contundente, en la misma línea se encuentra lo dicho por uno de los mayores referentes dentro de la historia del deporte, Carl Diem quien, en Historia de los deportes (1966: 8), afirma: "Este libro no podrá ocuparse de todo lo que hoy se denomina deporte, dado que además este concepto no puede delimitarse con exactitud".

En artículos más recientes, se observa cómo aún persisten las dificultades para encontrar una definición del polémico concepto. Tal es el caso del texto de Javier Olivera-Betrán (2006: 1), quien sostiene:

Aunque han existido múltiples intentos por parte de asociaciones del deporte, autores de prestigio y de organizaciones académicas internacionales propias y ajenas, para definir este concepto inequívoco denominado deporte, éste, por su complejidad simbólica, dimensión cultural y realidad social, resulta indefinible.

Por su parte, José Robles Rodríguez, Manuel Tomás Abad Robles, y Francisco Javier Giménez Fuentes-Guerra (2009: 2) afirman: 
(...) cabe destacar (...) la gran complejidad a la hora de definir un concepto como el de deporte, ya que abarca la mayoría de los ámbitos de la vida humana (económico, social, político, educativo, etc.), de hecho, José María Cagigal (1981: 24) nos comenta que "todavía nadie ha podido definir con general aceptación en qué consiste el deporte (...).

Las definiciones están basadas en un modelo epistémico que sostiene la posibilidad de acceder a lo real de la cosa o al ser de la cosa, es decir, que supone que el objeto a investigar, o que se investiga, está dado en lo real. El problema es que sobre él accionan una multiplicidad de fenómenos que imposibilitan saber qué es el objeto, en este caso el deporte.

No es necesario encontrar un sentido único, más aún no se puede afirmar que un concepto tenga un solo significado y para siempre, se puede precisar pero siempre queda un ápice de incertidumbre y ello se debe al menos a dos razones: por un lado, las limitaciones inherentes al lenguaje, lo que el lenguaje no puede nunca decir, en tanto que siempre hay algo que las palabras no dejan de no decir $y$, por el otro, prácticas que varían con el devenir de la historia que también presentan divergencias en un mismo momento histórico.

Este modelo (a priori) asume que el deporte no es más que una práctica con todo lo que ella implica y este es el punto de partida de un modelo teórico cuya interpretación parte de suponer el comienzo del fenómeno deportivo en el momento en que se empezó a hablar de él.

En este sentido, es necesario precisar qué modelos teóricos distintos construyen objetos distintos, con lo cual la búsqueda de un acuerdo transdisciplinario sólo tendría sentido en un proyecto común a un modelo teórico (ya que es desde las preguntas de un modelo que se indaga al objeto, se plantean respuestas y nuevos interrogantes que, producto del movimiento científico, cobran sentido en el universo conceptual de ese modelo y responden a un sector acotado de nuestro universo fenoménico). 
Disciplinas distintas pueden abordar un objeto siempre que haya acuerdo respecto al posicionamiento epistémico del modelo; esto solo permite asegurar la coherencia de los enunciados y, si bien una de las características de un modelo teórico progresivo es el poder de anticipación, éste es siempre probable y nada permite asegurar certezas respecto a dicha anticipación en futuros fenómenos aunque sí restringir la incertidumbre. Escribe Eric Dunning (en Elias y Dunning, 1992: 18):

(...) según Elías es necesario, por encima de todo, desarrollar un aparato conceptual y una terminología más a tono con la naturaleza dinámica y relacional de los seres humanos y de sus sociedades que los que hasta ahora se han utilizado.

Así es que las investigaciones en el campo de la Educación Física elaboran el concepto evidenciando su complejidad, sumando categorías de análisis y conceptos que tensionan la estructura, dando forma a una constelación o serie que permite articular realidad y pensamiento, y, de esta forma, relacionar lógicas diferentes como educación, economía, política, etc. Sin embargo, esto no habilita a sostener que las afirmaciones que de allí surgen pueden ser transportadas a otros sectores de la realidad y contar con el mismo carácter progresivo.

Planteada entonces la problemática actual, a la hora de definir el deporte -y con la pretensión de ganar precisión en el término- se realiza un análisis etimológico para continuar en la construcción del deporte como objeto de estudio.

\section{ETIMOLOGÍA. DEFINICIONES A-HISTÓRICAS CONTRA DEFINICIONES HISTÓRICAS}

Se encuentra en las primeras definiciones un intento de universalización que opaca el carácter histórico del fenómeno deportivo y muestra cómo la consecuencia de ello es una incongruencia entre la palabra que nombra y la cosa que recibe ese nombre.

Puede observarse en la etimología del término una historia que no será exactamente la del fenómeno deportivo. En el mismo sentido, se corroboró cómo 
un análisis histórico permite reflexiones pertinentes al objetivo, que no es otro que mostrar el deporte como una práctica histórica y política.

La decisión de realizar un análisis etimológico radica en identificar la aparición de la novedad del concepto, la restricción coyuntural al uso que del mismo se hace y la correspondencia consecuente con el fenómeno que nombra. Roque Barcia, en el Diccionario General Etimológico de la lengua española (1945: 665), propone la siguiente definición: "DEPORTE: Masculino. Recreación, pasatiempo, placer diversión. Etimología. 1. De deportarse: catalán antiguo, deport".

Etimológicamente, deporte deriva de deportarse y este de deport. En cuanto al vocablo deportar, este diccionario (p. 665) lo define como:

(...) desterrar a alguno a un punto determinado, y por lo regular, ultramarino.|| Descansar, reposar, hacer mansión.|| Anticuado. Divertirse. Etimología: del latín deportare, transportar, desterrar; del prefijo intensivo de y portare, portear, conducir: catalán, deportar, francés deporter; italiano deportare.

Del destierro a la diversión, esa es la amplitud del término. Claro que quitar los pies de la tierra (des-terrar), tanto para quien se va en barco como para quien cambia de lugar en el mundo puede suscitar diversión (vacaciones, ocio) y también la más profunda tristeza (refugiados, exiliados). Deporte deriva de deport, se hace importante destacar la novedad de éste con un sentido de diversión.

En referencia a ello, son pertinentes los rastreos del historiador Miguel Piernavieja -quien encuentra las primeras utilizaciones del vocablo deport en un poema de Guillermo de Poitiers en el que se utiliza para referirse a diversión-, retomado por Olivera-Betrán y Torrabadella-Flix (2015: 6):

(...) encontró la primera referencia escrita del término en la palabra deport que aparece en lengua provenzal (lengua de Oc) con el sentido de 'diversión' en un texto poético del siglo XII de 
Guillermo VII de Poitiers (1071-1127), VII conde de su nombre y IX duque de Aquitania.

Por su parte, Hernández Mendo (1999: 2) referencia a Piernavieja cuando afirma que: "En España la forma verbal deportar aparece por primera vez en el poema del Mío Cid (1140) (...)".

En el mismo sentido y sosteniendo lo mencionado anteriormente sobre el sentido de diversión con el que los provenzales utilizaban el término deport, "Es admitido que fueron los provenzales quienes emplearon por primera vez de una manera ya definida la palabra deporte, en el sentido de divertimento, distracción recreativa" (Cagigal, 1957: 33).

Cagigal menciona la palabra deporte. No se encuentran otros autores que así se refieran al empleo que los provenzales hacían del término, se encuentra deporter o deport. Un poco más adelante escribe: “(...) los marineros mediterráneos, sobre todo los provenzales, solían utilizar la expresión de portu (estar de portu) para significar las temporadas libres entre salidas que pasaban alegremente en el puerto" (Cagigal, 1957: 34).

No se encuentra claro el significado de portu, sino de porto. Puede parecer un sin sentido este grado de detalle, no obstante es preciso poner atención a estas pequeñas diferencias, ya que, transcurridos grandes trayectos de tiempo, la acumulación de variaciones tiene efectos en la interpretación de la realidad y se deslizan sentidos que la palabra deporte, en sentido riguroso, desconoce.

Un claro ejemplo de cómo se desliza el pensamiento forzando significaciones o generando un embrollo semántico se puede encontrar en la Gran enciclopedia del mundo (Durvan, 1965: 6-605) en donde la pretensión de una definición universal y ahistórica obtura cualquier análisis ulterior. En este texto, el deporte es definido como: “(...) el nombre con el que se conoce el conjunto de ejercicios corporales que, debidamente reglamentados, se realizan con diversos fines: recreo o entretenimiento de quien los practica o contempla". 
Aquí, el deporte es un fenómeno caracterizado por ser una actividad que supone el compromiso corporal por tener una reglamentación y que se lleva a cabo con alguna finalidad. A su vez, este texto agrega: "Las actividades corporales reglamentadas, es decir, el deporte, puede considerarse que surgen en la época de máximo esplendor de la cultura griega" (Durvan, 1965: 6-606).

Existe acuerdo en la bibliografía sobre dos características del deporte: el compromiso corporal y la regla. Si esto habilita llamar deporte a prácticas anteriores a la aparición del propio concepto, se pone en duda cierta insuficiencia en la definición. No alcanza sólo con entender que es una actividad reglada (ya que, por ejemplo, tanto el juego como la gimnasia son prácticas regladas). El deporte en tanto actividad reglada, ¿cómo podría diferenciarse del juego y la gimnasia? Las reglas en el juego no se encuentran escritas, mucho menos institucionalizadas, mientras que en la gimnasia se encuentran en su racionalidad (cuando se establece que ella debe tener sistematicidad e intencionalidad).

En cuanto al compromiso corporal, tanto el juego como la gimnasia y el deporte lo suponen. Hacer precisiones en cuanto al modo en el que la práctica particular requiere el compromiso corporal también es un camino para tensionar el término deporte. Tanto la gimnasia como el juego y el deporte son prácticas que toman por objeto al cuerpo, ahora bien, ¿es el mismo cuerpo? Y si lo fuera, ¿se presenta del mismo modo?, ¿se lo compromete del mismo modo?

El estudio del deporte en el campo de la Educación Física permite un doble accionar: por un lado poner en tensión el término con otras categorías del mismo campo, lo cual daría forma a una constelación o serie conceptual como, por ejemplo, juego-gimnasia-deporte que colaboran con la precisión del mismo. Por el otro, construir la precisión del objeto en función de las problematizaciones del campo, lo que se muestra más adelante, expresado como deporte educativo.

Es pertinente una revisión en torno a algunos de las diferentes definiciones que se han hecho del término deporte. En la actualidad, la Real Academia Española (RAE) define deporte como: 
Calco del inglés sport, a partir del desusado deporte 'diversión', y este deriva de deportarse 'divertirse'.

1. m. Actividad física, ejercida como juego o competición, cuya práctica supone entrenamiento y sujeción a normas.

2. m. Recreación, pasatiempo, placer, diversión o ejercicio físico, por lo común al aire libre. ${ }^{25}$

En esta definición que muestra dos interpretaciones bien distintas se encuentran los ecos del recorrido etimológico. Un deporte cuya sujeción a normas y carácter agonístico lo aleja de la idea de diversión y lo aproxima a la idea de competición desde el momento que dice juego o competición ${ }^{26}$.

En este punto se ve una asociación forzada o bien un preconcepto que se constituye en un obstáculo epistemológico (Bachelard, 2000), pues lo que viene a completar la definición (la necesaria preparación y el respeto por un marco reglamentario preestablecido) poco tiene que ver con las características del juego y mucho con la competición. Ese pasaje pone en evidencia cómo el sentido con que se lleva adelante una actividad determina la práctica. Y si lo que se busca es precisión, se podría decir que no es una práctica con dos sentidos, sino dos prácticas distintas: juego y deporte.

Si se analiza la segunda acepción, se nota que oculta (en la vaguedad de las características descritas como parte de una misma práctica) lo que podría diferenciar el deporte de la gimnasia, ya que el ejercicio físico no supone estrictamente un deporte,

(...) la similitud semántica de ejercicio físico y actividad física con la gimnasia se hace inevitable; pero, este grado de indiferenciación entre estos tres conceptos también se manifiesta al asociar el ejercicio físico con el deporte, los juegos,

\footnotetext{
${ }^{25}$ Disponible en http://dle.rae.es/?id=CFEFwiY

${ }^{26}$ Lo que, por otra parte, está de acuerdo con el concepto agon, que en griego significa competición, certamen, concurso y también juego adulto.
} 
la danza, las actividades en la naturaleza e, inclusive en algunos ámbitos, cuando las actividades cotidianas- como subir escaleras, barrer el piso o lavar el auto- son consideradas ejercicio físico o actividad física. En principio es imprescindible diferenciar las distintas prácticas corporales y, en segundo lugar, comprender que todas ellas están compuestas de distintos tipos de ejercicios; pero cuando se sigue un plan sistemático e intencionado de ejercicios indefectiblemente se está haciendo simplemente gimnasia (Carballo, 2015: 195).

Este obstáculo permite distinguir en este punto dos corrientes. La indistinción de estas prácticas es el punto en el que dos modelos chocan: por un lado, aquellos que buscan una definición ahistórica y, por el otro, los que pretenden una definición que no puede dejar de contemplar el marco histórico político (pues encuentran en él las condiciones particulares que permitieron la emergencia de nuevas o la transformación de viejas formas en deporte y, consecuentemente, la distinción de éste con otras prácticas como el juego o la gimnasia).

Como dice Gruschetsky (sf: 1) en referencia a autores que buscan una definición ahistórica:

Intentan definir el deporte a partir de delimitar las características intrínsecas que posee dicha actividad, buscando en algunos casos, líneas de continuidad en el paso del tiempo, considerando que el deporte es algo existente hace siglos, cuyas características han ido variando con el paso del tiempo.

En la definición de la RAE se observa la indistinción de prácticas como juego, deporte y gimnasia, debido a que la naturalización del fenómeno deportivo (inherente a esta definición ahistórica) supone la relación de continuidad entre estos nuevos modos llamados deportes y los juegos tradicionales. La frecuente asimilación de ejercicio físico a una práctica deportiva no permite la distinción con otra como la gimnasia. 
El recorrido etimológico acompaña esta continuidad entre deporte, juego y gimnasia sin enunciar diferencias de sentido. Las acepciones en torno al deporte se muestran ambiguas en un modelo que pretende historiografiar un fenómeno.

En sentido contrario, Bourdieu (en Barbero González, 1993: 59), en el Congreso Internacional de la Asociación de Historia de la Educación Física y el Deporte en 1978, referencia la importancia del trabajo histórico sobre el deporte en tanto que objeto de estudio bien determinado. Escribe:

(...) una de las más importantes tareas de la historia social del deporte podría perfectamente ser la de establecer sus fundamentos mediante la construcción de la genealogía histórica de la emergencia de su objeto como una realidad específica irreductible a ninguna otra (...).

De lo expuesto por Bourdieu y también por la decantación lógica del modelo teórico, se desprende que las definiciones de corte histórico son la opción más efectiva al momento de definir el deporte. Si se considera a éste como producto de ciertas condiciones particulares en un momento dado de la historia, no obstante no es cualquier historia. La misma debería tener un carácter genealógico si se pretende captar las particularidades que operaron como condición de posibilidad para la emergencia del fenómeno deportivo y poder distinguir diversidad donde aún no la hay. Este movimiento permite establecer también el camino inverso: donde no hay deporte, o qué no es deporte,

(...) para la genealogía una tarea indispensable: percibir la singularidad de los sucesos (...) encontrarlos allí donde menos se espera y en aquello que pasa desapercibido por no tener nada de historia (...) definir incluso el punto de su ausencia $(. .$. (Foucault, 1979: 7).

No se trata de encontrar el origen, entendiéndolo como el momento exacto en el que aparece este fenómeno, sino de captar en los detalles de la historia lo que resulta invisible al sondeo inocente. 
La búsqueda del origen "(...) es intentar encontrar [lo que ya estaba dado]" (Foucault, 1979: 9), cuando en realidad lo que se pretende es "(...) ocuparse en las meticulosidades y en los azares de los comienzos (...) El genealogista necesita de la historia para conjurar la quimera del origen (...)" (p. 11). En este sentido, para nosotros hacer una historia del deporte supone entonces: “(...) percibir todas las marcas singulares, subindividuales, que pueden entrecruzarse en él y formar una raíz difícil de desenredar, lejos de ser una categoría de la semejanza, un tal origen permite desembrollar para ponerlas aparte (...)" (p. 12).

Es de esperar entonces que un análisis de este tipo permita distinguir lo que de otra manera permanece indistinguible. Es este trabajo genealógico el que permite identificar juego, deporte y gimnasia como prácticas distintas.

Cuando se recurre a la historia y se busca ese momento a partir del cual poder hablar de deporte en un sentido estricto, "(...) aquello que se percibía inmóvil, fragmenta lo que se pensaba unido; muestra la heterogeneidad de aquello que se imaginaba conforme a sí mismo" (Foucault, 1979: 13).

De esta manera el deporte, en tanto que forma de ejercitación reglada (que bien podría hacer referencia tanto a los antiguos juegos griegos como al fútbol asociación de 1863), encuentra en un trabajo genealógico elementos que podrán establecer diferencias que separen lo que parece unido.

\section{LA GÉNESIS DEL DEPORTE}

Los rastreos etimológicos remiten al latín deportare y las relaciones en sus acepciones giran en torno a: placer, entretenimiento, diversión, recreación, pasatiempo, reposar, hacer mansión, descansar, trasladar, transportar, desterrar y anticuado; lo que se manifiesta como significativo y que debe señalarse con vehemencia es lo que Corominas (1961) menciona como su sentido moderno, lo cual da cuenta de un cambio, ese donde la palabra se resucita para nombrar un fenómeno con características tan particulares que necesitan de un término nuevo. 
Este cambio de sentido que se produce en la modernidad es fundamental, ya que -en términos de esta investigación- lo que convoca es este fenómeno particular que emerge en Inglaterra y se expande al mundo en un momento preciso de la historia que, como ya se ha descrito en el capítulo Sobre la civilización y la práctica deportiva, tiene una serie de tensiones que giran en torno a cuatro grandes ideas: progreso, libertad, política y educación.

Así como se han mostrado esos cambios a nivel profundo de la sociedad en términos de prácticas corporales, también se identifica allí una ruptura entre los modos de llevar adelante los juegos populares ( $y$ no tan populares) que venían desarrollándose y otras formas que comenzaron a ser conocidas como deportes.

Joan Corominas (1983: 205) logra resumir el recorrido que aquí se ha hecho del deporte, definiéndolo como:

"placer, entretenimiento", ant. h. 1440 (y depuerto, S. XIII). Deriv. Del antiguo deportarse "divertirse, descansar", h. 1260 y este del latín DEPORTARE "trasladar, transportar" (pasando quizás por "distraer la mente"); en el sentido moderno de "actividad al aire libre con objeto de hacer ejercicio físico" deporte fue resucitado en el siglo XX para traducir el inglés sport id. (Que a su vez viene del francés ant. deport, equivalente del castellano deporte).

DERIV. Deportivo, deportista, deportismo S XX. Del cultismo deportar, en el sentido latino: deportación.

Se encuentra aquí cierta congruencia con la definición de la Real Academia Española, por un lado, un deporte que se corresponde con $\operatorname{sport}^{27} \mathrm{y}$, por el otro, un deporte que se asocia a diversión. Las dos acepciones encuentran su cristalización empírica en tres actividades distinguibles en la cotidianeidad actual y que en el campo de la Educación Física se conocen como juego, gimnasia y

\footnotetext{
${ }^{27}$ En este aspecto, se encuentra (y muestra) la coherencia con lo expresado por Joan Corominas (1961) y Norbert Elias (1992), en tanto que la definición de la RAE permite suponer la resurrección del término en desuso para responder a la necesidad planteada por el término inglés.
} 
deporte, aunque los límites entre estas prácticas no son siempre claros, aún dentro de un campo específico.

Se observa que (volviendo sobre las dos acepciones de la definición) a pesar de la amplitud devienen etimológicamente del mismo término deport. Lo que resulta interesante remarcar es la idea de resurrección del término para traducir sport, ya que no es la única lengua a la que le faltó una palabra para ese fenómeno,

Así, en Alemania en 1810, un aristocrático escritor que conocía Inglaterra aún podía decir: 'sport es tan intraducible como gentleman'. En 1884 otro autor alemán escribió respecto al término deporte: sports... no tenemos ninguna palabra para eso y casi estamos obligados a introducirla en nuestra lengua. (...) En Francia, el Larousse du XIXiéme Siécle definía el término sport como sigue: «Sport - sportt -. Palabra inglesa derivada del francés antiguo desport, placer, diversión...», se lamentaba de la importación de palabras como ésta, «que obviamente corrompen nuestro idioma, pero no tenemos barreras aduanales que prohíban su entraba en la frontera» (Elías y Dunning, 1992: 158).

El lamento por la importación delata la novedad de una práctica para la cual no tenían palabra. Corominas (1961) y Elías (en Elías y Dunning, 1992) coinciden además en cierta cercanía temporal en torno a los siglos XIX y XX, respecto de un fenómeno nuevo que surge en Inglaterra, los sports.

El trabajo de Elías (en Elías y Dunning, 1992: 159) es más preciso, en este sentido, al describir el contexto histórico-político inglés, en el que da cuenta de la constitución del moderno fenómeno en el marco de un amplio y lento proceso de civilización,

En Inglaterra, la transformación de un juego popular y polimorfo en el Fútbol Asociación o soccer fue un desarrollo bastante prolongado dirigido hacia una regulación y uniformidad mayores. 
Este proceso culminó con la codificación del juego en casi todo el país en 1863.

La derivación del término deporte del latín deportare no es el problema, sino pensar esto como una continuidad en los fenómenos que nombra, pues la amplitud existente entre el traslado de algo, el destierro de alguno o la diversión al hacer un ejercicio físico no colabora con la búsqueda de precisión ni aporta al uso del término deporte ni a la delimitación del fenómeno que nombra.

Es cierto que la palabra deporte existía con anterioridad y que algunos sentidos podían acercarse a lo que suponemos hoy son características de este fenómeno que tiene lugar a partir del S XVIII en Inglaterra. Sin embargo, debe tenerse en consideración el carácter novedoso y la precisión que gana el término ${ }^{28}$.

Elías (en Elías y Dunning, 1992: 36-37) lo expresa así:

Queda sin responder por qué algunos modelos de competiciones físicas relativamente no violentas se desarrollaron en Inglaterra antes que en ningún otro lugar y fueron simbólicamente representados allí, con una evidente conciencia de su novedad y especificidad, mediante el empleo nuevo y más especializado de un concepto anterior, el concepto de deporte. Los torneos altamente regulados para los que se requerían ejercicio y buena forma física y que se habían clasificado como "deporte» tanto por los practicantes como por los espectadores, ¿por qué aparecieron durante el siglo XVIII entre las clases altas de Inglaterra, la aristocracia y la gentry terrateniente?

\footnotetext{
${ }^{28}$ Es importante mencionar la relación inextricable de este fenómeno con la modernidad y el proceso civilizatorio cuyas características se describen en el capítulo primero, Sobre la civilización y la práctica deportiva. Enunciado entonces como los cambios a nivel del fenómeno particular, se muestran como efectos de causas profundas de la historia humana (Berlín, 1998; Foucault, 1996).
} 
El párrafo hace referencia a la pregunta sin responder respecto de por qué surge en Inglaterra este fenómeno tan particular. Evidencia con claridad la resignificación que se hace del concepto deporte, y continúa más adelante:

(...) una vez que se ha descubierto que el concepto de deporte se asoció en el siglo XVIII con una característica de los pasatiempos de las clases altas de Inglaterra, no debe investigarse el deporte de manera aislada. Debe analizarse el acaecer, el desarrollo y sobre todo los cambios en la estructura de la personalidad, en la sensibilidad respecto a la violencia de los seres humanos que integraban aquellas clases (Elías y Dunning, 1992: 49).

Hay aquí una práctica que se desarrolla por primera vez. Es decir, que el surgimiento supone alguna novedad, en este caso, una actividad de los seres humanos (algunos) que supone características particulares. Lo cual se presenta aquí como radical, porque es a partir de estas novedades que se requiere el surgimiento del concepto con su exponencial precisión. $Y$ no solo lo hace declarando la novedad y la especialización, sino describiendo estos modelos de competiciones físicas cuyas formas suponen el aumento en la sensibilidad respecto a la violencia. Observa Elias (en Elías y Dunning, 1992: 186):

El código de normas, incluidas las que procuraban la limpieza del juego, la igualdad de oportunidades de ganar para todos los contendientes, se hizo más rígido; las reglas, más precisas, explícitas y diferenciadas; la supervisión del cumplimiento de las reglas, más eficiente; así, se hizo más difícil escapar del castigo por quebrantarlas.

Los cambios en los modos del juego dejan al descubierto cambios profundos en la sociedad que operan como condición de posibilidad y esto sin negar la afirmación en sentido inverso. La pacificación de los pasatiempos es un efecto de cambios en la sociedad en general que, a su vez, estos cambios y sus modos afectan las normas de la sociedad en general. La forma en la que estos pasatiempos (que en 
ese escenario son llamados deportes) también tienen un efecto en los niveles de violencia que una sociedad, en un momento determinado de la historia, está en condiciones de soportar. Afirma Elias (en Elías y Dunning, 1992: 202) al respecto:

El progresivo reforzamiento de los controles reguladores sobre la conducta de las personas y la correspondiente formación de la conciencia, la interiorización de las normas que regulan más detalladamente todas las esferas de la vida, garantizaba a las personas mayor seguridad y estabilidad en sus relaciones recíprocas, pero también entrañaba una pérdida de las satisfacciones agradables asociadas con formas de conducta más sencillas y espontáneas. El deporte fue una de las soluciones a este problema.

Si el problema eran las formas de conducta espontáneas y el deporte se mostró como la solución al mismo, se puede suponer que esta práctica modificó los modos en los comportamientos y, si estos cambios fueron orientados a la disminución de la violencia, es coherente pensar que la práctica deportiva conllevó aumentos en la satisfacción de las relaciones en su modo novedoso, producto de las tensiones entre lo permitido y lo prohibido, la agresividad y la docilidad. Esta mayor seguridad y estabilidad habilitan el universo fenoménico que emerge. Que no elimina la violencia, sino que la estructura en formas aceptables para los niveles de tolerancia de un momento determinado.

Esto se complementa y es coherente con el proceso civilizatorio descrito que también tiene lugar principalmente en Inglaterra y Francia, en los siglos XVII y XVIII y que, observados con cierta distancia, pueden apreciarse con un direccionamiento preciso hacia la pacificación de las conductas, el autocontrol, la definición de roles, la igualdad entre pares.

En este sentido, se destaca lo que en esta tesis es un paralelo significativo entre dos procesos que emergieron en Inglaterra durante el siglo XVIII: el de deportivización y el de parlamentarización (Elías y Dunning, 1992), desarrollado a continuación. El contexto mostraba un escenario con clases emergentes que se 
posicionaban en términos de participación política y el parlamento, en tanto que arena de conflicto en la cual dirimir cuestiones atinentes a los intereses de estas clases, parecía presentar características incompatibles con niveles de violencia que imposibilitaban la articulación de la palabra como medio para resolver conflictos. Siguiendo a Elias (en Elías y Dunning, 1992: 46):

Por circunstancias a veces fortuitas, los seres humanos pueden llegar a modelos de ordenación institucional u organizativa que, si funcionan bien, en seguida se vuelven tan obvios para los participantes que éstos los consideran «naturales», «normales» o, simplemente «racionales». Fue así como los grupos rectores de Inglaterra durante el siglo XVIII se acercaron paulatinamente a algo completamente nuevo -un gobierno de tipo parlamentario-sin percatarse en absoluto de que representaba una novedad.

Los acercamientos entre las diferentes clases de la sociedad inglesa, que se disputaban el poder político durante el siglo XVIII, implicaron la reducción en los niveles de violencia de manera significativa. Es el modo de este acercamiento lo que termina dando cuerpo a los modelos de ordenación institucional y es también lo que interesa resaltar.

En menos de un siglo, dos facciones de las clases altas, los Whigs y los Tories, que en una etapa violenta se habían tratado con rudeza y brutalidad, se transformaron en partidos de las clases altas respaldados por un electorado relativamente pequeño constituido por grupos privilegiados y que se enfrentaban con métodos que, tal vez no excluían la compra de votos y el soborno, pero que no eran violentos en términos generales. Este cambio constituyó un notable ejemplo del empuje civilizador (Elías y Dunning, 1992: 47).

Empuje civilizador del que tanto el deporte como el parlamento son ejemplos y que, además, se encuentran inextricablemente relacionados en términos de 
proceso civilizatorio. Tanto en el parlamento como en el deporte la práctica reclama un dominio sobre sí mismo, novedoso y particular. Son los mismos grupos de elite que componían el parlamento los que, al menos en principio, impulsaron cambios en los modos de realización de los pasatiempos en sus momentos de ocio. Idea que un siglo más tarde sostendrá los procesos llevados a cabo en las instituciones (como por ejemplo en las Public Schools). Tal como se observa en la siguiente cita de Dunning (en Elías y Dunning, 1992: 278):

Esta civilización del rugby tuvo lugar como parte de un proceso social de larga duración. Hubo en él dos momentos muy importantes: a) en 1845, en la Rugby School, la institucionalización de las primeras reglas escritas. Entre otras cosas, estas reglas tenían como finalidad restringir el recurso a las patadas y otros métodos físicos violentos, y prohibir por completo el uso de navvies (las botas con punta de hierro que socialmente habían sido vistas como parte importante del juego en la Rugby School y en otras escuelas privadas a mediados del siglo XIX).

En la medida en que el deporte fue adquiriendo forma se convirtió en fundamental para la construcción de la conciencia occidental.

DEL PROCESO CIVILIZADOR EN EL DEPORTE. REGLAS, VIOLENCIA Y TOLERANCIA

Se ha mencionado el proceso civilizador y merece en este punto algunas aclaraciones al respecto.

Los elementos centrales de este proceso civilizador han sido: (...) la elaboración y el refinamiento de los modales y normas sociales; el aumento concomitante en la presión social sobre los individuos para que auto-controlen su sexualidad, su agresividad, sus emociones en general, y en un número cada vez mayor de relaciones sociales; $y$, en el nivel de la 
personalidad, el aumento en la importancia de la conciencia (el «super-ego») como reguladora de la conducta (Elías y Dunning, 1992: 24).

En este sentido, el proceso civilizador supone algunas características claramente observables en el fenómeno deportivo como la elaboración de normas y modos, el autocontrol de la violencia, la regulación de la conducta, por lo que bien permite pensar los deportes como un ejemplo que muestra características del proceso civilizador. Esto permite (más adelante) elaborar hipótesis respecto a la actualidad y la relación existente entre las formas y modos que muestra la práctica deportiva (en sus diferentes ámbitos) y cambios profundos en las sociedades, a lo largo del tiempo.

Como respuesta a una necesidad de época, el campo de la política demanda, como condición de posibilidad indispensable para la práctica parlamentaria, cambios en los modos de ser en público y en los niveles de violencia con los que se dirimían diferencias, por lo que resulta determinante formar las juventudes de las clases que se disputaban este espacio político en este nuevo escenario histórico.

Se trataba de un problema cada vez más patente a medida que progresaba la pacificación, que aumentaba la necesidad de auto-imponerse restricciones, sobre todo en las clases terratenientes políticamente más poderosas de Inglaterra, y a medida que el aparato social para la prevención de la violencia ilegal -un aparato controlado en gran medida por los propios miembros de estas clases- perdía eficacia (Elías y Dunning, 1992: 211).

Es necesario destacar que no aumentaba la violencia sino que bajaba la tolerancia (hoy podría preguntarse si no es a la inversa: lo que sucede ¿Es un aumento de la violencia y un descenso en el control de las emociones?). Lo que parece ocurrir no es solo un aumento en la tensión, sino una ruptura entre las técnicas de gobierno y los niveles de tolerancia. Llegó un momento en el cuál estas técnicas no podían 
resolver un problema que se agravaba exponencialmente. En tanto, la tolerancia a la violencia disminuía desproporcionadamente más rápido que la seguridad que estas técnicas podían proporcionar.

Los juegos medievales no cuentan en su lógica interna con las herramientas necesarias para hacer elaboraciones sobre la violencia. El concepto deporte, y el juego en sí dan cuenta de cambios en la forma de llevar adelante aquellos juegos populares y estos tienen correspondencia con transformaciones de otra índole como las acaecidas en el campo político, las cuales siguen una tendencia hacia la pacificación con base fundamentalmente en acuerdos grupales y restricciones autoimpuestas. Un universo nuevo de técnicas que, por un lado, da forma al deporte y permite que emerja con sus características distintivas, mientras que, por el otro, estas técnicas que exceden el fenómeno deportivo, también dan lugar a formas y modos de la sociedad en general en otros campos.

¿Cuáles son, más específicamente, las características que hacen del deporte un ejemplo civilizador? El seguimiento de la racionalidad utilizada para elaborar los reglamentos y cómo éste establece modos de control externos que obligan a un límite de violencia y el movimiento de interiorización de estos controles puede precisar algunas de estas características. Describe Elias (en Elías y Dunning, 1992: 164) cuestiones comunes a las diferencias entre los modos presentes en juegos medievales y en los siglos XIX y XX

En la Antigüedad, las reglas consuetudinarias de los acontecimientos atléticos "pesados», tales como el boxeo y la lucha, admitían un grado de violencia física mayor que el aceptado por las reglas de los correspondientes tipos de juegos competitivos de hoy.

Aunque no por esto se asume la ausencia de reglas ni de jueces, Morir, ser lesionado muy gravemente o hasta quedar incapacitado de por vida eran riesgos que todo luchador de pancration tenía que asumir. (...) Había un juez, pero ningún 
cronometrista ni límite de tiempo. La lucha se prolongaba hasta que alguno de los contendientes se rindiera. Las reglas eran tradicionales, no escritas, indiferenciadas y, en su aplicación, probablemente elásticas. Al parecer, estaba prohibido, por tradición, morderse y sacarse los ojos, pero si uno de los dos, cegado por la furia del combate, atacaba al otro de esa manera, probablemente antes de que el juez pudiera separarlos el daño ya estaba hecho (pp. 168-169).

En cambio, si se piensa en el caso del boxeo moderno ${ }^{29}$, por ejemplo, la discriminación por peso y las regulaciones temporales garantizan por un lado la seguridad de los deportistas y además se asegura (o al menos esa es la intención) que las contiendas tengan una mayor duración, sean más parejas y que el resultado se mantenga incierto el mayor tiempo posible. En este sentido,

El aumento de la sensibilidad se manifestó con la introducción de los guantes $\mathrm{y}$, a medida que pasaba el tiempo, con el acolchamiento de éstos y la clasificación de los boxeadores en diversas clases, lo que permitía una mayor igualdad de oportunidades. De hecho, sólo así fue como una forma popular de lucha adquirió las características de un deporte (Elías y Dunning, 1992: 33-34).

Si bien aquí los autores hacen referencia al aumento de la sensibilidad, también dan cuenta de un cambio un poco más profundo en las formas en las que se disfrutaba de una contienda, las limitaciones reglamentarias reducían las posibilidades de finalización abrupta así como restringía las posibilidades de que las ventajas de un competidor sobre otro conlleven un espectáculo de baja

\footnotetext{
${ }^{29}$ Se plantea la necesidad de discutir sobre prácticas como la del Vale Todo o los combates de Artes Marciales Mixtas (MMA) donde los riesgos son altísimos aún con los recaudos reglamentarios. Incluso se podría pensar si la proliferación de éstas no se debe a un desplazamiento de los límites en la tolerancia a la violencia de las sociedades (en sus respectivos momentos), o bien en algunos sectores de ellas, lo que muestra un núcleo de discusión algo más complejo, en el que se debe considerar un momento histórico, en el que la diversidad es tan grande que los parámetros de tolerancia a la violencia se amplían de tal modo que pensar en un nivel unificado es sumamente dificultoso ¿el MMA tiene más similitudes con el Pancracio griego que con el boxeo?
} 
tensión. Las formas de obtener el triunfo fueron cada vez mas acotadas y (en parte en respuesta a este efecto) la preparación para la práctica deportiva va ganando relevancia en la medida en que la configuración de la misma va ganando precisión.

Las antiguas modalidades de esta lucha, siempre una manera de resolver conflictos populares entre los varones, no carecían completamente de reglas establecidas, pero a menudo se utilizaban las piernas como complemento de los puños para atacar. Si bien entre el pueblo la práctica de los combates con las manos y sin armas no era completamente anárquica, sus reglas sí eran bastante elásticas (Elías y Dunning, 1992: 33).

Es precisamente esta elasticidad la que parecía impedir la regulación de la violencia, los riesgos eran tan grandes como la amplitud de sus normas respecto a la integridad física. Eran combates que podían ser tan desparejos en las condiciones de posibilidad que la tensión era mínima en términos de proceso.

Si bien aquí se hace mención al boxeo y la lucha también se extiende a otros deportes, ya que se trata de condiciones simbólicas de época. Estas regularidades que permiten que el deporte se constituya como una práctica con particularidad desde lo normativo y la regulación sobre sí mismo (sin desatender las demandas sociales respecto a los niveles de violencia, ni la emoción que se le reclama a toda actividad recreativa mimética), tiene como efecto material un grado de detalle y precisión en las reglamentaciones mucho mayor que las que pueden observarse en los juegos populares, “(...) en las sociedades de la Edad Media las costumbres y reglas tradicionales eran tomadas con mucho menos rigor, de manera mucho más personal e informal que las reglas e incluso las costumbres y tradiciones de nuestro tiempo" (Elías y Dunning, 1992: 224).

Los procesos de regulación y el establecimiento escrito de un reglamento que responde a las demandas coyunturales, tanto políticas como sociales, permiten la homogeneidad necesaria para pensar el deporte como un fenómeno que emerge 
bajo ciertas condiciones de posibilidad. Condiciones que, en ese pasaje inicial que describe Elías, se cristalizan gracias a tratados y no tanto por consensos.

Elías (en Elías y Dunning, 1992: 223) recuerda cómo antes

El modo de jugar de la gente dependía de las costumbres locales, no de reglas comunes en todo el país. La organización del juego era mucho menos rígida que hoy, la espontaneidad emocional de la confrontación, mucho mayor; las tradiciones del enfrentamiento físico y las escasas restricciones -impuestas por la costumbre, no por reglas formales altamente elaboradas que requieren un elevado índice de entrenamiento y autocontroldeterminaban la manera de jugar e imponían un cierto aíre de familia a todos estos juegos.

De esta manera, las reglas elaboradas y escritas con un alto grado de detalle permiten, además de distinguir con claridad diferentes deportes, observar un desplazamiento en el objeto de placer.

(...) el brevísimo placer en el resultado de una batalla deportiva, en el momento de la consumación o victoria, fue ampliado y prolongado por el placer y la excitación que se experimentan antes de que comience el juego y durante él, participando o presenciando su tensión intrínseca (Elías y Dunning, 1992: 171).

La minuciosidad de la regla se justifica entonces, por un lado, en la menor tolerancia a la violencia y además (hay aquí una de las diferencias sustanciales), en un disfrute puesto más en el proceso que en el fin:

En este aspecto, fue tremendamente significativo el cambio ocurrido al pasar del interés en la victoria al interés aún mayor en la prolongada emoción placentera de la lucha. Posteriormente, este cambio halló expresión en la famosa ética deportiva según la cual lo importante no era ganar sino participar. Los cazadores de zorros aún podían herir y matar realmente aunque sólo delegando tal función y sólo a animales. Otras modalidades de deporte, como el críquet y el fútbol, 
muestran cómo se resolvió el problema en los casos en que todos los participantes eran seres humanos. (Elías y Dunning, 1992: 212).

La caza de zorros es un ejemplo contundente ya que muestra en las transformaciones de sus modos y formas los efectos de las demandas coyunturales, las regulaciones en su dinámica interna tienden a civilizar la caza complicando la consecución del objetivo, poniendo restricciones que pacifican la misma. Ahora quien termina ensangrentado es el animal que acompaña al cazador, quien, por otro lado, ya no mata al zorro; así como tampoco caza otros animales, ya no se lleva al animal a la mesa, ya no se caza para sobrevivir ni por el placer de matar, sino que se caza por deporte.

En las modalidades anteriores, el placer de matar, combinado quizá con el de comer el animal muerto, opacaba con frecuencia todos los demás aspectos de la caza. En la caza de zorros por el contrario, $[\ldots]$ se produjo un cambio en la naturaleza del goce que era -y es- característico asimismo de muchas otras variedades deportivas. Así, en un partido de fútbol no es sólo el climax, la victoria de uno de los equipos, lo que emociona y hace disfrutar a los espectadores (Elías y Dunning, 1992: 38).

La complejidad que adquiere tanto la caza de zorros como otros deportes a través de las regulaciones reglamentarias constituye lo que Elias describe y denomina figuración, la cual se da entre personas y se cristaliza en redes de interdependencia tanto más estables como determinantes y ponen en juego toda una serie de polaridades y tensiones. Se trata de tensiones entre polaridades presentes en la dinámica del juego (la existente entre lo pacífico y lo violento, el placer en la agresión y las restricciones, el control y el descontrol, el ataque y la defensa, el interés individual y el del equipo, entre la cooperación y la competición, entre la ley y el deseo), las que estructuran el deporte. Si bien las tensiones se manifiestan durante la práctica deportiva, es el reglamento escrito el que arma la figuración, establece las redes de interdependencia y pone los límites al tono del juego. 


\section{(...) es el equilibrio de tensiones entre estas polaridades}

interdependientes lo que determina el «tono» del juego, es decir, el hecho de que éste resulte emocionante o monótono, o bien que no pase de ser un "remedo de batalla» o estalle en un combate serio (Elías y Dunning, 1992: 250).

Cualquiera sea el final del juego, debacle o aburrimiento, el reglamento pone los límites. Lo cierto es que si estalla en un combate serio es porque la tensión se rompió y si el tono es muy bajo (y esto se repite durante un lapso importante) puede que el juego requiera alguna modificación reglamentaria. Veamos lo ocurrido con el reglamento en el críquet cuando el juego bajó el tono recurrentemente:

Se dice que el poste central del «rastrillo» o meta en el críquet fue introducido cuando los boleadores desarrollaron una técnica con la que introducían la pelota demasiadas veces y, según parece, con demasiada facilidad en la portería (...) (Elías y Dunning, 1992: 193).

Independientemente de las modificaciones reglamentarias (debido a la recurrencia del bajo tono, lo cual puede adjudicarse a una fase de madurez del juego), lo interesante se desprende de la dimensión interpretativa de la regla, pues es en este punto donde el juego adquiere los matices propios de lo indeterminado. La tensión surge entre la abstracción reglamentaria y la cristalización en el juego que realizan jugadores, árbitros, espectadores, técnicos, etc.

Este juego -teatro que permite observar el carácter mimético de la práctica- es la interpretación del guión, que es el reglamento por parte de la dinámica entre jugadores, árbitros, técnicos y espectadores. Relaciones que son atravesadas por la tolerancia a la violencia de un momento histórico determinado. Lo que dibuja una nueva serie conceptual: mimesis, reglas y tolerancia a la violencia. 


\section{EL NUDO ENTRE MIMESIS, REGLAS Y TOLERANCIA A LA VIOLENCIA}

Cuanto más aumenta la tensión interna del juego o -como lo llama Elías, el tono de juego- más al límite de la regla se juega y, por ende, más cerca de los límites de agresividad que ésta y los participantes permiten y admiten, lo que solo es posible cuando éstos cuentan con un alto grado de dominio sobre sus acciones en situaciones extremas.

Si los jugadores no se controlan lo suficiente, existe la probabilidad de que rompan las reglas y entonces la victoria puede ser para los del equipo contrario. Si se reprimen demasiado, carecerán del vigor y el impulso necesarios para conseguir la victoria. Si siguen las reglas al pie de la letra, se arriesgan a perder por falta de inventiva; si las evaden o las estiran hasta el máximo, se arriesgan a perder por haber quebrantado las reglas. Han de encontrar el punto medio entre seguir cuidadosamente las normas y convenciones y regatearlas o estirarlas al máximo y jugar cerca del punto de ruptura (Elías y Dunning, 1992: 194).

Es interesante la relación de dominación y violencia que supone la regla. El hombre, que en su devenir histórico ha accedido a dominios de la naturaleza antes impensados, en el mismo movimiento ha alcanzado un alto grado de dominación sobre sí mismo y, en este sentido, ha desarrollado todo un marco reglamentario que viene a determinar el control sobre las acciones de uno mismo que no puede tener sentido si la sociedad en la que se desarrolla prescinde de ellos.

Las reglas no son sino la contraposición del ideal de lo tolerable en un momento determinado. Escribe Foucault (1979: 17): "Universo de reglas que no está en absoluto destinado a dulcificar, sino al contrario a satisfacer la violencia". Se agrega al enunciado: satisfacer 'los niveles' de violencia, es decir, la regla de los deportes viene a controlar la violencia, es su obligación sostener el interés y la tensión del mismo, por lo que la regla viene a dibujar ese borde en el que el 
deporte cristaliza una de sus características principales: el deporte como acto mimético.

(...) al hablar de los aspectos «miméticos» del deporte nos referimos al hecho de que este imita selectivamente las luchas que tienen lugar en la vida real. El modo en que está diseñado o estructurado el juego deportivo, y la habilidad de los deportistas permiten que aumente el goce de la batalla sin que nadie resulte lesionado o muerto (Elías y Dunning, 1992: 65).

La tensión manifiesta en este carácter mimético radica precisamente en lo que anteriormente señala Foucault: la batalla que supone un encuentro deportivo debe satisfacer los niveles de violencia para mantener la tensión elevada y no caer en el aburrimiento, pero a su vez lograr que ésta no se rompa y el juego se desvirtúe. Es en este sentido pensar en términos de tensión permite armar una categoría que se corresponde muy bien con la dinámica interna de los deportes.

La figuración de las personas en un torneo de esta naturaleza está ordenada de tal modo que no sólo crea sino que también contiene en sí misma diversas tensiones. En su forma madura, conlleva un complejo de polaridades interdependientes en un estado de inestable equilibrio entre tensiones y permite -en el mejor de los casos- fluctuaciones moderadas que ofrecen a todos los competidores la posibilidad de ganar ventaja hasta que uno de ellos logra romper la tensión ganando el juego (Elías y Dunning, 1992: 192).

La idea de satisfacer la violencia significa alcanzar esos niveles y además no excederlos; si se traspasan esos límites la tensión se rompe y el deporte pierde su atractivo y se deja de jugar, lo que resulta un fenómeno no deseable y, además, llegado a situaciones extremas, tal adulteración convierte el fenómeno deportivo en otra cosa y la competencia no es posible: 
Es la imaginación humana la que convierte a un hombre que maneja sólo con los pies una pelota de cuero en el objeto de una acalorada pero controlada lucha entre dos grupos de personas. El problema a resolver, en este caso como en el de los demás juegos deportivos, es cómo mantener bajo el riesgo de que los jugadores sufran daño, manteniendo sin embargo en un nivel elevado la placentera emoción de la batalla (Elías y Dunning, 1992: 68).

La práctica deportiva podrá sostener su carácter mimético en tanto y en cuanto los niveles de violencia alcancen y respeten los niveles socialmente aceptables. El carácter mimético, los niveles de violencia que una sociedad está dispuesta a tolerar y el marco reglamentario del deporte son elementos de una constelación que se afectan unos a otros y que, al encontrar su campo de acción en la práctica deportiva, suponen algún tipo de tensión entre ellas, tensión que sostiene una relación directamente proporcional entre el aumento de la misma y el placer que provoca su práctica. El funcionamiento de este nudo: mímesis-tolerancia a la violencia-regla se materializa en dispositivos de creación, ejecución y control del marco reglamentario y, en ellos, un sistema institucional que da forma al mundo deportivo.

Se observa entonces cómo la articulación entre el carácter mimético, los niveles de violencia y el marco reglamentario cristaliza en la institucionalización del fenómeno. Éstos, junto a otros elementos de esferas más amplias, se constituyen como su condición de posibilidad aunque no puede afirmarse que esta relación de afectos sea unidireccional, sino todo lo contrario, la institucionalización también opera como condición de posibilidad de la mimesis, la tolerancia y la regla, contemplando que: "(...) la difusión de las prácticas deportivas supuso la puesta en acción de una serie de dispositivos que asegurasen unas determinadas formas de conducta y de disciplina corporal (...)" (Barbero González, 1993: 13).

Al articular lo antedicho con los sistemas disciplinarios institucionales se conforma una estructura compleja producto de un momento histórico-político que se ha 
recortado considerándolo pertinente para este trabajo y que, en el marco del proceso civilizatorio, es solo parte de un entramado social más general.

A partir de lo expuesto hasta aquí, mediante el recorrido etimológico y la deconstrucción del concepto deporte, las observaciones pertinentes del trabajo de campo y el análisis de los autores en diferentes momentos históricos, se ha demostrado que el deporte no es necesariamente algo tan amplio como se ha de creer, sino un concepto mucho más preciso, más aún si se piensa en términos educativos.

Hay interpretación y efectos de verdad. Claro que si se reproduce un deporteespectáculo, producto de lógicas que provienen del mercado, el consumo y la ganancia, es esperable que se encuentre un deporte con modos que se adaptan a su estructura pero que no le son propios. El obstáculo se impone cuando no se reflexiona sobre ello y se presenta como el modo necesario, porque en ese punto la lógica de mercado embebe las relaciones presentes dentro de la práctica y afecta las acciones del cuerpo.

La enseñanza del deporte en etapas formativas (en instituciones como clubes, escuelas deportivas, o cualquier organización encargada de formar a niños y jóvenes) debería contemplar estas influencias, no solo para descartar aquellas características que no colaboran con la formación ni del deportista ni del practicante ${ }^{30}$, sino para formar ciudadanos críticos y no consumidores irreflexivos.

En la actualidad -con todas las posibilidades de acceso a la información que existen- es válido pensar que se sabe muy bien lo que es el deporte, el problema es que de las cosas sobre las que se sabe mucho se duda poco y ésta es la cadena más pesada.

Es urgente y necesario elaborar un contenido que no condene a los nuevos a la esclavitud que supone la absoluta libertad individual (casos tales como los personalismos y exacerbación del éxito en términos de resultado, por ejemplo). Esto supone revisar dos cuestiones: la práctica deportiva incluye diferentes

\footnotetext{
${ }^{30}$ Categorías que permiten incluir a todo aquel que practique deporte.
} 
miradas, grupos de intereses, dinámicas, funcionamientos, lógicas (económicas, políticas, etc.) que difícilmente puedan separarse más que con fines analíticos (que de todas maneras hacen al fenómeno deportivo). Por otro lado, el deporte como práctica supone no solo considerar la configuración que arman sus reglas, el compromiso corporal que supone el entrenamiento de destrezas y habilidades, sino además cómo funcionan éstas ante la tensión que ejercen los distintos grupos, lógicas, funcionamientos, etc.

Ahora bien, ¿qué hace al buen deportista? Un accionar disciplinado, predisposición al trabajo, dedicación, el amor por lo que se hace, la importancia del colectivo, de la responsabilidad, el respeto por las normas, del interés por el otro, etc., atributos que muestran el equilibrio entre las dos libertades: positiva y negativa. Factores de vital importancia para pensar el deporte como contenido educativo.

Entonces, enseñar un deporte puede consistir en la trasmisión de las reglas, objetivos, tácticas y estrategias, pero también de aquello que responde a la pregunta acerca de qué se necesita para ser un buen practicante del deporte. Como por ejemplo una amplitud tal en los criterios de observación y valoración, que excedan el resultado del encuentro.

El deporte tiene características internas que son menos discutibles: las reglas, los objetivos, las tácticas, las técnicas, los aspectos tecnológicos de la práctica, donde es fundamental el carácter formativo y la función de quien enseña.

Si el deporte no forma parte de la formación moral, sino de una formación lógica, la pregunta sería: ¿qué es lo que se valora? Cuando se piensa en educar y enseñar una práctica deportiva lo que se valora debería estar vinculado al deporte. El equilibrio entre libertad positiva y negativa es lo más lógico en el deporte como en el juego social porque someterse a una ley es lo mejor para todos; en palabras de Julio Velasco, entrevistado por Vanesa Valenti para el diario La Capital el día 5 de abril de 2017: "Un jugador de fútbol hace pressing no por ser solidario, lo tiene 
que hacer porque es parte del juego. Así tenga un ego enorme. Si no lo hiciera es como si hiciera una cosa mal”31.

La coacción de la regla, la relación de autoridad con el entrenador o profesor, la disciplina de los alumnos y del grupo o grupos implicados en la práctica (considerada en las relaciones entre ellos, consigo mismos y con el saber), arman esa red de tensiones que tiene efectos en la práctica deportiva y en el proceso de enseñanza de los deportes.

El deporte como contenido educativo supone pensarlo como práctica, porque es en esa dimensión que se puede hacer de él algo más rico, un lugar donde reflexionar sobre el ethos que supone su puesta en juego. En esta dimensión se muestra el deporte no sólo como una disciplina en la que el jugador desarrolla sus destrezas sino en la que también aprende a ser con otros, a jugar y, además, a apreciar el juego y a ser civilizado. Lo que devuelve una hipótesis: Sin respeto por acuerdos colectivos no hay civilización posible y, por ello, no hay deporte sin civilización.

Disponible en https://www.lacapital.com.ar/ovacion/un-equipo-no-es-un-grupo-amigosorganizando-las-vacaciones-n1370769.html 


\section{CAPITULO III: SOBRE LA DISCIPLINA}

El capítulo I, Sobre la civilización y la práctica deportiva, mostró descriptivamente cómo se presenta el proceso civilizatorio y planteó la idea de progreso en relación a la historia de la libertad, movimiento que se ve reflejado en el control sobre la emotividad de los comportamientos, la reducción en los niveles de violencia aceptados y el aumento en las coacciones externas e internas que regulan las conductas.

En este capítulo se hace un análisis descriptivo y reflexivo del dispositivo disciplinario, mostrando la articulación necesaria que supone con la práctica deportiva.

Coincidente con el proceso civilizatorio se muestra el momento histórico político en el que las técnicas disciplinarias se generalizan y se expanden (Foucault, 2009), al menos si se entiende a la disciplina como táctica política (Castro, 2011). Es preciso describir estas técnicas con especial atención al contexto que resulta fundamental para la relación que traman en el proceso de la civilización.

A continuación, se presentan algunos ejemplos que recupera Foucault (2009: 17) en torno a las prácticas cotidianas de la sociedad a las que se supo llamar "espectáculo punitivo",

A fines del siglo XVIII, y en los comienzos del XIX, a pesar de algunos grandes resplandores, la sombría fiesta punitiva está extinguiéndose (...) El castigo ha dejado poco a poco de ser teatro. $Y$ todo lo que podía tener de espectáculo se encontrará en adelante con un índice negativo.

Se observa que el proceso durante el cual el espectáculo punitivo adquiere un signo negativo es un movimiento que muestra el proceso de la civilización. Hay en este índice negativo una tensión que recorre, por un lado, las relaciones entre el ser y el deber ser del ideal ciudadano y las garantías estatales y, por el otro, las que se establecen entre la libertad medieval y la libertad en términos modernos. 
Foucault (2009: 19) recupera un extracto escrito por un contemporáneo de la época,

(...) Rush, en 1787, dice 'no puedo por menos de esperar que se acerque el tiempo en que la horca, la picota, el patíbulo, el látigo, la rueda, se considerarán, en la historia de los suplicios, como las muestras de la barbarie de los siglos y de los países' (...).

El rechazo hacia este tipo de espectáculos y este cambio (esta transformación), se cristaliza en la manifestación de formas de sometimiento que actúan sobre el cuerpo, pasando de formas pesadas, esporádicas y violentas, a mecanismos sutiles, constantes y preventivos; mientras que en uno son castigos corporales largos, desgarradores, sangrientos, dolorosos, en otro se somete el cuerpo a otro tipo de manipulaciones que, si bien también lo toman por objeto, lo hacen de un modo que:

(...) puede muy bien ser directo, físico, emplear la fuerza contra la fuerza, obrar sobre elementos materiales y, a pesar de todo esto, no ser violento; puede ser calculado, organizado, técnicamente reflexivo, puede ser sutil (...) puede existir un saber del cuerpo, que no es exactamente la ciencia de su funcionamiento, y un dominio de sus fuerzas que es más que la capacidad de vencerlas: este saber y este dominio constituyen la tecnología política del cuerpo (Foucault, 2009: 35).

Mientras Foucault identifica aquí cómo la forma de sometimiento sobre el cuerpo muta hacia un modo más sutil, se observa en este movimiento cómo la tolerancia a la violencia de la sociedad en general va disminuyendo, y no solo a nivel del espectáculo punitivo, lo que se restringiría no solo a los implicados sino a nivel de toda la sociedad.

Estas dos caras del mismo movimiento son efectos del progreso que, entendido como historia de la libertad, pone en tensión el juego libertad-coacción. El juego libertad positiva/libertad negativa es la muestra de esta tensión en las relaciones 
entre las personas, en un juego social que supone acuerdos colectivos que garantizan libertades individuales, impulsado principalmente por la disposición estratégica de los funcionamientos institucionales. Se retomará este punto más adelante.

Estos cambios ocurren principalmente en Inglaterra y Francia y, si bien son cambios que en principio pueden observarse bajo la influencia de los estratos sociales más altos, rápidamente comienzan a producirse en todos los niveles de la sociedad, probablemente como producto del funcionamiento de los aparatos de Estado (que están destinados a reproducir las ideologías dominantes en sus funcionamientos y que responden a los intereses de clase). Si bien puede no ser estrictamente de clase, es posible suponer que quienes toman las decisiones que impactan sobre grandes sectores de la sociedad responden a un ethos aristocrático, como se ha mostrado en capítulos anteriores.

Tanto en la vida institucional como en la cotidianeidad la violencia (si bien no desaparece) cambia. No solo se observa un giro en el protagonismo que adquieren los diferentes modos represivos e ideológicos de la vida, sino en las mismas formas de violencia dentro de cada aparato del Estado y de la sociedad en general.

La disciplina es, precisamente, ese conjunto de técnicas que se arman y disponen en la sociedad que recorre transversalmente aparatos e instituciones y que dan un impulso a este cambio, regulando los modos en los que se llevan adelante diferentes prácticas. Esta configuración que se observa en los siglos XVIII y XIX no se puede hallar en una institución específica, al igual que no se puede descubrir en una forma única, sino que se trata de,

(...) una microfísica del poder que los aparatos y las instituciones ponen en juego, aunque su campo de validez se sitúa en cierto modo entre esos grandes funcionamientos y los propios cuerpos con su materialidad y sus fuerzas. Ahora bien, el estudio de esta microfísica supone que el poder que en ella se ejerce no se 
conciba como una propiedad, sino como una estrategia, que sus efectos de dominación no sean atribuidos a una apropiación, sino a disposiciones, a maniobras, a tácticas, a técnicas, a funcionamientos; que se descifre en él una red de relaciones siempre tensas (...) este poder se ejerce más que se posee, que no es el privilegio adquirido o conservado de la clase dominante sino el efecto de conjunto de sus posiciones estratégicas, efecto que manifiesta, y a veces acompaña, la posición de aquellos que son dominados. Este poder (...) los invade, pasa por ellos y a través de ellos; se apoya en ellos del mismo modo que ellos mismos, en su lucha contra él, se apoyan a su vez en el lugar de presas que ejerce sobre ellos. Lo cual quiere decir que estas relaciones descienden hondamente en el espesor de la sociedad (Foucault, 2009: 36).

Estas técnicas políticas a las que hace referencia se distinguen por la especificidad y sus modos de acción, que no son tanto una pertenencia como el efecto de su uso. Sin embargo, que esto sea así no implica -al menos necesariamente- que los aparatos e instituciones no respondan a los intereses de una minoría.

Esto permite pensar la relación en términos de tensiones: por un lado, el dispositivo cuyo funcionamiento implica y afecta a toda la sociedad (o al menos a todos quienes participan en alguna de estas instituciones sin distinciones de clase) $y$, por el otro, los mecanismos disciplinares establecen posiciones estratégicas que, si bien pueden ser ocupadas por cualquier persona, su acceso se ve restringido por las condiciones de posibilidad.

La disputa por estas posiciones representan tensiones diferenciables entre lo que se puede apreciar como la lucha dentro de las instituciones y la lucha por su control, lo que claramente restringe el potencial en una dirección o en otra. El resultado evidente es un tipo de funcionamiento que coloca en posición de ventaja a un sector de la sociedad, en este caso la burguesía. Vale recordar que el 
proceso de la civilización no es otra cosa que la reproducción de la cultura occidental y, para ello, se vale del Estado. En la actualidad, es necesario reflexionar acerca de qué intereses persiguen los funcionamientos institucionales y su impacto a nivel de la práctica deportiva.

Las descripciones respecto a la disciplina en el cuartel muestran correspondencias con las acciones del juego. Escribe Foucault (2009: 164), "Es preciso asentar el ejército, masa vagabunda; impedir el saqueo y las violencias (...) evitar los conflictos con las autoridades civiles". En el plano de la práctica deportiva se encuentra en una descripción de Elías respecto a un juego conocido:

Nada más revelador sobre la clase de juego que entonces se practicaba bajo el nombre de fútbol que los constantes $y$, en general, aparentemente fallidos esfuerzos de las autoridades estatales y locales por suprimirlo. Debía de ser un juego salvaje, acorde con el temperamento de la gente en aquella época. (En Elías y Dunning, 1992: 213)

Y agrega:

Los encuentros de fútbol y otros parecidos no eran en aquel tiempo simples trifulcas accidentales. Constituían una actividad recreativa restauradora del equilibrio y profundamente tejida en la trama y urdimbre de la sociedad. Puede parecernos un sinsentido que año tras año la gente se complicara en una pelea los días de los santos y festivos. Es evidente que nuestros antepasados, que se hallaban en una fase distinta del proceso civilizador, la vivían como una providencia perfectamente obvia y obviamente placentera (p. 218).

Al analizar los ejemplos se encuentra un proceso en desarrollo que marca el momento en el que determinadas costumbres se entienden como poco productivas, demasiado violentas, y deseables de ser transformadas en formas más civilizadas. Además, los intentos fallidos sobre el control de la violencia muestran la ausencia del monopolio estatal que requiere el proceso de la 
civilización. En este punto se advierte el denominador común en el juego como en el ejército y el control monopólico sobre la violencia comienza a mostrarse como una necesidad coyuntural.

Esta problemática bien podría encontrar solución en la disciplina, a pesar de que ésta se remonta mucho más allá del siglo XVIII. En épocas anteriores el cuerpo ya era tomado como objeto de poder. Entonces, ¿por qué analizar este momento específicamente? Foucault (2009: 159) lo expresa en una pregunta: "En estos esquemas de docilidad, que tanto interés tenían para el siglo XVIII, ¿Qué hay que sea tan nuevo? No es la primera vez, indudablemente, que el cuerpo constituye el objeto de intereses tan imperiosos y apremiantes (...)".

El sometimiento del cuerpo, en tanto que objeto de poder, data de mucho tiempo. Lo novedoso se encuentra en el grado de detalle en el objeto de control y en las modalidades del mismo. Si "A estos métodos que permiten el control minucioso de las operaciones del cuerpo que garantizan la sujeción constante de sus fuerzas y les imponen una relación de docilidad-utilidad es a lo que se puede llamar disciplinas" (Foucault, 2009: 159), debemos entonces conocer cuáles son estos métodos y cómo es el funcionamiento de estos esquemas, para precisar a que llamamos disciplina.

Entre las novedades de estas técnicas disciplinares se destacan tres grandes cuestiones: la escala de control, su objeto y la modalidad. La primera hace referencia al nivel en el que opera sobre el objeto-cuerpo, se trata "(...) de trabajarlo en sus partes (...) poder infinitesimal sobre el cuerpo activo" (Foucault, 2009: 159), el detalle adquiere aquí un rol protagónico, no es ya el cuerpo en su totalidad, sino en sus partes mínimas en las que se ejerce el control.

La segunda, su objeto, refiere a "(...) la economía, la eficacia de los movimientos, su organización interna (...)" (p. 159), son las fuerzas productivas del cuerpo las que preocupan y aquí lo que resalta es el ejercicio. Por último, la modalidad, que es permanente e "(...) implica una coerción ininterrumpida, constante, que vela por los procesos de la actividad más que por su resultado (...)" (Foucault, 2009: 
$159)^{32}$, lo que destaca la constancia. Por ello es que la disciplina que pretende producir un cuerpo dócil piensa la docilidad en términos de obediencia y utilidad, es dócil un cuerpo en tanto y en cuanto responda como se espera, lo más rápido posible y durante el mayor tiempo posible.

En el proceso civilizador las acciones del cuerpo y su uso se refinan, se estructuran y regularizan. Este proceso comienza con controles y normativas externas, las cuales, paulatinamente, se interiorizan ${ }^{33}$.

En este sentido, se piensa la mecánica disciplinar como colaboradora en este proceso civilizador. Tal como plantea Foucault (2009: 160)

El momento histórico de las disciplinas es el momento en el que nace un arte del cuerpo humano que no tiende únicamente al aumento de sus habilidades, ni tampoco a hacer más pesada su sujeción, sino a la formación de un vínculo que, en el mismo mecanismo, lo hace tanto más obediente cuanto más útil, y viceversa. Se conforma entonces una política de las coerciones que constituye un trabajo sobre el cuerpo, una manipulación calculada de sus elementos de sus gestos, de sus comportamientos.

Es difícil establecer si es el momento histórico el que plantea las necesidades así como también si las disciplinas son su efecto, o bien, si son las disciplinas las que hacen al momento histórico.

Si se recuerda que, a veces, "(...) los seres humanos pueden llegar a modelos de ordenación institucional u organizativa que, si funcionan bien, enseguida se

${ }^{32}$ Este caso no es el mismo giro que dieron los deportes respecto a los juegos medievales. Recordando la caza de zorros y el desplazamiento del placer de matar al animal por el placer en la dificultad de la caza y la separación del acto bárbaro.

${ }^{33}$ La expresión externo-interno es útil solo si se entiende en términos de gobierno y de libertad. Si el gobierno pretende el orden para la libertad o si el gobierno domina y coacciona. En este sentido, la interiorización de la disciplina, puede referir al control del propio individuo sobre sí mismo, lo cual no implica un signo negativo necesariamente. Si esta disciplina anula cualquier iniciativa y obtura cualquier resistencia, se puede hablar de un estado de dominación y, lo que parece ser la libertad del individuo de autocontrolarse, resulta en la represión política. 
vuelven tan obvios para los participantes que éstos los consideran 'naturales', 'normales' o, simplemente 'racionales'” (Elías y Dunning, 1992: 46), se encuentra el por qué los mecanismos disciplinarios se reproducen de manera significativa en este momento particular. Según Foucault (2009: 160),

La invención de esta nueva anatomía política debe entenderse menos como un repentino descubrimiento que en tanto una multiplicidad de procesos, con frecuencias menores, de origen diferente, de localización diseminada, que coinciden, se repiten o se imitan (...) convergen y delinean poco a poco el diseño de un método general. Se los encuentra tempranamente actuando en los colegios, mas tarde en las escuelas elementales (...) el espacio hospitalario (...) la organización militar (...).

Se sostiene la relación dialéctica entre el momento histórico y las disciplinas. Lo interesante es la coherencia y cómo se ajusta la teoría del proceso de la civilización a la realidad que se describe, sobre todo si se piensa que es la violencia en general lo visto como signo negativo, marco en el cual esta meticulosa disciplina encuentra un espacio con las características necesarias para su funcionamiento.

\section{DISCIPLINA, DEPORTE Y PUBLIC SCHOOLS}

El deporte responde a un momento histórico en el que la regulación de los comportamientos es prioritaria; se enmarca en el proceso de la civilización e implica, entre otras cosas, la formación del Estado y el control unificado de la violencia, el aumento en las redes de interdependencia y la necesaria estabilidad y previsibilidad en el funcionamiento de la vida cotidiana. Esto tiene una serie de consecuencias de las cuales interesa destacar la reducción en los niveles de tolerancia respecto a la violencia que estaba en condiciones de soportar la 
sociedad $^{34}$, y sus efectos en la política como en el trabajo y en otros campos como el de la práctica deportiva. Ahora bien, esta regulación se ve mediada por un conjunto de técnicas que hacen al dispositivo disciplinario y que toman por objeto al cuerpo. Así como se ha descrito respecto de esta coyuntura,

(...) la difusión de las prácticas deportivas supuso la puesta en acción de una serie de dispositivos que asegurasen unas determinadas formas de conducta y de disciplina corporal, fueron producto de nuevas sensibilidades que dieron lugar a un conjunto de regulaciones del cuerpo individual y colectivo antes inexistentes (Barbero González, 1993: 13).

Se observa aquí el entrecruzamiento manifiesto entre el fenómeno deportivo, la educación y el dispositivo disciplinar. Al respecto agrega Barbero González (1993: 13) "(...) fue en el amurallado mundo de Tom Brown ${ }^{35}$ donde las clases dominantes inglesas experimentaron por primera vez el dispositivo de lo deportivo con sus propios hijos". La cita da cuenta de la coyuntura y el entrecruzamiento entre deporte y disciplina. Sostener que es en estas instituciones donde se presenta el primer encuentro con el fenómeno deportivo podría representar una apreciación sesgada.

En la apertura del Congreso Internacional de la Asociación de Historia de la Educación Física y el Deporte en 1978, Bourdieu (en Barbero González, 1993: 196) (de aquí retoma la idea Barbero) manifiesta:

Me parece indiscutible el hecho de que la transición del juego al deporte propiamente dicho se llevó a cabo en las grandes escuelas reservadas para las "elites" de la sociedad burguesa,

\footnotetext{
${ }^{34}$ Esto puede interpretarse en un doble sentido, por un lado, la violencia que pueden soportar las personas $\mathrm{y}$, por el otro, la tolerancia que puede tener el funcionamiento del sistema a las distorsiones provocadas por la violencia.

${ }^{35}$ La cita hace referencia a una historia escrita por Thomas Hughes, uno de los impulsores principales del deporte en la institución, titulada Tom Brown's School days, que narra la vida en la Public School de Rugby durante 1834 (período en el que el propio Thomas Hughes fue alumno mientras el Director de la institución era Thomas Arnold, discípulo del Barón Pierre De Coubertin impulsor de los Juegos Olímpicos modernos cuya primer edición fue en 1896- ).
} 
en las public schools inglesas, donde los hijos de las familias aristocráticas o de la alta burguesía tomaron algunos juegos populares, es decir, vulgares y transformaron su sentido y función de manera muy similar en que la misma música culta transformo los bailes populares (...).

Si bien lo observado hasta aquí coincide en que hubo deportes (como el fútbol o el rugby) que se desarrollaron notablemente en estas instituciones, las transformaciones respecto a otros deportes pone en duda las afirmaciones de Barbero y Bourdieu. "Uno de los primeros ejemplos de pasatiempo con las características distintivas de deporte fue la modalidad inglesa de la caza de zorros" (Elías y Dunning, 1992: 196). No se encuentran referencias de este desarrollo circunscriptas al interior de las Public Schools.

El deporte -que emerge en Inglaterra entre los siglos XVIII y XIX- es un fenómeno complejo que se desarrolla en simultáneo a otros fenómenos que, a su vez, responden a cambios coyunturales a nivel de esferas más amplias. Entonces, no sólo la manifestación de la práctica deportiva en las Public Schools es un acontecimiento trascendental en la historia de la práctica deportiva, sino que también lo son las manifestaciones encontradas en las diferentes esferas de la vida social, política, económica, etc.

Afirmar que el encuentro con el fenómeno deportivo se da por primera vez en las Public Schools parece tan difícil como sostener el encuentro con un fenómeno en los límites de una institución (cuando la emergencia del mismo responde a cuestiones que exceden estos límites).

Tal como se practicaba en sus primeros tiempos, no sólo en Inglaterra sino también en muchos otros países, el fútbol, al igual que casi todos los juegos de pelota, era realmente un juego muy salvaje.

Siglos después entre 1845 y 1862, cuando al menos en algunas de las principales escuelas privadas la práctica del fútbol se hubo reglamentado mucho más, el nivel de violencia permitida 
era aún mucho más alto que hoy y la dinámica de las tensiones de grupo, por tanto, muy diferente (Elías y Dunning, 1992: 238).

El desarrollo del fenómeno se muestra como un proceso el cual puede haber tenido un gran impulso en estas instituciones. Sin embargo, esto no significa que se encontrara ahí al deporte original, sino que, el proceso de deportivización de los pasatiempos y las características que va adoptando el fenómeno deportivo, son efectos de causas cuya producción excede los muros del "universo de Tom Brown", aunque los análisis en dichas instituciones permitan ver la especificidad de mecanismo y de modalidad de las técnicas disciplinarias.

Se encuentran referencias a las elites de las escuelas privadas en el trabajo de Elías (en Elías y Dunning, 1992: 260). Esto no invalida las reflexiones hechas hasta el momento, el autor precisa un poco más la categoría diciendo: "He llamado «élite de las escuelas privadas» a la clase gobernante de Inglaterra de fines del siglo XIX para subrayar el papel de estas escuelas en la unificación de sus sectores burgueses predominantes, hacendados y establecidos".

Esta precisión permite pensar si la confusión en torno a la aparición del deporte en las public schools no podría radicar en la suposición de que la elite de las escuelas privadas se reduce a los agentes de la propia institución, lo cual supone el tratamiento aislado de la misma, desconectada de las redes de interdependencia de toda la sociedad.

Elias y Dunning (1992: 237) hacen referencia a las transformaciones acaecidas a largo plazo y cómo estas manifiestan una tendencia hacia prácticas más controladas:

(...) el desarrollo de una forma de tensión de grupo altamente regulada y relativamente no violenta, desde una etapa anterior en que las correspondientes tensiones tendían mucho más que ahora a descargarse en algún tipo de violencia, es parte medular de la dinámica a largo plazo del fútbol como juego. Es representativa -casi podríamos decir simbólica- de ciertos 
aspectos del desarrollo a largo plazo de las sociedades europeas.

Y agregan:

(...) logramos descubrir algunas razones por las que, aunado a similares corrientes dentro de la sociedad en general, un juego como el fútbol pasó de una variedad más violenta a otra menos violenta e incontrolada $y$, consecuentemente, a una forma distinta de patrón de juego, de dinámica de grupo (p. 238).

El funcionamiento interno de dichas instituciones, como cualquier otra, son permeables a los cambios en las redes de interdependencia de la sociedad en general y muestra de esto son las técnicas disciplinarias, por ello es dable suponer que los cambios que en ella acaecen responden, al menos en parte, a cambios acontecidos en otras esferas de la vida humana; es más acertado pensar estos cambios como consecuencias de transformaciones profundas en la sociedad y no como propios de una esfera particular. Esto no invalida la existencia de cambios que respondan a causas internas; resulta más significativo el sostener esta tensión que obturarla con el supuesto de que el dispositivo deportivo se encuentra por primera vez en las public schools. El mismo Barbero González (1993: 17) afirma un poco más adelante:

Paralelamente en el mundo exterior, durante la primera mitad del siglo XIX, las recreaciones populares se habían venido convirtiendo en objeto de atención e intervención por parte de los sectores más moralizantes y puritanos de las clases dominantes.

No parecen ser los sectores más "moralizantes y puritanos" sino la aristocracia y la burguesía incipiente. El fair play y la caballerosidad propia de los deportes pueden verse como cuestiones morales. El sentido tiene que ver con la necesidad de relaciones más estables para las cuales es necesario educar, no tanto por moralidad, sino por necesidad política. 
El mundo exterior tiene efectos en el interior de estas instituciones. Barbero González (1993: 15) menciona estos cambios en otro sentido: los cambios en el exterior van en la misma dirección que los del interior. Esto puede observarse en cómo, por ejemplo, las reglamentaciones más rigurosas sobre deportes, como el rugby o el fútbol, surgieron a partir de reuniones dentro de estas instituciones,

(...) las primeras Leyes del Fútbol en la forma en la que se juega en la Escuela de Rugby fueron resultado de una asamblea de los chicos de sexto año en 1845 y fueron sancionadas en 1846 por una asamblea de toda la escuela (...).

Lo que recuerda a la idea de proceso de democratización funcional desarrollada por Elías (Elías y Dunning, 1992: 24). En este sentido, se observa y sostiene cómo los cambios van en la misma dirección dentro de algunas de las public schools y al exterior, tanto en términos de control de la violencia como de participación política.

Los cambios acaecidos en el fenómeno deportivo (que están en plena emergencia) deberían observarse considerando lo siguiente: los deportes aún están en proceso de institucionalización, por lo que la manifestación más institucionalizada del fenómeno emergente se observa en instituciones como las public schools; también se manifestaban apariciones de éstos nuevos modos en la ciudad y zonas rurales, como se ha mencionado, respecto a la Caza del zorros o el Boxeo en el capítulo II, "Sobre el deporte".

Si es en estas escuelas donde se muestran los cambios en el fenómeno deportivo, ¿es allí donde ocurren las primeras y/o únicas apariciones del deporte? Que el fenómeno se haya expandido a todo el mundo conservando su forma singular implica que las condiciones de posibilidad del fenómeno no se encontraban tanto en el interior de una institución como en cambios histórico-políticos profundos, a nivel nacional primero y mundial después.

Otras de las cuestiones es que en estas instituciones también se observan cambios respecto a lo disciplinario que van al ritmo de los acaecidos en otras instituciones (fábricas, cuarteles, etc.) $y$, finalmente, se puede apreciar la 
articulación entre la disciplina y los deportes en esta afirmación de Barbero González (1993: 16): “(...) la aparición de las formas deportivas en los recintos amurallados de las 'Public Schools' muestra la puesta en juego de iniciativas paralelas coercitivas y de consenso".

Resulta interesante tomar estas instituciones como punto de anclaje para la reflexión sobre el fenómeno deportivo por dos razones: encontrar allí la articulación de cuatro pilares fundamentales en la investigación: progreso, libertad, política, educación y, en segundo lugar, por habilitar la posibilidad de cuestionar estas instituciones como el único espacio en el que se pudieran encontrar estas prácticas.

La relación entre estos pilares (dentro y fuera de estas instituciones, con matices diferentes) es inextricable y, en términos de esta investigación, se observa la puesta en tensión del dispositivo disciplinario y nuevas prácticas corporales que, en línea con el proceso de la civilización, muestran cambios que se vinculan directamente con estos pilares. No es por encontrar allí la invención ni del dispositivo disciplinario ni del fenómeno deportivo, sino para mostrar estos fenómenos emergentes en las redes de interdependencia que constituyen una sociedad en un momento determinado.

Los cambios en las acciones que se llevaban a cabo en los juegos eran acompañados por transformaciones a otros niveles de la vida en la institución (y de la sociedad, al menos algunos sectores). Todo un régimen de controles sobre el cuerpo que afectaban desde su gestualidad hasta sus comportamientos. La complejidad radica en el carácter microfísico de estos controles, de lo que el fenómeno deportivo o las public schools no son -ni pueden ser- más que 'cuadros vivos $^{36}$. (Foucault 2009), paradigmáticos. Inclusive circunscribir la práctica

\footnotetext{
36 "La primera de las grandes operaciones de la disciplina es, pues, la constitución de 'cuadros vivos 'que trasforman las multitudes confusas, inútiles o peligrosas, en multiplicidades ordenadas. (...) inspeccionar a los hombres, comprobar su presencia y su ausencia (...) Se trata de organizar lo múltiple, de procurarse un instrumento para recorrerlo y dominarlo, de imponerle un 'orden"” (Foucault 2009: 172).
} 
deportiva a estas instituciones hace a la precisión o bien a la complejización del ejemplo, no al origen del fenómeno.

Son relevantes los aportes hechos por Bourdieu (en Barbero González, 1993: 197) respecto a esta práctica dentro de las public schools. Escribe:

En la escuela sede de las skhole, el ocio, las prácticas provistas de funciones sociales e integradas al calendario colectivo son transformadas en ejercicios corporales, en actividades que tienen un fin en sí mismas, una especie de arte por el arte corporal, y sujetas a reglas específicas que son cada vez más irreductibles a cualquier necesidad funcional (...) La escuela es la sede por excelencia del ejercicio llamado gratuito (...).

Se recupera la mención respecto al ejercicio en tanto que técnica disciplinaria, lo cual permite establecer la importancia del ejercicio y destronar la escuela como sede única de las técnicas disciplinarias,

En el taller, en la escuela, en el ejército, reina una verdadera micro penalidad del tiempo (retrasos, ausencias, interrupciones de tareas) de la actividad (falta de atención, descuido, falta de celo), de la manera de ser (descortesía, desobediencia), de la palabra (charla, insolencia), del cuerpo (actitudes incorrectas, gestos impertinentes, suciedad), de la sexualidad (falta de recato, indecencia) (Foucault, 2009: 208).

Si bien no hace una referencia explícita al ejercicio, éste queda implícito en la elaboración de una gimnasia que favorece el funcionamiento del sistema en el que opera. El deporte se muestra así como un subsistema dentro del sistema institucional, ya que penaliza los retrasos o las interrupciones, regula las acciones y los gestos, así como se penaliza la falta de atención o descuido, etc.

Lo disciplinario (presente en las diferentes esferas de la vida en ese momento histórico) puede parecer, en primera instancia, un carácter típico de algún campo 
específico. En tanto que táctica política, hace al ethos de la época según lo que menciona Elías respecto a modelos de ordenación institucional, cuyo funcionamiento se amolda tan bien a las necesidades coyunturales que se naturalizan.

No se puede olvidar el necesario escenario político que manifestaba la demanda cada vez más imperiosa por parte de las clases ascendentes, de formar a sus jóvenes en materia política.

El Fair Play es la manera de jugar el juego de aquellos que no se dejan llevar por el juego al punto de olvidar que es un juego, de aquellos que saben mantener la "distancia respecto del papel", como dice Goffman, que implican todos los papeles con los que se encontrarán los futuros dirigentes (Bourdieu en Barbero González, 1993: 197).

El entrecruzamiento entre la vida de la sociedad en general y la vida en las Public Schools en referencia al autocontrol y la regulación de las conductas presenta un contexto complejo que, gracias a éste, permite comprender mejor cómo el contexto histórico político se transforma al tiempo que las técnicas disciplinarias y las prácticas en las que ellas actúan, admiten y promueven determinados modos de comportamiento, las que a su vez se corresponden con las necesidades funcionales de redes de interdependencia cada vez más extensas.

El análisis del dispositivo disciplinario en el deporte permite observar cómo, a través de sus técnicas, va dando lugar a esta proliferación en las figuraciones que permite un comportamiento que tiende a buscar el equilibrio entre la previsibilidad que permite el funcionamiento y la indeterminación necesaria para sostener el carácter mimético y el interés.

\section{EL DISPOSITIVO DISCIPLINARIO Y LA INSTRUMENTALIZACIÓN DEL CUERPO}

El dispositivo disciplinario (táctica política que emerge con características definidas en los siglos XVIII y XIX) opera sobre diferentes micro dimensiones de la vida y 
por ello las sociedades de esta época pueden recibir el nombre de sociedades disciplinarias; el objetivo de esta táctica son los detalles en las partes y los movimientos del cuerpo, la minucia en la regulación sobre la articulación del cuerpo, los objetos y los otros que, para el sometimiento, recurre a diferentes técnicas. Ahora bien, ¿cómo operan éstas en el fenómeno deportivo?

\section{Técnicas espaciales}

Haciendo referencia a lo que podría llamarse dimensión espacial la disciplina "exige a veces la clausura, la especificación de un lugar heterogéneo a todos los demás y cerrado sobre sí mismo" (Foucault, 2009: 164). En este sentido se puede pensar tanto el espacio de entrenamiento como el terreno de juego. Dos espacios donde operan determinadas reglas que, si bien se articulan, se enmarcan en una lógica diferente. Las subdivisiones espaciales en el interior del juego que responden a una lógica particular estructuran o preconfiguran los sentidos que pueden tener los espacios de clausura en los momentos de preparación para la competencia.

Se encuentran aquí dos espacios bien diferenciables con lógicas que se articulan. Por un lado, un tiempo destinado al entrenamiento; la puesta en ejercicio del cuerpo y/o momento de la preparación para, en el que las reglas del deporte se articulan con las de la gimnasia para obtener como resultado mejoras en el desempeño deportivo. Por el otro, en el partido se ponen en movimiento las reglas descritas en el reglamento del deporte propiamente dicho.

Es, por ejemplo, la descripción reglamentaria del terreno de juego la que, en tensión con el objetivo y los modos de conseguirlo, dan forma a técnicas específicas que se configuran en función de estos espacios. La obligación de realizar determinadas técnicas en los sectores que dispone el reglamento es la causa eficiente de acciones complejas que entran en tensión con el sistema de juego. En este marco se establecen las articulaciones con el espacio destinado a la enseñanza, del entrenamiento y del juego. 
En estos espacios se observan las dos dimensiones de la libertad que se distinguen en el capítulo I, "Sobre la civilización y la práctica deportiva", tanto en el juego propiamente dicho como en el entrenamiento: la libertad y su dimensión negativa (ese terreno donde el que manda es uno: yo decido la gambeta o el pase, el dribling o el lanzamiento). La libertad y su dimensión positiva, donde se responde al mando del sistema, que es a priori un acuerdo colectivo.

En el entrenamiento, la libertad se pone en juego en otros niveles, conservando su doble dimensión: libertad individual (de poner más o menos entusiasmo e intensidad, esto es relativo al objetivo del entrenamiento, sin embargo siempre hay un resto de libertad) y libertad colectiva (por ejemplo de entrenar, gracias a un acuerdo colectivo de juntarse para ello). Esto último podría ponerse en discusión y dar lugar a la pregunta acerca de si se pone en juego la dimensión negativa, es decir, la libertad individual de participar. Sin embargo es un acuerdo necesario ya que, de no respetarse no hay equipo posible, por lo tanto esta elección será primera y, una vez aceptado el pacto, no supone más una elección sino un deber, el respeto por el acuerdo.

Al hacer relevos entre la edad media y la modernidad (tomando como punto de anclaje juegos y deportes para analizar sus transformaciones con especial atención a las técnicas disciplinarias) se observa con claridad el contraste entre prácticas que podían parecer indistinguibles y la posibilidad de articular estos cambios con transformaciones a niveles más profundos de la sociedad en general.

Se mencionó en el capítulo II, "Sobre el deporte", que las reglas en los juegos eran mucho menos elaboradas, asociadas a la tradición y sin manifestar espacios de clausura específicos. Así describe Elías un juego medieval (en Elías y Dunning, 1992: 225):

Las metas son o las mansiones de esos caballeros o algunos pueblos o aldeas situados a cinco o seis kilómetros de distancia, los cuales son elegidos por cada bando según la proximidad de sus moradas. Cuando se reúnen, no se equipara el número de jugadores ni se contrasta a los hombres: sólo se lanza al aire 
una pelota de plata y el equipo que logre atraparla y llevarla, por su fuerza o pericia, hasta el lugar que se le ha asignado, obtiene la pelota y la victoria.

Mientras que, al leerse el reglamento de fútbol contemporáneo, se encuentra:

REGLA 1 - EL TERRENO DE JUEGO

Área penal

Se trazarán dos líneas perpendiculares a la línea de meta, a $16.5 \mathrm{~m}$ de la parte interior de cada poste de meta. Dichas líneas se adentrarán $16.5 \mathrm{~m}$ en el terreno de juego y se unirán con una línea paralela a la línea de meta. El área delimitada por dichas líneas y la línea de meta será el área penal (FIFA, 2015: 8).

Esta comparación no solo muestra el contraste entre una actividad poco regulada, como los juegos medievales y los altamente regulados deportes modernos, sino que también permite apreciar características espaciales que lo hacen fácilmente controlable y la elaboración de una micro-penalidad que regula las acciones. Por ejemplo, "Los castigos [penalties] por romper abiertamente las reglas son suficientemente costosos para impedir que se produzcan demasiadas faltas, demasiadas fracturas en el autocontrol de los jugadores" (Elías y Dunning, 1992: 71). Esto da cuenta de otra técnica de la disciplina: la "división de zonas. A cada individuo, su lugar" (Foucault, 2009: 166).

En el fútbol, por ejemplo, el arquero en el área se puede comportar de una manera distinta, lo que lo distingue, mientras que los jugadores también se ven afectados por esta subdivisión y la penalidad que opera en su interior. En líneas generales se encuentran espacios heterogéneos en todos los deportes, en su interior se subdividen zonas y en ellas los jugadores ocupan espacios con roles que pueden conservar cierta homogeneidad, que no dejan de tener su especificidad.

Estos funcionamientos (que exceden la práctica deportiva) se repiten en las escuelas, las fábricas, las instituciones. Como dice Foucault (2009: 169): "La disciplina, arte del rango y técnica para la transformación de las combinaciones. 
Individualiza los cuerpos mediante una localización que no los implanta, pero los distribuye y los hace circular en un sistema de relaciones".

Al analizar algunos ejemplos se observa que los esquemas de formación en los diferentes deportes distribuyen los jugadores: en fútbol (4-4-2; 4-3-3; 4-3-1-2; etc.); en vóley $(\mathrm{W}, \mathrm{M})$; en básquet $(4-1 ; 3-2)$, aunque ellos no tienen prohibida su circulación ${ }^{37}$ por la cancha, el cómo de esta circulación está regulado y acordado por el sistema de juego. El sistema enunciado en estos términos es simplista y no cuenta con la especificidad de la circulación interna, ni la complejidad en términos de funciones específicas que un sistema requiere. Estas funciones se articulan unas a otras con un amplio abanico de opciones que no son apreciables con esta descripción, como las que podrían establecerse al considerar la práctica deportiva entre jugadores, cuerpos técnicos, espectadores, árbitros, dirigentes, barras bravas, medios de comunicación masivos y periodistas, etc.

"No los implanta pero los distribuye", escribe Foucault (2009: 169) y, más adelante, agrega (respecto a la composición de fuerzas), "Armada de picas y de mosquetes- lentos imprecisos, que apenas permitían apuntar a un blanco- una tropa se utilizaba ya como un proyectil, ya como un muro o una fortaleza" (2009: 189). Da cuenta de las dificultades que encuentran los regimientos militares al comenzar el siglo XVIII para superar las limitaciones de una estructura basada en el modelo físico de la masa.

Tomando en consideración esta composición de la Edad Media, Elias (en Elías y Dunning, 1992: 226) recupera un fragmento de un informe de la Europa medieval en referencia al juego llamado fútbol:

Los jugadores emprenden luego su camino sobre colinas, valles, setos, zanjas; sí, y por entre cualesquiera arbustos, zarzas, lodazales, charcos y ríos; de modo que a veces se verán 20 ó 30 metidos en el agua luchando, trepándose unos sobre otros y arañándose con tal de conseguir la pelota. Un juego (en verdad)

\footnotetext{
${ }^{37}$ En algunos deportes hay lugares que se vuelven prohibidos para algunos o todos los jugadores, sea de forma transitoria o permanente.
} 
a la vez rudo y duro y que como tal, sin embargo, por no estar falto de sistemas, recuerda en cierto modo las acciones bélicas, pues habrá compañías desplegadas por una parte para hacer frente a quienes vienen con la pelota $y$, por otra, para socorrerlos, a modo de primera línea de combate. Además, otras tropas se sitúan a los lados, como alas, para ayudar o detener su huida; y dónde va la pelota misma parecen trabarse las dos batallas principales; los de paso más lento, que vienen rezagados, ofrecen el espectáculo de una retaguardia: sí, también hay hombres a caballo colocados a ambos lados (como si se tratase de una emboscada) y listos para partir al galope con la pelota si pueden hacerse con ella (...).

El funcionamiento muestra algunas similitudes en la batalla como en el juego, una masa de personas que, organizada groseramente, busca un objetivo. Los cambios que va a sufrir la organización militar pueden pensarse, tomando los recaudos necesarios, en cierta correlación a los ocurridos en estos juegos medievales y que dieron origen al deporte.

En términos militares el dispositivo disciplinar habilita la transformación, "(...) la unidad -regimiento, batallón, sección, más tarde "división"- se convierte en una especie de máquina de piezas múltiples que se desplazan unas respecto a otras para llegar a una configuración y obtener un resultado específico (...)" (Foucault, 2009: 189).

Estos cambios observables entre la armada de picas y la división en el funcionamiento militar también son observables en las diferencias entre los juegos medievales y el deporte; se encuentra en éstos divisiones por categorías, por edad, por peso, etc. En definitiva, las diferentes técnicas disciplinarias (los espacios de clausura, la división de zonas, el rango) operan en estos campos y tienen como resultado cambios tan significativos que dan lugar a novedades: "Asistimos así al nacimiento del ejército como una institución que en el fondo no existía como tal en pleno medioevo" (Foucault, 1996: 46). En paralelo, se 
encuentra en la práctica deportiva una tecnología política del cuerpo inscrita en su núcleo duro que da forma a un fenómeno que tampoco existía en la Edad Media.

Todo deporte -aparte de lo demás que pueda ser- es una actividad de grupo organizada y centrada en la competición entre al menos dos partes. Exige algún tipo de ejercicio o esfuerzo físico. El enfrentamiento se realiza siguiendo reglas conocidas, incluidas -en los casos en que se permite el uso de la fuerza física- las que definen los límites de violencia permitidos. Las reglas determinan la figuración de partida que forman los jugadores y el esquema cambiante de ésta a medida que avanza la competición (Elías y Dunning, 1992: 190).

En el fútbol, por ejemplo, un equipo se compone por once jugadores que tienen un tiempo determinado para cumplir un objetivo y con formas legítimas de conseguirlo, lo que, puesto en movimiento y al observar su funcionamiento, se podría distinguir como lo que Foucault (2009: 172) identifica como 'cuadros vivos': "La primera de las grandes operaciones de la disciplina es, pues, la constitución de "cuadros vivos" que trasforman las multitudes confusas, inútiles o peligrosas, en multiplicidades ordenadas".

Por ello, describe el carácter celular de la individualidad que producen las técnicas

disciplinares. Siguiendo este razonamiento y recordando cómo la forma que adquieren los juegos populares va de lo masivo, descontrolado, violento, a formas mucho más organizadas y controladas, se puede apreciar la marca del dispositivo disciplinar en ambos campos.

\section{Técnicas temporales}

La vida en las instituciones de la sociedad moderna comienza a mostrar una nueva racionalidad sobre las regulaciones del tiempo: "1) El empleo del tiempo es una vieja herencia (...) Sus tres grandes procedimientos -establecer ritmos, obligar a ocupaciones determinadas, regular los ciclos de repetición- coincidieron muy pronto en los colegios (...)" (Foucault, 2009: 173), y agrega más adelante: 
“(...) en las escuelas elementales el recorte del tiempo es cada vez más sutil” ( $p$. 174).

Esta regulación detallada del tiempo, apreciable en toda institución, puede observarse en la regulación temporal de las acciones y los actos más específicos, por ello Foucault (2009: 195) enuncia que la disciplina produce una individualidad que "(...) es orgánica (por el cifrado de las actividades), es genética (por la acumulación del tiempo (...)".

A partir de otro ejemplo Foucault (2009: 175-176) recupera (de una ordenanza del siglo XVIII) una descripción detallada de cómo deben ser los pasos del regimiento de infantería, tanto en términos de longitud como de tiempo:

La longitud del paso corto será de un pie (...) en cuanto a la duración, la del paso corto y el paso ordinario será de un segundo (...) Se ejecutará el paso ordinario de frente llevando la cabeza alta y el cuerpo derecho (...).

Es interesante la descomposición del acto en sus partes mínimas y la preocupación por aprovechar el tiempo en su máxima expresión, la técnica deportiva muestra claramente esta descomposición elemental del gesto, llegando a establecer patrones de movimiento que exprimen la mayor cantidad de tiempo a los segundos,

(...) el control disciplinario no consiste simplemente en enseñar o en imponer una serie de gestos definidos; impone la mejor relación entre un gesto y la actitud global del cuerpo, que es su condición de eficacia y de rapidez. En el buen empleo del cuerpo, que permite un buen empleo del tiempo, nada debe permanecer ocioso o inútil (...) Un cuerpo bien disciplinado forma el contexto operatorio del menor gesto. Una buena letra, por ejemplo, supone una gimnasia, toda una rutina cuyo código riguroso domina el cuerpo por entero (...) (Foucault, 2009: 176). 
Es pertinente pensar el cuerpo no solo en términos individuales, sino además en términos de multiplicidad, de grupo organizado, de equipo. En este sentido, el control disciplinario opera de igual manera aunque a otra escala, ordenando e imponiendo un funcionamiento general del equipo que sirve de base al funcionamiento individual eficaz. Se amplía este tema un poco más adelante.

Las acciones que habilita el reglamento del deporte también suponen una gimnasia. La técnica emerge como aquella combinación de los gestos del cuerpo que arman acciones y situaciones que entran en tensión con lo permitido y lo prohibido, lo que se toma como los aspectos tecnológicos y también con los aspectos estratégicos, por lo que debe ser elaborada, pulida y, en algunos casos, actualizada con frecuencia.

Las acciones referenciales y posturas referenciales ${ }^{38}$ de un deporte suponen, por un lado, características posibles desde lo reglamentario (por ejemplo, que la pelota debe ser trasladada con los pies y no con las manos determina todo una serie de técnicas - exceptuando al arquero/a-) y, por el otro, el aprovechamiento de esa legitimidad para potenciar los efectos productivos que ésta admite (por ejemplo, el dominio de la pegada con ambos pies, que permite mayor amplitud de tiro y la posibilidad de mayores opciones). Estos aprovechamientos de legitimidad que el juego admite a la vez generen más incertidumbre para el oponente.

Podría ser que la misma acción cumpla los requisitos reglamentarios y que a la vez genere menos incertidumbre, en el caso del fútbol, el dominio de un solo perfil muestra cómo se reducen las opciones drásticamente (podría citarse aquí un caso de observación en la Escuela San José. Situación de partido en Chascomús, Agustina juega de volante por izquierda, es zurda y domina ambos perfiles; en un momento del partido elimina a un rival en el medio campo $y$, antes de entrar al área grande engancha hacia adentro, remata con derecha y mete la pelota en el ángulo superior derecho. Al volver, su entrenador le pregunta: ¿Por qué le pegaste

\footnotetext{
${ }^{38}$ Refieren a las acciones y posturas básicas de cada deporte que se desprenden del reglamento establecido y de las condiciones de posibilidad que el cuerpo admite. También se considera el momento o fase evolutiva del deporte (técnicas que aparecen en un momento que hasta entonces no habían sido observadas).
} 
con derecha? A lo que ella responde: "porque me quedó más cómodo". Entonces, se puede tomar la libertad de optar por lo más cómodo, gracias al dominio de ambos perfiles. La jugadora ahorró un tiempo y eso contribuyó a generar el espacio para el remate.

La posición que pretende abarcar la mayor cantidad de opciones potencia las posibilidades de éxito de cada una de éstas $y$, en este sentido, se podría considerar que "Un cuerpo disciplinado es el apoyo de un gesto eficaz" (Foucault, 2009: 178) ya que el buen uso del cuerpo permite un buen uso del tiempo ${ }^{39}$.

Esto pone delante otra cuestión: la articulación cuerpo-objeto, lo que, en el caso precedente, puede ser cuerpo-pelota y que se ven determinados mutuamente. La composición del gesto (que en este caso muestra dos elementos evidentes: cuerpo y objeto) encuentra sus limitaciones, al menos en parte, en la materialidad de ambos y tiene como resultado lo que en términos militares se conoce como maniobra y en el campo del deporte se ha de llamar gesto deportivo.

Este gesto tiene como condición de posibilidad el reglamento y, por ello, es coherente con la idea que expresa Foucault (2009: 178) cuando dice que "...la reglamentación impuesta por el poder es, al mismo tiempo, la ley de construcción de la operación....". Además se ponen en juego aspectos estratégicos que no son precisamente las disposiciones reglamentarias y que aumentan (o podrían aumentar) la tensión al incrementar la indeterminación.

La lógica del deporte implica una competencia entre dos partes y son estas fuerzas las que ponen en movimiento el juego; en este sentido, la técnica se ve también tensionada por factores que exceden lo reglamentario, lo que complejiza aún más su entrenamiento.

Las técnicas de la disciplina que regulan el espacio y que desmenuzan la globalidad de un gesto exprimen el tiempo multiplicando la producción,

${ }^{39}$ Los efectos no solo aumentan las fuerzas productivas. Si se considera que las acciones responden también a acuerdos colectivos, se abre la posibilidad a la potenciación de las fuerzas políticas, no en el juego propiamente dicho (donde no hay lugar a discusión sino sometimiento) pero sí en los espacios de formación donde la lógica admite la discusión. 
(...) cuanto más se descompone el tiempo, cuanto más se multiplican sus subdivisiones, mejor se lo desarticula desplegando sus elementos internos bajo una mirada que los controla, más se puede acelerar entonces una operación, o al menos regularla de acuerdo con un grado óptimo de velocidad (Foucault, 2009: 179).

Las disciplinas que analizan el espacio, que descomponen y recomponen las actividades deben también entenderse como aparatos para sumar y capitalizar el tiempo. En el deporte, uno de los aspectos que lo evidencia es, por ejemplo, cuando la mayor velocidad individual no hace a la efectividad si ésta no va en sintonía con la velocidad del equipo; hay una positiva que, en la medida en que va fuera de sintonía con el equipo, se vuelve en su contra (tal es el caso de Ricardo con quien se trabajó para que su velocidad se dé en función del colectivo, regulando momentos, espacios y el uso estratégico de esa velocidad, para citar uno de los casos que así lo grafican dentro de la Escuela de Fútbol San José).

\section{EL EJERCICIO Y EL DISCIPLINAMIENTO DE LOS CUERPOS}

Los ejercicios son procedimientos de carácter temporal que, en la práctica deportiva, se manifiestan con claridad en la preparación para la misma y cumplen con las características descritas hasta el momento, con un grado de detalle que alcanza lo elemental del acto, como así lo expone una revista especializada en deporte al indicar que:

(...) es posible descomponer las porciones de fuerza empleadas por un saltador en cada uno de sus movimientos, la resistencia del aire, la mecánica de trabajo de sus músculos en cada fase (...) Y así determinar con toda precisión donde están los puntos débiles de su salto (Cuerpo y Mente Deportes, 1988: 5).

Escribe Foucault (2009: 184): “(...) gestos simples que son por demás los componentes de base para las conductas útiles y que así mismo garantizan una 
educación general de la fuerza, de la habilidad, de la docilidad", la descomposición de los gestos complejos en partes simples sirven de base a comportamientos que el deporte reclama, es decir, su utilidad responde a las necesidades del juego; mientras que, por otro lado, permiten el mejoramiento de la fuerza, la habilidad y la docilidad. Sin embargo, es necesario destacar cómo el mejoramiento siempre es en términos de las necesidades del juego o la práctica deportiva en cuestión. Sin olvidar que la disciplina es el apoyo del gesto eficaz, mensurable éste sólo en función del juego. En este plano, la disciplina puede encontrar su funcionamiento en el ejercicio propiamente dicho.

Se debe agregar la gradualidad, un tiempo seriado que se acumula y a partir del cual se puede pensar en la preparación o la enseñanza del deporte. Lo que da lugar a una operación determinante, el ejercicio, el cual tiene lugar en el entrenamiento que supone perfeccionar el dominio técnico,

(...) el ejercicio es la técnica por la cual se impone a los cuerpos tareas a la vez repetitivas y diferentes, pero siempre graduadas. (...) permite una perpetua caracterización del individuo ya sea en relación con ese término con los demás individuos o con un tipo de trayecto. Así garantiza, en la forma de la continuidad y de la coerción, un crecimiento, una observación, una calificación (Foucault, 2009: 187).

Aquí, se reflexiona sobre este crecimiento que garantiza la coerción, bien puede establecerse un lazo con la idea de libertad que se viene trabajando. Agrega Foucault (2009: 188):

Los ejercicios cada vez más rigurosos que se propone la vida ascética se convierten en las tareas de complejidad creciente que marcan la adquisición progresiva del saber de la buena conducta (...) métodos destinados a producir aptitudes individualmente caracterizadas aunque colectivamente útiles 
(...). El ejercicio convertido en elemento dentro de una tecnología política del cuerpo y de la duración, no culmina (...).

Se aprecia cómo el ejercicio hace al entrenamiento para el dominio técnico y, en tanto que articula el gesto con la utilidad que pueda tener para el colectivo, muestra una elaboración táctica que además ponen en relación las dimensiones negativa y positiva de la libertad, en tanto que el ejercicio propone un entrenamiento que aceite los funcionamientos, no solo del carácter orgánico del individuo (la relación con su cuerpo) sino además el carácter celular, genético y combinatorio de su individualidad en tensión con el funcionamiento de un equipo.

Por ejemplo, una de las máximas de Marcelo Bielsa (2015: 119) -reconocido entrenador de Fútbol Argentino- es: "El juego tiene enumeraciones y descripciones de las situaciones extraídas y elegidas del juego real para ser resueltas por medio de los ejercicios que las representan", lo que permite suponer desde ejercicios para el trabajo técnico individual (como puede ser la pegada) hasta combinaciones complejas asociadas a un trabajo colectivo.

Se lee en la representación que realiza Loïc Wacquant (1999: 248) una descripción del reconocido boxeador Michael Spinks en referencia al cuerpo y en general:

Gracias a un régimen especialmente diseñado de trabajo intenso de velocidad, ejercicios aeróbicos y comida -tres comidas diarias de 5.500 calorías, ricas en carbohidratos y proteínas (...) los boxeadores construyen una armadura muscular específica a través de ejercicios que les permiten reforzar y expandir aquellas partes del cuerpo que más necesitan para su protección.

Esto permite dar cuenta de cómo el ejercicio en el deporte es constante, siempre que se quiera conseguir cierto grado de dominio será condición sine qua non el ejercicio continuo y permanente. Una disciplina que organice espacios y tiempos de estos ejercicios (en detalles que van desde la posición de un pie a los metros de distancia con un compañero, del horario de inicio de la clase a la duración de la 
acción), de espacios de discusión y resistencia a espacios de silencio y obediencia.

De este modo, la disciplina pretende conseguir el aumento exponencial de las fuerzas de producción con el domino técnico, además con la combinación calculada de las partes que funcionan en un doble juego: por un lado,

El cuerpo singular se convierte en un elemento que se puede colocar, mover y articular sobre otros (...) el lugar que ocupa, el intervalo que cubre, la regularidad, el orden según los cuales lleva a cabo sus desplazamientos (Foucault, 2009: 191).

Por el otro, un cuerpo parte de un conjunto:

(...) piezas igualmente, las diversas series cronológicas que la disciplina debe combinar para formar un tiempo compuesto. E tiempo de los unos debe ajustarse al de los otros de manera tal que la cantidad máxima de fuerzas pueda ser extraída de cada cual y combinada en un resultado óptimo (Foucault, 2009: 192).

Se observa, una vez más, cómo es la combinación del domino técnico individual la que se encuentra en permanente relación tanto con la lógica del juego como con el sistema al que pertenece (sostenidas por un sistema de códigos compartidos por el equipo). Continuando con un ejemplo previamente expuesto, puede parecer bueno contar con un jugador muy rápido pero de nada sirve $-\mathrm{y}$ hasta puede resultar perjudicial- si esta velocidad no va en armonía con el sistema que organiza al resto del equipo. Entonces, esta capacidad necesita de un sentido,

Toda la actividad del individuo disciplinado debe ser ritmada y sostenida por órdenes terminantes cuya eficacia reposa en la brevedad y la claridad (...) Entre el maestro que impone la disciplina y aquel que está sometido a él, la relación es de señalización: se trata no de comprender la orden sino de percibir la señal, de reaccionar enseguida, de acuerdo con un código 
más o menos artificial establecido de antemano (Foucault, 2009: 193).

La certidumbre que genera la relación de señalización proviene de acuerdos previos que hacen a funcionamientos democráticos. Lo que negativiza la relación es sólo la instancia en la que se encuentran, el juego completo viene dado por toda una serie de eslabones que hacen a la práctica deportiva punto clave para pensar el deporte como contenido educativo.

En términos de señales podría preguntarse quién da las órdenes, ya que bien podría ser el maestro o entrenador en los momentos de preparación, pero también el propio juego en los momentos de juego. Lo interesante resulta de la pregunta: ¿Qué ordena?, ordena los funcionamientos.

A partir de los acuerdos previos establecidos por maestro y alumnos, entrenador y entrenandos, podría analizarse si es que logran un sistema que funcione como apoyo firme en la vorágine que propone el juego y que, en la medida que se presenten situaciones contempladas a priori, funcionen como señales que el equipo identifica y a partir de ello los jugadores actúen en consecuencia respetando los roles asignados. Esto logra un orden que disminuye la incertidumbre y en el mismo movimiento es la base para un gesto eficaz.

La pregunta en torno a quién ordena podría responderse afirmando que es el reglamento y los acuerdos colectivos. Respecto al qué, podría decirse que ordena las relaciones que se establecen con los otros, las cosas y consigo mismo.

Esta descomposición e instrumentación técnica del cuerpo que lo transforma en un objeto y lo articula con el elemento deportivo (con los otros jugadores e incluso con él mismo) da lugar, construye y elabora una individualidad material en términos corporales y otra abstracta en términos de fuerza,

En resumen, puede decirse que la disciplina fabrica, a partir de los cuerpos que controla, cuatro tipos de individualidad, o más bien, una individualidad que está dotada de cuatro 
características: es celular (por el juego de la distribución espacial) es orgánica (por el cifrado de las actividades), es genética (por la acumulación del tiempo), es combinatoria (por la composición de fuerzas). $Y$ para eso utiliza cuatro grandes técnicas: construye cuadros, prescribe maniobras, impone ejercicios $y$, por último, para garantizar la combinación de fuerzas, dispone tácticas. La táctica, arte de construir, con los cuerpos localizados, las actividades codificadas y las aptitudes formadas, aparatos donde el producto de las fuerzas diversas se encuentra aumentado por su combinación calculada es, sin duda, la forma más elevada de la práctica disciplinaria (Foucault, 2009: 195).

Es interesante la producción de individualidad si se contempla el impacto que puede tener un dispositivo que no solo alcanza una práctica como el deporte, sino que atraviesa transversalmente la vida de la estructura social, como se ha mencionado al respecto en el campo militar, laboral, político, etc.. Elías (en Elías y Dunning, 1992) escribe haciendo alusión a la violencia específicamente y, a su vez, al proceso civilizatorio en general:

(...) cuando decimos que las luchas parlamentarias o los deportes requerían más autocontrol que las luchas políticas del período precedente, reguladas con menos rigor y a menudo más violentas, no nos referimos a un cambio en la cantidad de autocontrol de cada individuo aislado, que podríamos imaginar susceptible de ser medida; ni tampoco a un cambio cualitativo de los seres humanos, sino a los seres humanos que formaron entre sí figuraciones tales como un Parlamento o un equipo de críquet, que demostrablemente se regulaban con más severidad que las que les precedieron y que demandaban de sus miembros un control más riguroso, uniforme y estable de sí mismos. (pág. 64) 
Lo disciplinario opera en los funcionamientos de estas figuraciones en las que se ponen en juego la singularidad de los cuerpos y se combinan para multiplicar sus posibilidades productivas. En este sentido, las redes de interdependencia se intensifican al paso de las regulaciones necesarias para su funcionamiento, dando lugar a la emergencia de individualidades, al tiempo que las articula en un sistema más complejo que las hace funcionar:

Puede que cada equipo haya planeado su estrategia según el conocimiento que posea de las capacidades y debilidades tanto propias como del equipo contrario. Sin embargo, a medida que el juego avanza, produce situaciones no planeadas ni previstas por ninguno de los bandos. De hecho, el modelo o esquema móvil formado por los jugadores y el balón en un partido de fútbol puede servir como ilustración gráfica no sólo del concepto de «figuración» sino también del de 'proceso social' (Elías y Dunning, 1992: 70).

Se observa cómo el deporte no sólo se muestra como una figuración (con todo lo que ella implica respecto a las redes de interdependencia y la articulación entre la individualidad y el sistema) sino también cómo éste fenómeno responde a lógicas de época. Lo cual lleva a la pregunta sobre cómo responde el deporte, o bien la enseñanza del deporte, a las condiciones que plantea la actualidad.

Reflexionar sobre la disciplina hoy implica pensar en las lógicas que subyacen a las prácticas para así tensionar el dispositivo y romper con la estigmatización y las representaciones en torno al concepto de disciplina (asociadas a aspectos negativos y su vínculo con cuestiones ligadas a la violencia). La intensificación del mismo provoca relaciones de dominación o su desaparición o debilitamiento, teniendo un efecto de anomia total $\mathrm{y}$, consecuentemente, un caos que hace imposible cualquier relación de enseñanza (o cualquier relación con sentido).

Es interesante pensar en cómo se ponen en funcionamiento los juegos de poder en la microfísica de las relaciones (entre profesor y alumno, entre compañeros, por ejemplo). Si se entiende que el poder en este contexto no se posee sino que se 
ejerce, resulta un imperativo tener presente dos preguntas: ¿qué ordena? y ¿sobre qué ordena?

Estas preguntas pueden balizar un camino posible para la configuración de un proceso educativo, donde poner en juego un dispositivo de poder que no atente contra las libertades individuales ni las del grupo, sino que las potencie. Una disciplina que no descarga su peso ni en la dominación y el autoritarismo, ni en la anomia y la libertad negativa absoluta que resulta esclavizante, sino en una tensión inestable que hay que cuidar, que sea la base para un funcionamiento eficaz en términos productivos, pero además en términos políticos, equilibrando la tensión entre la libertad negativa y la positiva.

Recuperar la idea de disciplina como multiplicadora de fuerzas productivas resulta pertinente, tanto más significativo es tener presente la dimensión política de este dispositivo.

Se ha mostrado en detalle sus funcionamientos en un momento preciso de la historia que da cuenta de los contemporáneos, lo que permite pensar un futuro posible hoy, donde la ley no desaparezca en nombre de la libertad que se supone necesaria para responder a la multiplicidad del deseo caprichoso, sino que estableciendo los límites de acuerdos mínimos de toda red de interdependencia y encauce las fuerzas productivas en favor de una responsabilidad política.

Esto requiere adultos que se responsabilicen del mundo que presentan a los nuevos. Y si bien el mundo que se presenta aparenta no dar seguridad alguna, al menos lograr que se efectivice lo practicado. La pura libertad y el no límite, lejos de terminar con el autoritarismo y la represión, establece una esclavitud que paradójicamente devuelve a un estado cuasi animal. Quitar la posibilidad de resistencia en la relación que se establece en los ámbitos educativos es condenar a la esclavitud, ya que no hay deseo sin ley. 


\section{CAPITULO IV: SOBRE LA EDUCACIÓN}

Antes de entrar en el campo de la educación propiamente dicho es necesario situarlo en la actualidad como momento histórico-político donde existen problemáticas que son evidentes respecto a las ideas centrales que atraviesan esta tesis: libertad, progreso, política y educación.

Las transformaciones que dieron cuenta del progreso en la modernidad se apreciaban, entre otras cosas, en las acciones y en los niveles tolerados de violencia que se adoptaban en las prácticas y en la vida cotidiana. En la actualidad continúan mostrando transformaciones y es por ello que merece una reflexión al respecto. Si se considera la aparición y fortalecimiento de una relativamente nueva doctrina político-económica-social como el neo-liberalismo ${ }^{40}$ y que, acompañada de cambios tecnológicos, genera estados de violencia distintos a las formas físicas y políticas más evidentes de los siglos XVIII y XIX.

El monopolio estatal sobre la violencia se sostiene con relativa estabilidad respecto a determinados tipos de violencia; sin embargo, otros han logrado permear la membrana de este monopolio. El peso del mercado y las políticas neoliberales agujerean la membrana del monopolio estatal, permitiendo que algunas cuestiones económicas terminen siendo violentas, directa 0 indirectamente, para la ciudadanía.

La educación es un campo que no queda exento de ellas. Se encuentran casos puntuales que bien pueden materializar el drama cultural en que está anclada la educación, en términos generales (y del deporte en particular). En un día cualquiera en la Escuela de Fútbol San José, algunos alumnos en clase le dijeron al profesor, a modo de sugerencia: Profe, justed tiene que gritar!, ante el ambiente ruidoso y exaltado que creaban sus compañeros; de la misma manera puede observarse caos en el caso polémico del partido de fútbol suspendido entre Boca y River, en el año 2015 en la bombonera, donde los simpatizantes de Boca le tiraron gas pimienta a los jugadores de River en el momento en que éstos ingresaban a la

\footnotetext{
${ }^{40}$ Este concepto aún presenta controversias en el pensamiento político. Es utilizado aquí para mostrar un extremo del pensamiento liberal.
} 
cancha luego del receso intermedio o, simplemente, observando diferentes escenas en la vida cotidiana.

Siguiendo con esta línea de ejemplos, se citan tres momentos que dan cuenta de situaciones de evaluación donde el criterio que prima es el resultado como garante del éxito. Primero, una situación de partido: se juega de local con 12 de Octubre la cuarta fecha del Torneo de Escuelas de Fútbol Infantil (TEFI) ${ }^{41}$. Como es de su costumbre, el equipo local es quien se encarga de contratar al árbitro. Ya ubicados ambos equipos en los extremos correspondientes comienza el partido. El entrenador de San José había acordado con el árbitro que colaboraría con la asistencia en las salidas de banda y que levantaría la mano cuando la pelota se salía. Lo hizo durante todo el partido. Al finalizar, la jornada fue para San José y, antes de ir a vestuarios, los entrenadores se reúnen en el centro, mientras que el de 12 de Octubre le dice al otro muy exaltado: ¡Protestaste todos los fallos levantando la mano todo el tiempo! Se ve que el enojo del partido perdido no le permitió ver que lo que realmente se estaba haciendo era ayudar al árbitro, ante las circunstancias presentes.

En segunda instancia, se ejemplifica sobre la discriminación de quien se considera torpe. En partidos disputados por San José (donde el resultado es desfavorable) se ha observado que hay casos de alumnos que no quieren entrar a la cancha (en situación de partido) porque consideran que el jugador que sale es mejor que ellos (siempre pensando en la relación del jugador con la pelota y nunca ${ }^{42}$ en cuestiones tácticas o estratégicas) y, sin embargo, exigen el cambio si es por algún miembro del equipo que no tiene tanto dominio técnico.

En tercer caso, el ejemplo corresponde a una situación poco frecuente en las observaciones sobre la Escuela de Fútbol San José, durante los entrenamientos o también en algunos partidos.

\footnotetext{
${ }^{41}$ Torneo en el que participan escuelas de futbol de la ciudad de La Plata de carácter recreativo. Entiéndase por recreativo al juego con un reglamento propio, con reglas adaptadas y donde la máxima es que jueguen todos. Se juega por puntos, hay una tabla de posiciones y no hay premios. ${ }^{42}$ No es una exageración: literalmente nunca, durante las observaciones, un alumno/a jugador/a (al momento de cuestionar un cambio) aludió a cuestiones tácticas.
} 
El caso es el del jugador libre (el que juega literalmente de cualquier cosa, que no cumple ningún rol, el que llega incluso a inventar posiciones). Durante una de las tantas observaciones en campo, al inicio de un partido (en situación de entrenamiento) el profesor asigna todas las posiciones y uno de los alumnos no acepta la asignación de ningún rol. Ante la negativa a las opciones propuestas, el profesor pregunta: Entonces, ¿de qué quieres jugar? y contesta: Yo juego en la posición Garza.

El alumno inventó la posición Garza, la cual consiste en jugar de lo que él quiere y en el momento en que lo desea, lo cual puede ser muy creativo pero que no coincide con los objetivos del grupo (este carácter individual de la práctica puede verse claramente, no así el aspecto del carácter colectivo). Garza es su apodo desde hace mucho tiempo, el cual se desprende de una contracción en su apellido. En tanto para él la posición Garza es una forma de ser, una forma de juego, no solo propia, sino que busca adhesión, aceptación y multiplicación (hasta la complicidad de sus compañeros).

Garza participó del juego mientras que sus compañeros le hicieron notar que era muy difícil jugar con él y que incluso era mejor jugar con uno menos. El jugador quería la libertad absoluta de hacer lo que quería todo el tiempo y en esa libertad quedó maniatado, los compañeros no sabían cómo contar con él: parecía uno más pero era peor que tener uno menos.

Si en los siglos XVIII y XIX el progreso se apreciaba en términos de aumento en la libertad negativa, en tiempos donde ésta ha llegado al extremo, el hombre parece ser más esclavo que nunca. Sin embargo, lo que no parece evidente es el carácter de esta esclavitud $y$, por ello, la apariencia libertaria de la vida del sujeto autónomo.

La representación del mundo que se presenta (atravesadas por las lógicas pregnantes) acerca de los modos posibles de relación con el saber, con los otros y con uno mismo como únicos modos posibles, legitima todo un sistema de funcionamiento que prioriza el consumo y la autonomía del individuo como el 
objetivo supremo de la calidad de vida. Algo de esto ya sostenía Adorno con la idea de que a los hombres ya no les preocupa vivir, dado que eso está asegurado, sino que lo que quieren es vivir bien. Para tensionar el presente, la pregunta a responder sería: ¿qué es vivir bien hoy?

En la actualidad, la libertad se interpreta -en parte- como el extremo de la libertad negativa, una especie de ortodoxia de la misma. El fundamentalismo se expresa en la idea de sé tú mismo, sé quien quieras ser, haz lo que tú quieras, del cual el sujeto autónomo es su máximo exponente y, como continuidad en clave de consumo, se expresa en el eres lo que consumes, teniendo en cuenta el valor simbólico con que carga esta categoría, en tanto que constructor de sentido (y el cual conforma todo un universo de análisis por demás interesante y que pertenece ya a otro nivel de la discusión sobre los temas aquí tratados).

El tiempo y el espacio que se transforman, dan forma a nuevos sentidos y nuevas formas de sociabilidad. El tiempo se presenta como continuo, permanente, saltatorio (del pasado al presente y viceversa, en tiempos de hipervínculos ${ }^{43}$ ) de un dispositivo a otro y de una pantalla a otra. Esta dinámica manifiesta modos particulares en las relaciones que se mantienen en la cotidianidad, algunas de ellas problemáticas.

Somos seres humanos que vivimos en un mundo donde los individuos no actúan en un vacío sino dentro una matriz social en la que, el consumo veloz de los objetos, produce significados intra e intersubjetivos. Zygmunt Bauman lo definió como una modernidad líquida (para oponerla a lo estable y permanente) y sostuvo esta imagen como una metáfora de la era moderna. El

\footnotetext{
43 Un hiperenlace (también llamado enlace, link, vínculo) es un elemento de un documento electrónico que hace referencia a otro recurso, como por ejemplo otro documento o un punto específico del mismo. Combinado con una red de datos y un protocolo de acceso, un hipervínculo permite acceder al recurso referenciado en diferentes formas, como visitarlo con un agente de navegación, mostrarlo como parte del documento referenciador o guardarlo localmente. Los hipervínculos son parte fundamental de la arquitectura de la World Wide Web, pero el concepto no se limita al HTML o a la Web. Casi cualquier medio electrónico puede emplear alguna forma de hiperenlace. Disponible en https://es.wikipedia.org/wiki/Hiperenlace.
} 
ordenamiento económico "domina la totalidad de la vida humana volviendo irrelevante e inefectivo todo aspecto de la vida que no contribuya a su incesante y continua reproducción". Así, esta sociedad, alcanza los vínculos humanos y los tiñe con representaciones consumistas asociadas al trabajo y la diversión, el placer y las penas, la socialización y el aislamiento. El sentirse libre resulta, entonces, de un precario equilibrio entre "recortar la imaginación y el deseo" por un lado y/o "ampliar la capacidad de acción" por el otro. Lo cierto es que esta "libertad dentro de la jaula" tiene sus hiatos, dada la inequidad para el acceso a los objetos que completan los vacíos del "compro, luego existo". (Míguez, 2008: 7)

En este sentido, por ejemplo, se encuentran comerciales de bebidas especializadas que, en el campo del deporte, son reconocidos hidratantes y cuyo consumo por parte de cualquier ciudadano no sólo satisface una necesidad de hidratación (beneficios y atributos de la bebida) sino que carga consigo representaciones y proyecciones aspiracionales: lo acerca al ideal del deportista que tiene (y que quiere). La pregunta aquí sería: ¿de dónde proviene este ideal? y ¿qué representa?

Si bien no es el objetivo de este trabajado ahondar en dichos imaginarios y representaciones (ni en el análisis propio de estos discursos que lo atraviesan y modifican las prácticas) se ve que este ideal no es solo del sujeto autónomo, en tal caso está más cerca de elegir uno de los ideales que el mercado propone como condiciones de posibilidad.

Si se considera el ideal del deportista se observa que quien juega al fútbol se muestra más deportista si consume lo que consume su ídolo, si se mueve igual, si realiza la misma pirueta con la pelota. En los entrenamientos de San José se observó con frecuencia a Francisco practicar tiros libres imitando la parada previa al disparo de Cristiano Ronaldo, o bien a Juan haciendo una y otra vez la vuelta al 
mundo ${ }^{44}$, también a Franco en cada entrenamiento con los últimos botines que habían salido.

Esto pone de manifiesto contradicciones lógicas, tales como llegar a entrenamiento con su bebida hidratante sin haber merendado. Se reproduce una forma de hidratarse, un modo de jugar, una forma de vestir. En el camino se olvida, se esconde, se deslegitima la dedicación, el trabajo, el esfuerzo, la preparación. Basta ver la recopilación de publicidades del año 2012 de la bebida hidratante Gatorade ${ }^{45}$ para apreciar algunas de estas cuestiones: el enojo o los festejos desmedidos de jugadores para los cuales el deporte en su vida no es más que un juego.

La gravedad del asunto (al menos para los educadores) es notable. La pregnancia que los medios masivos de comunicación tienen en la vida cotidiana de las personas tiene una gran participación en la construcción de este orden simbólico. Los efectos de esta dinámica que se describe alcanzan la enseñanza de los deportes en sus diferentes ámbitos: en la escuela, el club, la familia.

La pregunta relevante en esta instancia es acerca de qué hacen los educadores con el deporte, reflexionar sobre qué deportista forman y educan. "Para el educador progresista coherente, la necesaria enseñanza de los contenidos está siempre asociada a una 'lectura crítica' de la realidad (...) en una práctica educativa progresista competente también se busca, al enseñar los contenidos, descubrir la razón de ser de aquellos problemas" (Freire, 2007: 35).

Esto no refiere al ámbito escolar únicamente sino que se extiende a todo espacio en que la trasmisión de bienes culturales -el deporte como uno de ellos- tiene lugar. Por ejemplo, se debe tomar una posición respecto a la relevancia otorgada al resultado de un partido, siendo fundamental destacar el desplazamiento en el objeto de evaluación. Es frecuente y así lo muestran las observaciones en la Escuela de Fútbol San José que, en cada partido que ha perdido o ganado la

\footnotetext{
${ }^{44}$ Pirueta popularizada por Diego Maradona en la que, mientras se mantiene la pelota en el aire, se le da una vuelta alrededor con la pierna.

${ }^{45}$ Disponible en https://www.youtube.com/watch?v=oER-VDFiLRY
} 
satisfacción o el desencanto, la alegría o la tristeza descansan sobre los números del tanteador final sin el menor reparo en otros criterios.

En San José (durante los años 2014, 2015, 2016 y 2017) existieron dificultades para completar las tres categorías del torneo, por lo tanto se completaban los equipos con chicos de otras categorías (algunos jugadores jugaban tres partidos y la mayoría dos. Consecuencias: fatiga acumulada, merma en el rendimiento, la contextura física de un equipo respecto a los otros era de menor envergadura), sin embargo al finalizar un partido en que el resultado era desfavorable, lo recurrente era escuchar: ¡Tenemos que pedir documentos!, lo que supone que los oponentes tienen jugadores más grandes, cuándo, en realidad, San José también tenía jugadores más grandes ¡El árbitro cobró cualquier cosa!, ¡otra vez nos tiran para atrás!, cuando los fallos eran favorecedores de ambos equipos. Lo cierto es que los arbitrajes eran parejos y que en definitiva no se trata de eso sino de otros factores y, no por ser éstos los verdaderos, sino porque son los que suman en un proyecto de enseñanza. Si la responsabilidad es del árbitro ¿Qué hay que mejorar?

Es necesario ampliar el abanico de criterios de observación sobre el juego: ¿salen las cosas trabajadas en entrenamiento?, ¿se falla en defensa o en ataque?, ¿se juga bien y los otros son superiores?, ¿fue un buen partido?, ¿se jugó en equipo o fue individualista?, ¿se cumplió el plan o se hizo lo que quiso cada uno? Se volverá sobre este tema más avanzada la lectura.

En función del marco teórico, resulta adecuado pensar en una práctica educativa progresiva; de este modo se encuentra en ella la tensión progresión-regresión. Es importante establecer cómo se pone en juego la educación en este espacio de tensiones y, antes aun, responder a una pregunta fundamental: ¿Qué es educar? "(...) por educación debe entenderse la transmisión y práctica de un ethos en tanto que modo de ser del sujeto en relación con el saber, con los otros y consigo mismo, más que la mera instrucción o la estricta formación de competencias" (Crisorio en Toro y Tallone, 2011: 198). En conjunto, los aportes anteriores de Freire y más recientes de Crisorio, permiten pensar en una educación que no es 
nunca la mera enseñanza del contenido, sino la enseñanza de una práctica, con todo lo que ella implica.

Teniendo en consideración estos aportes, se lee en clave lo que relata Gustavo Matosas ${ }^{46}$ en el programa televiso La caja negra, emitido en el canal TV Ciudad, en el mes agosto de $2016^{47}$ :

(...) el 87 fue importantísimo por dos cosas, primero porque tuvimos a Roque Maspoli en Peñarol que fue un tipo que más que un entrenador era como que tu abuelo te dirigía. Un tipo que nos sabía llevar muy bien a los jóvenes, que siempre tenía una palabra de aliento, que cuando te tenía que retar te retaba, pero que sabía llevarte muy bien para que vos te sintieras totalmente liberado. Y la segunda cosa que pasó en ese año 87, fue la llegada del maestro Tabares, que fue un tipo que nos enseñó a vivir la profesión y nos dio responsabilidad profesional, porque éramos todos muy jóvenes de diecinueve y veinte años, entonces él nos trató de una manera diferente a la de Roque; donde ya tenías la exigencia de la responsabilidad, había libertad, pero había libertad con responsabilidad y eso creo que nos mejoró mucho a todos en cuanto a la manera de vivir la profesión (...) a mi me marcó por cómo vivir esta profesión, por cómo no había que tener exabruptos en una declaración, de comportarte siempre de la misma manera, que eran mensajes que él te los iba soltando en el día a día, y vos lo veías en su forma de conducirse también, ¿no? Con otro gran ayudante en el cuerpo técnico como era el profe Herrera, que también era un tipo que estaba todo bien con él hasta que empezaba el trabajo, cuando empezaba el trabajo se acababa la joda. $Y$ esas son cosas que te iban marcando, sobre todo porque a los diecinueve

\footnotetext{
${ }^{46}$ Hoy ya ex técnico del club Estudiantes de La Plata después de 7 partidos.

${ }^{47}$ Disponible en https://www.youtube.com/watch?v=tGfuoWeLm5k
} 
y veinte años, como teníamos en esa época, te estaban dando el último golpe de horno, para formarte el carácter (...).

En un proceso de enseñanza, educar implica no solo la relación con un contenido sino además hacer frente a todas las problemáticas que puede suscitar su práctica histórica y política. Como manifiesta la cita anterior, Oscar Washington Tabares ${ }^{48}$ educa, ya que no sólo enseña fútbol sino toda una forma de ser con el saber, con los demás y con uno mismo, dentro y fuera del campo de juego.

De la misma manera se observan diferentes tensiones en torno a la concepción de libertad: por un lado, con Maspoli, la relación que sostenía prioritariamente se basaba en una libertad negativa que no apuntaba precisamente a educar. La otra, con Tabares, quién sostenía esa libertad negativa en función del respeto por ciertas normas que hacen a lo que Crisorio (en Toro y Tallone, 2011) menciona como modos de ser de las personas en la relación con el saber, los demás y uno mismo y que aquí se enmarca en la otra dimensión de la libertad, la positiva.

Al pensar en el deporte como contenido educativo es necesario tener presente dónde se adaptan mejor los principios de la educación con la estructura de la práctica deportiva, si como afirma Crisorio (en Toro y Tallone, 2011: 191):

(...) la trasmisión de las reglas del juego social, en todos sus aspectos y dimensiones es un objeto principal de la educación en general, en tanto apropiación del sentido de las regulaciones externas, a la que la enseñanza de los deportes puede contribuir casi como ningún otro contenido de nuestra cultura, tiene una amplitud y una profundidad que sobrepasan por mucho los límites del ámbito escolar: constituye un problema político y no solo pedagógico o didáctico.

Lo que se pone en discusión es, precisamente, las reglas del juego social. Es necesario definir cuáles son estas reglas: si el juego social deriva en un juego de reglas de mercado o si las reglas son las de la vida en sociedad. Si bien estas

${ }^{48}$ Docente, ex jugador y actual Director Técnico de la Selección Uruguaya de fútbol (2018). 
cuestiones nunca se encuentran desvinculadas, la distinción permite apreciar aquello que puede ser distinto, es decir, una relación con las lógicas de mercado que no vayan en detrimento del progreso de la libertad.

En este apartado se observa cómo las reglas del juego social derivan en un juego perverso, en el que las reglas no parecen construidas sino naturales, un mundo en funcionamiento en el que se supone a los nuevos un mayor saber por sobre los viejos (quienes, a su vez, asumen que es así). Las lógicas que construye el mercado fundan el andamiaje de un juego social cuyos funcionamientos aumentan exponencialmente la libertad negativa $\mathrm{y}$, en el mismo movimiento, resultan regresivos en términos de libertad.

Muchos de los que se desempeñan en el campo de la práctica deportiva (casos tales como técnicos encumbrados y jugadores como Julio Velasco, Marcelo Bielsa, Emanuel Ginobilli, Pablo Aimar, Agustín Pichot, Luis Scola, librados de la interpretación que realizan los medios masivos de comunicación) plantean una formación del deportista que muestra una posición cercana a la que se manifiesta en esta tesis, al pensar la práctica deportiva como contenido educativo.

Los que trabajan en el alto rendimiento comunican conocimientos que la interpretación de los grandes medios de comunicación (también) sepulta, deslegitima y diluye. El deporte que promueven filtra determinadas dimensiones de la práctica y destaca otras, las que se instituyen, en ocasiones, como únicas. Por otro lado, lo que se hace en el alto rendimiento no es precisamente lo que debiera hacerse en otros momentos y ámbitos de la práctica deportiva y tampoco constituye en su totalidad el parámetro de formación y educación deseables.

\section{LA PRODUCCIÓN DEL CIUDADANO IDEAL}

Hay algo que no parece haber cambiado, tanto ayer como hoy se produce un ciudadano, la diferencia radica en que cada momento histórico requiere un ideal distinto: ayer un ciudadano educado, civilizado, dócil, con obligaciones y derechos; 
hoy un ciudadano con derechos, emprendedor y consumidor, lo que muestra que el juego social ha cambiado.

El carácter educativo es pobre. El ethos que se trasmite, la forma de ser con el saber, con los otros y con uno mismo resulta, en una práctica irreflexiva, funcional al juego social que dispone el mercado. Sin embargo éste (como entidad abstracta) ni siquiera es un alguien responsable de que esto sea así. Es el funcionamiento en torno a cómo están dispuestas las cosas y los modos y usos irreflexivos los que hacen del juego social un producto, en tanto objeto de consumo.

El juego social no es otra cosa que las reglas de funcionamiento que acuerdan los hombres y éstas se enseñan y se transmiten. Por lo tanto, no hay civilización posible sin educación. Siguiendo esta línea de pensamiento, podría plantearse un momento regresivo en la historia de la libertad.

Alejarse de lo bárbaro supone civilidad y, por ende, una educación que enseñe estos acuerdos básicos para sostener la complejidad de las relaciones entre las personas y para colaborar en la garantización de los derechos ciudadanos. Después de todo, el pasaje a la modernidad fue una liberación política del pueblo que se sostenía en la sujeción a ciertas normas.

Para el pensamiento liberal de la época, el potencial poder del Estado era tan grande que el temor por los abusos de poder ponía la lupa sobre la defensa del individuo y, consecuentemente, en la libertad negativa. Ésta bien puede ser una de las tantas causas que, en conjunto con otras lógicas, colaboran con la aparición del individualismo como un comportamiento que exalta la libertad negativa y anula lo colectivo. En la actualidad el individuo abusa de su poder y, mientras ayer era el miedo al Estado lo que empujaba la elaboración de normas y reglas de funcionamiento, hoy es el miedo al individuo lo que debería estimular el fortalecimiento de los acuerdos colectivos, lo que en otros términos significaría educar. 
El individuo completamente autónomo ${ }^{49}$ (el que no depende de nadie, el que responde a nadie) es pura libertad negativa, como el caso de Garza y la observación de sus comportamientos en la Escuela de Fútbol San José, donde se da cuenta de que éste no está solo, está aislado en redes de interconexión y es esta contradicción precisamente uno de los problemas actuales, la tensión entre el individuo autónomo y una red de interdependencia cada vez más compleja. Amontonadas soledades, escribía Ernesto Sábato (1998: 14), frase que da sentido a imágenes cotidianas de la actualidad.

El sujeto autónomo es más libre, el problema es que la libertad al extremo no admite ningún contrario y, en ese punto, se pierde. El individuo que responde solo al juego de mercado cree que por tomar Gatorade, juntarse a jugar a la pelota una vez a la semana y mirar cuanto programa deportivo se emita en la televisión realiza una práctica deportiva y, por ende, es un conocedor del deporte.

El joven que va a clases de fútbol cree que solo por ir a clase, tomar una bebida, tener los botines de Ronaldo y la camiseta de Messi será un jugador de fútbol. Estas cuestiones que hacen al carácter mimético del deporte y por lo que es tan potente en términos educativos, lo son sólo si son acompañadas por un sistema de pensamiento que reflexione en torno a las diferentes problemáticas que ellas mismas suscitan.

En este teatro en el que hay roles no es lo mismo ser espectador o jugador, aunque en ambos casos haya ciertas reglas a respetar. En la actualidad se pretende sostener el sujeto de derecho, mientras que los deberes quedan en un segundo plano. Los individuos están dispuestos a reclamar cada uno de sus derechos, en cambio las obligaciones y los deberes que se encontraban con tanta claridad en el siglo XVIII hoy están des-dibujados. Afirma Adela Cortina (en Toro y Tallone, 2011: 103):

(...) la nuestra es una época de ética indolora. Las gentes están dispuestas a exigir derechos, pero no a pechar con las

\footnotetext{
${ }^{49}$ En griego, autónomo significa: "me rijo por mi propia ley".
} 
responsabilidades correspondientes, no a asumir obligaciones (...) si los ciudadanos no asumen sus responsabilidades, difícil será que vean protegidos sus derechos por mucho que los reclamen.

Si la lógica del derecho implica el respeto de los acuerdos, al no poner énfasis en estos últimos difícilmente los ciudadanos puedan encontrar seguridad en las relaciones dentro de una sociedad. En consecuencia, si educar es la transmisión de un modo de relacionarse con el saber, con los otros y consigo mismo -y que hoy estos modos enaltecen los derechos y olvidan las obligaciones- es necesario repensar si este modo es o no regresivo.

Las relaciones que se establecen en los tres registros mencionados -con el saber, con los otros y consigo mismo-, en términos deportivos, parecen claramente regresivas en la actualidad al verse impregnadas por las lógicas que produce el mercado, que sobrevaloran el individualismo, es decir, la libertad negativa por sobre todas las cosas. Por ejemplo, la libertad de consumir bien puede ser un derecho individual ${ }^{50}$ ¿Se es más libre con mayores posibilidades de consumo?, ¿mejores posibilidades de consumo implican una mejora en la calidad de vida?

\section{EL OLVIDO (?) DE LO FUNDAMENTAL: EL EQUILIBRIO DE LAS LIBERTADES}

Se puede caracterizar este momento actual como de olvido: se ha olvidado ese primer contrato que la vida en sociedad supone, quizás porque nunca fue contraído efectivamente. No es un contrato que se firma y ya, sino que es un proceso y ese proceso se efectiviza a través de la educación.

En este sentido, educar puede entenderse como el proceso durante el cual las personas legitiman su participación en un orden que es más grande que ellos

\footnotetext{
${ }^{50}$ Es interesante pensar cómo comienzan a observarse espacios en los que ni la medicina puede decir que no al consumo. En el pasado, una persona con diabetes no podía ingerir alimentos dulces, en cambio en la actualidad puede acceder a un dulce de leche light; una persona con hipertensión no debía consumir sal y hoy tiene la opción de consumir sal sin sodio, por citar algunos ejemplos.
} 
mismos. Educar, en un sentido restringido, es mostrar a los nuevos cómo funciona el mundo, enseñando las reglas del juego social y cómo es necesario conducirse en él para que continúe funcionando como se acordó. Sin embargo es esta misma educación la que sostiene, permite y admite la transformación.

En este punto se encuentra al menos uno de los problemas de la educación en la actualidad y es que, por el énfasis puesto en la libertad negativa y en el imaginario de que cuanto más libre se es de todo mejor es, se ha llegado a un punto tal en el que la individualidad se convirtió en individualismo y éste socava los acuerdos necesarios para la vida en sociedad e incluso para la libertad misma porque, para que haya libertad debe haber resistencias $y$, la pura libertad, no admite resistencias.

Lo que sostiene la vida en sociedad no es ni la libertad negativa ni la libertad positiva sino la combinación exacta entre ambas según el momento históricopolítico y las necesidades coyunturales.

La igualdad frente a la ley equipara a todos como sujetos de derecho, esconde desigualdades culturales y económicas a la vez que tiene efectos negativos sobre la libertad.

El exceso de libertad negativa supone un mundo de personas totalmente libres, que no responden a nada ni a nadie, un lugar donde se pierden todos los vínculos con los demás. En estos términos, ¿podría llamarse progreso al fin de la libertad?

Por ello, para la Educación Corporal es fundamental hacer del deporte un contenido educativo para lo cual se entiende como camino posible el recuperar ambas dimensiones de la libertad y equilibrar las tensiones.

Para trabajar en pos de ambas dimensiones de la libertad es necesario reflexionar sobre cuáles son las lógicas que muestran los medios de comunicación masivos sobre el deporte y cuáles las inherentes al deporte mismo para discriminar qué puede recuperarse y en qué sentido y qué debe elaborarse desde el propio campo. 
Los relatos de actores deportivos no dejan de mostrar que sus mejores desempeños han sido en equipos de trabajo y esto se puede apreciar en espacios donde se encuentre una buena articulación entre los acuerdos colectivos, la creatividad y la responsabilidad de cada persona para mantenerse dentro de esa estructura normativa.

Afirma Julio Velasco, entrevistado en el programa La llave del gol, emitido el día 8 de mayo de 2017 en el canal Fox Sports ${ }^{51}$ :

¿Diez Maradonas y un buen arquero es el mejor equipo posible? No. Y no es casual que todos los grandísimos jugadores siempre tenían en la palma de la mano a los que no eran como ellos: Maradona con De Napoli, Platini con Bonini, porque sabían que necesitaban de ellos para poder ser lo que eran (...).

Continúa Velasco: “(...) el equipo se basa en que jueguen personas y jugadores diferentes y que por esas diferencias funcionen bien, esta es la clave del equipo (...)". Para ello, no debe hacerse más que respetar los acuerdos celebrados en el sistema y disponer las diferencias con una participación activa y creativa.

En este sentido, el control de las emociones para mantener la tensión entre la regla y la creatividad en momentos de alta intensidad hace al interés de la práctica deportiva y se encuentra íntimamente relacionado con aspectos educativos vinculados al progreso de la libertad y la política. Dice Greg Popovich -técnico de San Antonio Spurs- en el documental Campeones al descubierto, emitido por NBA TV 52 :

Siempre fui un creyente de que los jugadores reaccionan mejor ante la verdad que engañándolos, manipulándolos o diciéndoles algo para que hagan una $u$ otra cosa. Pero si les dices la verdad y realmente la sostienes (...) logras que la enfrenten y sepan

\footnotetext{
${ }^{51}$ Disponible en https://www.youtube.com/watch?v=MCccNIQGQUU

52 Disponible en https://www.youtube.com/watch?v=GOlwo-YwLO4\&t=198s
} 
que pasos tienen que tomar para ocuparse de lo que están viendo ahora y no les gusta.

La libertad positiva que reflejan aquellas relaciones que emergen en el marco de acuerdos colectivos, en tensión equilibrada con la libertad negativa que se muestra en la creatividad personal, muestran articulaciones posibles con las técnicas de la disciplina y la elaboración de uno mismo, siempre sobre la base de una verdad que debe ser sostenida. Si se dice que el deporte es educativo se debe tener presente qué verdad supone, para sostenerla durante todo el proceso de enseñanza, aun sabiendo que puede haber resistencia y precisamente para sostenerla.

Es interesante la distinción que hace Velasco respecto a jugar a la pelota y jugar al fútbol, lo que en esta investigación es también la diferencia entre lo que puede entenderse por deporte hoy y el deporte como contenido educativo:

(...) la gente juega a la pelota, todos creemos tener la experiencia de jugar al fútbol; en realidad todos hemos jugado a la pelota y al fútbol han jugado muy pocos. (...) los demás un poquito más ordenados, un poquito más como equipo de fútbol, pero la relación principal era yo y la pelota, no era yo y mis compañeros, yo y el espacio. El problema es entonces que se juzga muchas veces a los entrenadores como si se jugara a la pelota cuando el problema es otro. $\mathrm{Y}$ esto pasa en todos los deportes.

En la categoría gente se incluye a los periodistas porque, de alguna manera, el deporte que muestran los medios de comunicación masivos se acerca más a lo que Velasco llama jugar a la pelota que al fútbol y aquí también se encuentran algunos aportes para pensar en clave educativa la práctica deportiva que rompe con la lógica mediática.

Basta conocer las causas por las que un jugador es seleccionado como el mejor de un partido para confirmar los acotados pero accesibles valores que sostienen 
los medios masivos de comunicación: si no es quien hizo el mejor gol, es el que hizo el gol; o el que hizo el gol decisivo -porque siempre es uno-. Es uno el que gana el partido con su genialidad individual, o gracias al don de su pegada magistral o de su habilidad para eludir a los rivales, o de su fuerza, su velocidad, entre otras cosas.

Se corresponde mucho mejor con la realidad pensar que hay un equipo que genera la posibilidad de llegar a una definición de la jugada, hay un equipo que juega los noventa minutos y que entrena para que la dinámica interna del juego se muestre como se espera. Este juego, por lo general, es mucho más de lo que posteriormente se interpreta. En una conferencia de prensa realizada el día 30 de mayo del 2013, Marcelo Bielsa sostuvo:

(...) las evaluaciones no deben hacerse en función de lo que se obtiene sino en función de lo que se merece, cuando se hace la evaluación exclusivamente en función de lo que se obtiene y lo que se obtiene no es merecido, se corre un grave riesgo de interpretar mal lo que se está evaluando (...) el juego solo puede ser analizado desde tres puntos de vista: la primera es la fidelidad al estilo (jugar de una manera cualquiera sea), la segunda es el dominio del equipo que posee la pelota, y la tercera la cantidad de llegadas (...) para evaluar el funcionamiento de un equipo lo que uno ve es cuantas veces llega, la más importante de esos elementos es la cantidad de llegadas (...) lo importante no son los porcentajes de posesión lo importante es la cantidad de llegadas que usted obtiene, si son acompañadas por posesión que es la mejor manera para aumentar la cantidad de llegadas, bienvenido $(\ldots)^{53}$.

Es necesario recuperar al menos la reflexión sobre el problema que plantea Bielsa, respecto a los criterios de evaluación. De lo que ya decía algo Bourdieu (en Barbero González, 1993) e incluso plantea Velasco en líneas anteriores: el público

${ }^{53}$ Disponible en https://www.youtube.com/watch?v=eUWTeX6ROg8 
consumidor de deporte, la mayoría de las veces, no cuenta con las herramientas necesarias para valorar la práctica deportiva en su total dimensión, por ello la opinión se basa en aquellos elementos más visibles y espectaculares, como los puntos, los goles, las formaciones, etc. La educación del deporte o el deporte como contenido educativo puede y debe pensar en la formación de estos aspectos y la creación de nuevos criterios que hacen tanto al buen deportista como al buen espectador, buen dirigente, profesor, técnico, periodista, etc.

Se debe prestar atención a los puntos de contacto entre el deporte como contenido educativo y el que practican estos referentes del deporte. Interesante y directo resulta lo que dice Julio Velasco en una entrevista realizada por Sebastián Fest para La Nación el día 24 de agosto de 2015:

(...) yo vivo de esto, vivo de ganar, estoy acá porque he ganado, si no estaría otro, pero eso no quiere decir que éste tenga que ser el paradigma o el modelo para todo, yo creo que tiene que haber un filtro para eso fundamental que es que pensemos en el otro, hagamos las cosas correctas, respetemos las reglas fundamentales, después hay algunas con las que no estoy de acuerdo y las puedo combatir, no es que tengo que respetar todo $(\ldots)^{54}$.

Esta es la cuestión fundamental, el filtro que separa el deporte como espectáculo (funcional a una sociedad de consumo irreflexivo) del deporte educativo que trabaja con cuestiones como la importancia del otro, el hacer lo correcto, respetar las reglas, generar resistencias, sostener diferencias. En este sentido, la enseñanza del deporte y las relaciones de autoridad que se ponen en juego con tensiones relacionadas a las dos dimensiones de la libertad, están vinculadas a la formación del ciudadano y al practicante deportivo que se necesita producir.

\footnotetext{
${ }^{54}$ Disponible en http://www.lanacion.com.ar/1821906-julio-velasco-en-conversaciones-de-la-nacion
} 


\section{EL DEPORTE: UN CONTENIDO EDUCATIVO (LA DISCIPLINA COMO ACUERDO COLECTIVO)}

En el fútbol argentino se acostumbra a ver las tribunas con banderas de un solo color, estadios homogéneos, sin diferencias y esto plantea la pregunta en torno a cuál es el costo de esta homogeneidad: ¿es esta ausencia de las diferencias la muerte de la política? El espectáculo es lo de menos si se detiene a pensar que, en la actualidad, alguien puede morir por apoyar a un equipo de fútbol. Si una diferencia tan liviana tiene esos efectos entonces hay que preguntarse si el deporte ha sido pensado educativamente.

Si se recuerda el carácter mimético inherente al deporte es esperable que las tensiones aumenten, pero si éstas estallan en luchas verdaderas la tensión se rompe y, si este hecho se repite constantemente, la práctica deportiva no es posible. Esto es pertinente en términos educativos porque de lo que se trata es precisamente del gobierno sobre sí mismo, necesario para actuar en cadenas de interdependencia. La cotidianidad muestra que estos excesos no ocurren sólo en la práctica deportiva, corroborando lo que el modelo permite predecir: que las prácticas deportivas admiten niveles de violencia similares a los presentados en otras prácticas en un momento y una cultura determinados.

El deporte y su enseñanza suponen nunca olvidar que es un juego. Sin embargo, hacer del deporte un juego es algo serio y hacer del deporte un contenido educativo no es sencillo ${ }^{55}$. Si esta situación que se atraviesa (en la que el deporte adquiere una seriedad superlativa) no llama la atención es por la lógica que impera, porque no es correcto que alguien asuma que está bien insultar a un jugador en la cancha, ni escupirlo, ni agredir a otro hincha; no es correcto que un técnico deje o lo alejen de su puesto sin respetar ningún contrato porque pierde cinco partidos, así como tampoco se puede decir que un jugador es un burro porque erra un penal. Por un lado se trata de una falta de respeto $y$, por otro, se está faltando a la verdad y empobreciendo el juego al máximo. De igual modo,

\footnotetext{
${ }^{55}$ No es un juego de palabras, sino que verdaderamente para hacer del espectáculo deportivo un juego, es necesario educar, es necesario civilizar, para que las personas, jugadores, espectadores, etc., no olviden nunca que se trata de un juego y puedan vivir emociones fuertes, pero controladas. Este es el movimiento que permite sostener el carácter mimético del deporte sin el cual pierde gran parte de su potencial educativo y su atractivo.
} 
tampoco se puede creer que un periodista tenga más razones que un director técnico para cuestionar una decisión.

Con esto no se está diciendo que el deporte sea malo o bueno sino que puede ser algo más interesante, educativo, divertido y desafiante que el simple resultado de un partido o el desproporcionado desborde emotivo de un hincha. Puede que sean hechos normales, pero ¿desde cuándo lo normal es lo correcto? Y, en tal caso, ¿qué se ha de llamar normal? Puede no interesar demasiado esta cuestión, sin embargo, para los implicados directos en la obligación de hacer del deporte un contenido educativo las consecuencias están a la vista. La disciplina, en este sentido, desnormaliza normatizando, es decir, rompe con coacciones y cambia la dirección de una práctica que se acostumbró a un funcionamiento regresivo.

En clave educativa, en el deporte escolar o en el deporte de rendimiento no se encuentran diferencias, ni debería haberlas. El deporte es uno y debería pensarse siempre educativo: ¿acaso no serían mejores deportistas los jugadores si fuesen educados? Por otro lado, si espectadores, dirigentes, técnicos y todos los practicantes fuesen educados, ¿cumplirían mejor su rol?

A propósito de la evaluación, afirma Velasco, en una entrevista realizada por Gonzalo Bonadeo para su programa \#Bonadeo en el canal TyCsport ${ }^{56}$ : "(...) le insisto mucho a los jugadores para que entiendan dónde estuvo el error: ¿no te diste cuenta de la situación?, ¿la solución que encontraste para esa situación era la adecuada?, o ¿todo eso lo hiciste bien y solo te falló la mano?”.

Frente a esto, se plantean tres observaciones. La primera: los espectadores deberían evaluar también estas preguntas que hace Velasco a sus jugadores. En vez de juzgar el éxito o el fracaso en función del resultado debería valorarse la toma de decisión respecto a cómo se presentó el juego. La segunda, sobre la libertad restringida del jugador ante la búsqueda de una solución creativa (la discusión pasa por la tensión entre el sistema y la creatividad, por ejemplo, cuando el jugador decide romper con el sistema donde, en estos términos, no importa el

${ }^{56}$ Disponible en https://www.youtube.com/watch?v=MyC7-uHmbG8 
resultado de la acción sino la toma de decisiones y la evaluación que de ello pueda hacerse). Y la tercera, la forma de trabajo que permite observar un modelo, un sistema: el "solo te falló la mano" indica una discriminación entre un problema táctico y uno técnico ya que la selección de la acción depende de un sistema táctico y no se puede juzgar sólo por su resultado. Se critica a un jugador por la realización de una acción tras un fallo pero ¿si el sistema le requiere eso? y ¿si el acuerdo implica que accione de esa manera y lo que finalmente falló fue la ejecución? El espectador, el jugador, los practicantes en general, enriquecerían su práctica si contaran con herramientas que les permitieran análisis de este tipo.

Un punto aparte merece una cuestión supervalorada: el ganar. En la entrevista realizada por Sebastián Fest, Velasco responde:

(...) el deporte no es solo lindo cuando se gana (...) en las olimpiadas, sobre todo en ciertas pruebas (...) hay muchos atletas que saben que no van a ganar, lo saben. No es la pelota es redonda como en el fútbol. Atletismo, no van a ganar. $Y$ sin embargo se preparan como si fueran a ganar, durante el año y en la misma olimpiada, ¿por qué? porque combaten contra ellos mismos, ellos quieren bajar un segundo, una décima de segundo, quieren lanzar un metro más. $Y$ eso es parte de ganar. Ganar no es solamente salir campeón, es superarse, es mejorarse. $Y$ yo creo que el deporte enseña esto en los jóvenes $(\ldots)^{57}$.

Efectivamente el deporte enseña esto en los jóvenes pero también podría ajustarse el final diciendo "podría enseñar" porque para ello es necesario pensarlo de ese modo. Parecen increíbles las cercanías entre lo que piensan, dicen y hacen aquellos que se desempeñan en el mejor rendimiento deportivo con lo que puede entenderse como un deporte educativo. Una advertencia que no se puede pasar por alto es el hecho de que en el alto rendimiento ganar ocupa un lugar

\footnotetext{
${ }^{57}$ Disponible en https://www.facebook.com/librodelacabeza/videos/1774892302781396/
} 
superlativo por lo que deberían recuperarse estos enunciados desde una perspectiva diferente.

Respecto a la sobrevaloración del deporte, Kilian Jornet, corredor y alpinista (entrevistado en el programa Late Motiv, emitido en el canal \#0 de la plataforma Movistar+, el día 13 de julio de 2017), plantea:

Bueno, al final el deporte está sobrevalorado, tú me estás haciendo una entrevista a mí porque yo corro un poco más rápido que otros señores (...) yo corro, no soy filósofo, no pienso, las cosas que digo no van a ser más interesantes que las de un científico o un educador, hay gente que tiene cosas mejores que decir. Es algo muy egoísta, al final pones tu vida en peligro para conseguir una emoción, una sensación (...), es una cosa muy egoísta. Que eso sea valorado por la sociedad, muy bien, felicidades, pero...

Entrevistador: -¿Por qué crees que pasa? Nos gusta reflejarnos en eso ¿Es como un sueño que alguien cumple por los demás?

-Yo creo que sí, es un poco que motivas a la gente (...) Y si pues, motivas a la gente a decir, bueno cosas difíciles con trabajo pues se pueden hacer $(\ldots)^{58}$.

La humildad que se aprecia en el entrevistado hace parecer paradójica la respuesta -porque evidentemente es así como lo piensa-. Se destacan dos cuestiones interesantes: la primera es la sobrevaloración del deporte y, la segunda es que (tanto en el deporte como en la vida) con trabajo se pueden llevar adelante cosas difíciles. Más adelante explica por qué ha ido cambiando de disciplina y deja entrever su permanente deseo de aprender:

A mí me gusta hacer un poco de todo, yo no me quiero hacer especialista en algo porque me gusta correr (de hecho el sábado

\footnotetext{
${ }^{58}$ Disponible en https://www.youtube.com/watch?v=WEY558bFPNI
} 
hice una carrera) me gusta hacer larga distancia, esquí, montaña, más técnica, menos técnica, al final es abrir el abanico porque si te especializas en algo vas a llegar mucho más lejos pero no vas a conocer emociones distintas (...) y creo que es interesante ponerte en situaciones en las que no estés confortable para aprender más.

Más adelante, continúa:

(...) te vas conociendo y sobre todo vas conociendo cuáles son tus límites. Al final, al conocerte tú mismo vas siendo más humilde: éstas son mis capacidades, mi experiencia y éstos son los riesgos que quiero asumir hoy. $Y$ hay días que llegas a un sitio y dices pues hoy esta cosa no la veo capaz, otras dices esto soy capaz pero hoy no lo siento, hoy no hay condiciones (...) y hay otros días que llegas a casa y dices soy un gilipollas he estado a esto, he tomado más riesgo de los que quería aceptar ( ...).

Algunas de estas cuestiones son las que el deporte debería enseñar o bien habilitar: un profundo conocimiento de sí mismo y de las posibilidades del cuerpo, las herramientas para identificar el riesgo y para asumir las responsabilidades, reflexionando en torno al desempeño ocasional y a la práctica en general y cómo se inserta en el momento histórico-político. Esta libertad es la que debe asegurar un deporte educativo, la posibilidad de evaluar riesgos que no solo se asumen individualmente, sino en consideración con el colectivo ( $\mathrm{y}$ la libertad de tomarlos o no), la posibilidad de conocer y la libertad de ser humilde. Si como escribe Enríquez (2009: 5):

(...) lo esencial de la formación y la educación es precisamente formar individuos que pueden pensar por cuenta propia, capaces de actuar pensando en las consecuencias de su actuar y 
capaces de interrogarse y cuestionarse cuando su acción tuvo efectos distintos a los que esperaban.

La estructura del deporte admite el trabajo sobre estas cuestiones que enuncia Enríquez y así lo relata anteriormente Kilian Jornet. La educación permite formar individuos que, como se ha desarrollado aquí, no los constituye en tanto individuos autónomos sino en relación con el colectivo de manera prácticamente inigualable: es en el trabajo en equipo que las personas actúan junto a otras, afectándose y generando un movimiento en el que, si hay disciplina y se equilibra la tensión libertad positiva/negativa, se logra que el proceso sea radicalmente diferente en términos educativos.

Algunos pasajes de la charla entre Gregg Popovich (entrenador desde 1996 al presente, 20018), Tim Duncan, Emanuel Ginobilli y Tony Parker, jugadores del equipo de Básquet de San Antonio Spurs (NBA), registrada en el documental Campeones al descubierto, muestran cómo en las relaciones de la práctica deportiva se ponen en juego dimensiones que hacen a las relaciones de autoridad y de respeto que se establecen en función de roles y también en función a la relación con el saber:

Info técnica 1: Fuera de campo, trasmisión de video documental.

Escena 1: Los jugadores están en cancha practicando una jugada. Popovich detiene el juego (toca el silbato) y dice a Manu Ginobilli:

-Popovich: ¿Qué les dijiste que hagan? ¿Qué le digo yo al equipo al entrar a un cuarto? Ése es tu problema (...)

Info técnica 2: Mientras tanto, se vuelve a la entrevista en piso y Manu dice:

-Ginobilli: Nos gritaba mucho (risas).

Info técnica 3: Se vuelve a la situación de entrenamiento (documental). 
Escena 2: Misma situación de entrenamiento.

-Popovich: (...) esas son las pequeñas cosas de disciplina que nos harán ganar o perder un juego. Todos tienen que saber en qué estamos todo el tiempo.

Info técnica 4: Termina el tape, se vuelve a trasmitir la entrevista en vivo.

-Popovich: (...) Tengo el trabajo más fácil en la NBA porque ustedes dejaron que diga las cosas del modo en que deberían decirse.

-Ginobilli: Él (por Popovich) te marca tu rol muy claramente (risas).

-Duncan: Es lo que decíamos, te encasilla en un rol y luego tienes que luchar para salir de ahí (...) él nunca tuvo un molde para vos (refiriéndose a Ginobilli), lucharon todo el tiempo.

-Popovich: Lo hiciste, fuiste duro, fuiste duro (...) él me enseño a mí a ser un poco más paciente, a ampliar mis horizontes y pensar fuera de lo común un poco más y fue genial. ${ }^{59}$

$\mathrm{Ni}$ indisciplina ni rebeldía, resistencia; una resistencia que no puede darse sin disciplina ni libertad y que es absolutamente necesaria para sacar lo mejor de cada uno y del colectivo.

La relación de autoridad en el equipo muestra verticalidad y, también, horizontalidad. No deja de haber un ida y vuelta (con disciplina y libertad). Cuando, en el minuto 18:30, Popovich dice: "Tengo el trabajo más fácil en la NBA porque ustedes dejaron que diga las cosas del modo en que deberían decirse (...)" lo que da cuenta es de una relación de autoridad legitimada por el colectivo y que aún admitiendo resistencias permiten su buen funcionamiento.

\footnotetext{
${ }^{59}$ Disponible en https://www.youtube.com/watch?v=ISbmbBuxTs4 (desde min. 17:30).
} 
Es importante observar que el maestro o formador que no ejerce ninguna autoridad (que niega la relación) también ejerce un poder con riesgos nocivos iguales a los de su extremo contrario.

La disciplina con la idea de libertad se pone en juego en sus dos dimensiones: una en la esfera de la libertad negativa (en la dimensión del sí mismo) y otra en una libertad positiva (que garantiza el buen funcionamiento de lo colectivo). El respeto de los acuerdos que regulan las acciones individuales manifiesta la necesidad de mantener la actividad reflexiva sobre la acción creativa para que ésta no se desvincule del sistema colectivo y que, efectivamente, en términos de libertad negativa, la disciplina sea el apoyo del gesto eficaz (por un lado) y en términos de libertad positiva, la disciplina como garante del buen funcionamiento colectivo.

\section{LA DISCIPLINA APOYO DEL GESTO EFICAZ: HERRAMIENTA DE REGULACIÓN DE LA TENSIÓN CERTIDUMBRE VS. INCERTIDUMBRE}

La confianza es fundamental en la vida en sociedad, las relaciones deben contar con cierto grado de previsibilidad que permita el funcionamiento de la dinámica cotidiana. En el deporte la confianza es prioritaria dado que todo el equipo debe respetar un plan. En la construcción de lazos de confianza es vital la disciplina porque habilita, precisamente, esta previsibilidad. Pierre Rosanvallon (2007: 23) retoma la siguiente frase del filósofo y sociólogo alemán, Georg Simmel:

(...) la confianza es también un estado intermedio entre el saber y no saber sobre el prójimo. El que sabe todo no necesita confianza, el que no sabe nada no puede razonablemente tener confianza.

En este sentido es necesario construir lazos de confianza que no pueden crearse sin su par antagónico: la desconfianza. Se trata entonces de "(...) buscar los medios que permitan mantener la exigencia inicial de un servicio al bien común" (Rosanvallon, 2007: 26). 
En el deporte no se puede saber todo; es un campo en el que el resultado es siempre incierto por más probabilidad que declaren los antecedentes estadísticos. Esta incertidumbre se controla mejor si se cuenta con referencias que permitan conocer algo y habiliten una línea de tensión que se manifiesta en la confianza en el otro. Para la construcción favorable de esta confianza la previsibilidad es fundamental.

En este punto, la mecánica disciplinaria habilita el aumento de las fuerzas productivas y además aumenta las fuerzas políticas. Las fuerzas productivas porque a partir de un accionar disciplinado las posibilidades en el campo deportivo aumentan (por ejemplo, un mejor aprovechamiento del tiempo y del espacio en clase); las fuerzas políticas aumentan porque las normas que regulan las acciones son acordadas y/o aceptadas por el colectivo.

La obediencia a cierta normativa habilita prácticas de libertad. Obedecer un mandato o una orden puede no ser precisamente un acto de docilidad sino una decisión política, una decisión de aceptar la norma o la orden. El respeto por el plan colectivo reprime alguno de los intereses individuales en pos de conseguir un bien mayor (a veces hay que sacrificar un bien por otro más grande). La obediencia muta en una experiencia de libertad.

Es necesario contemplar los efectos que las lógicas del mercado tienen sobre la institución educación y no sólo en ellas sino también sobre la exacerbación del individuo autónomo que, en la medida en que aumenta su libertad negativa, se vuelve regresivo en términos de libertad positiva y afecta cualquier funcionamiento que requiera un compromiso colectivo.

La disciplina como garante de las tensiones entre determinismo y azar, orden y caos, certidumbre e incertidumbre, sistema y creatividad. La disciplina resulta el contrapeso y el potenciador de esta línea de tensión, tal como plantea Luis Scola, ante las preguntas de Juan Pablo Sorín, en torno a sus cábalas (en el capítulo 9 del programa Capitanes que se trasmite en Deportv): 
(...) creo mucho en la rutina, ¿no? una rutina que te permite a vos estar preparado para algo. Entrenar de una manera, comer de una manera, dormir de una manera, todo lo que haces previo a un partido. Pero no tiene nada que ver con la suerte, tiene que ver con que uno busca su forma de relajar y de prepararse mental y físicamente para estar bien o lo mejor posible a la hora de jugar ${ }^{60}$.

Esta rutina es un buen uso de la técnica disciplinaria. En la entrevista, lejos de observarse una persona dócil en términos políticos, lo que se observa es alguien capaz de respetar acuerdos establecidos con él mismo y con un colectivo, su nivel de previsibilidad le permite despreocuparse de cuestiones para enfocarse en el verdadero asunto y funcionar en un colectivo. Por otro lado este orden de base le permite un aumento en su potencial creativo, a él y al equipo, que puede contar con la seguridad y previsibilidad que el accionar disciplinado permite.

El deportista que se ajusta demasiado a la normativa corre el riesgo de perder vigor y agresividad pero, si se extralimita y rompe las reglas, el resultado también es negativo. El asunto es sostener esa tensión.

La dimensión política se pone en juego tanto en el deporte como en la vida, cristalizándose en las relaciones con el otro. Las mismas tejen una red entre acuerdos y diferencias donde lo político aflora.

La crisis de autoridad generalizada, la desconfianza, el individualismo constituyen, entre otras cosas, la trama social en la actualidad. La regresión de la confianza se visibiliza en tres grandes campos: el científico, el económico y el social. Respecto al científico se puede decir que (en la segunda mitad del siglo XX) la desconfianza en la tecnología aumentó, sea por el potencial o por el uso irresponsable de ese potencial. Sin embargo, la demanda a los científicos no deja de manifestarse ante los problemas de causas tecnológicas donde no hay más alternativa que recurrir

${ }^{60}$ Disponible en https://www.youtube.com/watch?v=s5nUNCPFA6k 
nuevamente a ellos. En cuanto a la economía parecería no haber seguridad alguna; las repetidas crisis, la flexibilidad laboral y la recesión son ejemplo de ello.

Hay una fuerte identificación con el deporte, primero porque resulta que su estructura articula muy bien con la lógica capitalista y además porque es su producto y hoy también su productor. Entonces la competitividad que se manifiesta en el juego o la gimnasia puede que se corresponda con la estructura del deporte, pero tanto más significativa es la influencia de otras esferas mucho más amplias, como la economía y la política.

\section{REFLEXIONAR SOBRE EL DEPORTE}

Parece ser menos riesgoso presentar un mundo del que no se está seguro (pero del cual todos como adultos se hacen cargo) a no presentar nada. Al correrse de este lugar, se desdibuja el rol de adulto y, por ende, se opaca toda posibilidad de resistencia.

Las relaciones intergeneracionales no hacen más que refrescar esta imagen de adultos que no se hacen cargo del mundo que dejan a los nuevos, profesores que enseñan pensando que en realidad los nuevos saben más que ellos. Ante esto vale la pregunta: ¿qué es saber de fútbol?, ¿es solo el dominio de la pelota y la habilidad de superar rivales? Se ha mostrado que saber de fútbol (y de cualquier práctica corporal), al menos si se piensa en clave educativa, refiere a algo más interesante y complejo como son los modos en los que se relacionan las personas entre ellas, con las cosas y consigo mismas.

El caos o el desorden genera incertidumbre y, en términos deportivos, esto se pone en juego en todos los niveles de la práctica en cuestión. La disciplina positiva se comprende como resultado de un acuerdo colectivo y la seguridad que brinda el respeto de estos acuerdos garantizará un cuerpo disponible a las acciones que la práctica requiere; además, un funcionamiento equilibrado de fuerzas que se

ponen en tensión con una ética de la libertad, tanto en la enseñanza como el entrenamiento. 
(...) al fin de cuentas el objetivo de la formación podría ser, más allá de todo lo que acabamos de decir, formar gente que tenga convicciones profundas y que no cambie de idea como cambia el viento. Seres que tengan sentido de la responsabilidad respecto de las consecuencias de sus propios actos, ya sean consecuencias respecto de sí mismos, ya sean consecuencias del impacto de sus actos en la vida cotidiana de todos los demás. Si se logra esto podríamos decir que el contrato de formación ha sido cumplido en gran medida (Enríquez, 2009: 110).

Es necesario matizar las palabras de Enríquez: que no cambie de idea como el viento, pero que sea capaz de hacerlo si la situación lo requiere.

La relación de enseñanza, que es una relación de autoridad, debe contemplar en las técnicas disciplinarias herramientas para fortalecer los acuerdos colectivos, destacando y mostrando tanto los efectos nocivos como los positivos que puede tener el respetar o no estos acuerdos. Así como también debe mostrar los efectos que la libertad negativa puede tener, cuando se piensa en función de estos acuerdos y cuando no se piensa en ellos.

La práctica de un deporte requiere compromiso: para entrenar, para aprender, para controlarse, presentarse a una determinada hora, escuchar, leer, mirar. Si la persona es disciplinada sus compañeros saben que llegará a horario, que cumplirá un rol, que se controlará, cuidará, entrenará y que se preocupará.

Estas cuestiones no son otra cosa que el telón de fondo sobre el que transcurre la relación de enseñanza en la práctica deportiva. La disciplina como apoyo del gesto eficaz se reconfigura y se amplía a la disciplina como apoyo de una práctica eficaz. En los niños y jóvenes debe ser el adulto quien garantice, por regulación, que esto ocurra.

Ahí radica el potencial educativo del deporte cuando se puede trabajar para reflexionar, repensar y hacer de la práctica deportiva una experiencia sobre el 
respeto de los acuerdos y su dimensión política en su momento mimético que es la competencia misma, tanto o más importante lo es en los momentos de formación donde esas técnicas deben ser enseñadas.

La mimesis del juego, que refiere en gran medida al jugador, hoy también impacta sobre todo en el espectador, ese al que también se debería enseñar y educar. Cuando se piensa en la enseñanza de la práctica deportiva es fundamental la construcción de criterios para pensarla. El futuro espectador debe ser educado para poder cuestionar el deporte, apreciar el juego y disfrutar de una práctica corporal.

Para sostener el equilibrio en la disciplina, entre sus dimensiones positiva y negativa, entre la libertad positiva y negativa, entre la autoridad y el autoritarismo, es necesario respetar ciertas leyes y, para ello, en la relación de enseñanza se encuentra el mundo adulto, del cual el profesor es el garante. En la entrevista realizada a Fernando Signorini en el programa televisivo La llave del gol, emitido por Fox Sports el día 12 de septiembre de 2016, se muestra de manera clara un efecto de la ausencia de educación:

(...) la instrumentalización del deportista de los últimos años ya cae en situaciones que a mí me parecen tragicómicas. Y los jugadores, como siempre, agachan la cabeza porque nadie se preocupa porque se rebelen y la levanten y digan sus cosas, porque el que lo intenta corre muy mala suerte y nadie los educa porque educarlos es peligroso (...). ${ }^{61}$

La disciplina bien puede ser una de las herramientas que libere del estado de minoridad y otorgue la libertad que solo ofrece la responsabilidad. Después de todo, no solo se trata de dar libertad, sino de dar lo necesario para hacer uso de esa libertad.

${ }^{61}$ Disponible en https://www.youtube.com/watch?v=SxOi4sDr2Tk 
Se ha mostrado un problema actual y las alternativas posibles para abordarlo, tanto desde la lógica que permite razonamientos posibles, como la precisión terminológica que hace de un concepto una herramienta.

Se usó como punto de anclaje la práctica deportiva y la disciplina para pensar en técnicas fundamentales para educar, no entendiendo por educación un dominio absoluto, sino el otorgamiento de libertades (o libertad). Las técnicas disciplinarias que ponen orden no se legitiman en la autoridad de quien comanda sino en el acuerdo colectivo que las sostiene. En este sentido, la autonomía supone la libertad de someterse a la ley. Es este sometimiento el que habilita la posibilidad de elegir, tanto a partir de conocer los riesgos y los beneficios, como de hacer balances en función de las posibilidades que brinda valorar lo hecho y lo conseguido.

La educación en la práctica deportiva es mucho más que el desarrollo técnico sumado al de las capacidades fisiológicas. Debería formar ciudadanos que estén habilitados para participar de una práctica deportiva, sea como jugadores, dirigentes, profesores, padres, espectadores, etc.

En estos términos, la disciplina es liberadora. Tanto en el deporte como en la vida el orden puede hacer la diferencia, que el otro pueda tener certidumbre respecto a mi comportamiento permite el desarrollo de las relaciones y establece las bases para un proyecto en equipo. Como bien expone Luis Scola (en la entrevista previamente citada) la disciplina es el apoyo para el gesto eficaz, el poder despreocuparse de algunas cuestiones gracias a la rutina admite mejores posibilidades de atención, propia y de los otros. En este sentido, la importancia del detalle y el orden radica en su potencial liberador. Parafraseando a Popovich (en la charla registrada en el documental Campeones al descubierto) son pequeñas cuestiones disciplinarias que hacen la diferencia entre ganar y perder el juego.

La disciplina equilibra las tensiones entre la libertad negativa y la positiva en términos deportivos, pero también en cualquier emprendimiento colectivo. La tensión certidumbre-incertidumbre se pone en juego en la medida en que se 
pueden establecer relaciones de confianza con los demás, con uno mismo y con lo que se está haciendo. Si todo es caos los proyectos colectivos pierden su potencial por verse sumidos en el miedo. El riesgo que supone la inestabilidad y la incertidumbre opacan y hasta anulan cualquier proyecto colectivo.

Lo fundamental en los deportes es generar certidumbre interna e incertidumbre externa. Que el equipo sea lo más previsible a nivel interno (cuando todos saben a qué juegan) y lo más impredecible para el oponente (a partir de generar desconcierto). Puede observarse cómo el sometimiento a la ley tiene efectos liberadores. La disciplina (que ordena el juego) es la que abre el espacio para la manifestación de la acción creativa. Esta acción individual no es individualista, sino que se da en función de una estrategia colectiva. Por ello se dice que la disciplina es el apoyo del gesto eficaz y también que sujetarse a estas cadenas libera de cadenas más pesadas. 


\section{CONCLUSION}

Un deporte educativo es posible con la disciplina como condición necesaria para garantizar el buen funcionamiento de la práctica y una acción eficaz. La práctica deportiva requiere personas civilizadas; quienes ofician como jugadores, espectadores y todos aquellos que practican el deporte deben sostener las tensiones elevadas entre las diferentes polaridades que estructuran sus funcionamientos sin que ninguna se rompa. Esto fue así en los inicios de la modernidad y puede observarse en la actualidad.

En este sentido, respecto al ensayo: Dinámica de los grupos deportivos con especial referencia al fútbol, del libro Deporte y ocio en el proceso de la civilización, escrito por Norbert Elias y Eric Dunning (1992: 28), éste menciona en su prefacio:

Este ensayo critica la tendencia vigente a ver los procesos sociales de cooperación y competición, armonía y conflicto, como los dos polos opuestos de una dicotomía, y conceptualiza los grupos deportivos como 'grupos en tensión controlada', en los cuales hay que imponer un 'equilibrio de tensiones', entre los contrarios de un 'complejo de polaridades interdependientes'. 'La dinámica del deporte moderno' trata de profundizar en esta teoría del deporte, pero constituye principalmente un intento de elaborar una explicación figuracional y desarrollista de la importancia social cada vez mayor que cobra el deporte en las sociedades modernas y de la creciente tendencia del deporte en tales sociedades a caracterizarse por la búsqueda del éxito.

Equilibrio de tensiones que se logra, en parte, gracias al respeto por los acuerdos colectivos que permite la disciplina mediante un trabajo sobre las libertades (positiva y negativa). El equilibrio de éstas garantiza mayor productividad en términos de juego social y supone un aumento en las fuerzas políticas en tanto que la disciplina es parte de los acuerdos colectivos que contribuye a la formación 
del ciudadano ideal (respecto a las relaciones con el saber, con los otros y consigo mismo).

La conceptualización de deporte que aquí se amplía encuentra en su transmisión como contenido educativo un carácter transformador que permite trabajar sobre las tensiones entre las libertades. Éste se construye, en parte, con la disciplina como acuerdo colectivo, garante de la organización individual y colectiva en la que la libertad es una relación a sostener y no un estado a conseguir. Esta interpretación permite separarla de la mirada estigmatizante y estigmatizadora con la que se ha dotado al concepto en distintos momentos en los que ha mutado a estados de dominación, al tiempo que obliga a sostener una vigilancia permanente que regule el dispositivo y sostenga las tensiones equilibradas.

Esto nos permite afirmar nuestra hipótesis de trabajo: la disciplina es condición necesaria para ser un buen practicante e insoslayable en los procesos de formación y educación en tanto ordena al sí mismo en relación con el saber, con los otros y consigo mismo.

La relación entre disciplina y deporte es inextricable, no hay deporte sin disciplina, en tanto que el deporte se estructura mediante mecanismos disciplinarios. Así lo muestra el necesario autocontrol sobre las emociones en el plano individual y la asignación de roles para el funcionamiento en redes de interdependencia en el plano colectivo.

La disciplina resignifica al deporte y lo reivindica como medio para la educación y la transformación hoy. Un deporte que, en tanto contenido educativo, supone superar las polaridades y equilibrar las tensiones entre las dos dimensiones de la libertad donde se hace necesaria también una indisciplina, un descontrol controlado, en cualquiera de las formas que adquiere el deporte y en todos sus ámbitos de desarrollo.

Reflexiones en torno a la tecnología disciplinar en la práctica deportiva da cuenta sobre lo indeterminado de la práctica: la tecnología disciplinaria, que es un conjunto de técnicas, así como también una táctica política como acuerdo 
colectivo. En estos términos, esta tecnología hace al arte de gobernar que alcanza la práctica deportiva en su totalidad y opera en tres niveles: las relaciones con el saber, los otros y consigo mismo.

Un deporte pensado en clave educativa debería formar deportistas que sepan jugar dentro y fuera de la cancha. El deporte para ser educativo deber ser pensado como tal $\mathrm{y}$, en este proceso, la disciplina tiene una participación sustantiva. Estas técnicas que hacen a la mecánica disciplinaria se observan en algunos casos dentro del alto rendimiento y parecen desvanecerse cuando se trata del deporte con niños y jóvenes en cualquier ámbito de enseñanza, como ha podido observarse en el caso de laboratorio aquí citado y a partir de ejemplos de trabajos que nos anteceden, lo cual complementa esta visión y construye un punto de observación de una realidad posible.

Ser mejor o buen practicante implica poner atención, interés, deseo de aprender, predisposición a la escucha, a la ayuda, a la protección del otro, a la pregunta, a la búsqueda de precisión, a la acción (que haga, que intente, que pruebe) y al pensamiento (que cuestione, que reflexione para sí y con los demás -y con el saber-), que construya y avance, que cuestione las relaciones de saber, poder y ética, es decir, las relaciones con el contenido, los otros y con uno mismo. Mientras que, como educadores, deberíamos brindar las condiciones y herramientas necesarias, asumir el lugar de adulto y el rol de autoridad necesaria para su buen funcionamiento.

Desentramar las lógicas que construyen el deporte hoy es preguntarse sobre cuál es la práctica deportiva que se conoce y por qué; también qué lugar ocupa la reflexión crítica sobre esta práctica en las clases, particularmente en el proceso educativo.

El mercado y las lógicas que produce dan cuenta de cómo se construyen sentidos en torno al deporte y que se comparten socialmente, en tanto forman parte de su construcción a los cuales se accede, por ejemplo, mediante lo que muestran los grandes medios de comunicación (a través de la televisión, radios, diarios, revistas e Internet, por ejemplo). Estos sentidos circulan y se instalan, dan forma a esos 
imaginarios que cargan consigo representaciones del mundo y de una cultura en ese momento y no en otro.

La formación deportiva que se limita a la enseñanza de capacidades y técnicas poco colabora con la formación del deportista y menos aún con la educación del ciudadano. Para ello debería incluir y reflexionar sobre las relaciones que se establecen con el saber, entre las personas y con uno mismo, lo que hace del deporte un contenido educativo.

Un ejemplo de la escuela de fútbol San José muestra los alcances de este movimiento: hace años que Juan (13 años) concurre a la escuela de fútbol y al mismo tiempo juega en un club de la liga platense. En San José siempre ha preferido jugar de delantero mientras que en aquel club de la liga lo hace de lateral defensivo. Un día llega a la escuela y le cuenta a su entrenador que está jugando de 4. El entrenador le dice que está muy bien y le pregunta si quiere entrenar de 4, con la condición de que en el partido juegue de 4. A Juan le gusta la idea y entrena según el plan. El sábado San José juega de local y Juan ocupa la posición de lateral. A la mitad del primer tiempo el equipo visitante hace un gol, a lo que el padre de Juan le grita al entrenador: ¡Ponelo de 9!, ¡no sabe jugar de 4! Pasados unos minutos de la jugada el entrenador le responde que Juan quiere jugar de 4 y que "lo están trabajando", haciendo referencia a la posición y al desempeño del jugador, además agrega que es una buena oportunidad para que aprenda a jugar en más posiciones. Lo más importante no estaba ahí, sino en lo que el padre, enfurecido, agrega: ¡Ya son grandes para aprender! Tales son los alcances de esta formación deportiva que criticamos.

El rendimiento deportivo supone la especialización, el dominio de un sistema y el ganar, en momentos en los que además debería pensarse en la educación y en la formación general. El problema es el costo que implica hipotecar la formación del deportista. Este se genera cuando se copia lo que se hace en el alto rendimiento y no se escucha o se mal interpreta lo que éste dice respecto a lo que debería hacerse en momentos de formación. El pensamiento asocia rápidamente la 
preparación con el producto y supone que esa preparación sirve para cualquier persona y para cualquier momento.

Pierre Parlebás escribe en su blog personal el día 8 de diciembre de $2009^{62}$.

Con relación al deporte (...) la escuela debe tomarlo como un medio valioso para educar, dado que su ejemplo está presente en la vida diaria del niño a través de los medios de comunicación; no obstante, debe considerarse como una actividad más de la acción motriz, aunada a todas aquellas que el profesor sea capaz de implementar en su clase.

El autor sostiene que el deporte es un medio valioso para educar, ¿lo es disciplinando positiva o negativamente? Considerar al deporte una actividad más de la acción motriz es negar o no ver su dimensión política, puesto que ninguna acción motriz la tiene.

Si solo se encuentra en el deporte un conjunto de acciones regidas por un reglamento institucionalizado y no se pone en tensión el cómo funciona económica y políticamente (ni se analiza desde una perspectiva crítica) el individualismo, el exitismo y la competitividad serán los factores que darán forma a la práctica y, en consecuencia, a la enseñanza, lo que lo convierte en una amenaza para la educación.

Las observaciones realizadas durante cinco años en la escuela de fútbol San José dan cuenta de la dificultad que radica en las valoraciones del juego. Las situaciones planteadas demuestran que se hacía difícil desplazar la prioridad del resultado por sobre la actuación, tanto de parte de jugadores como de espectadores (entre ellos sus padres). Un ejemplo de ello se describe a continuación: luego de finalizado el partido donde San José había perdido se reúnen profesores, jugadores y algunos de los padres que participaron como espectadores. Durante un minuto y medio no se hizo más que hablar todos al mismo tiempo. Uno de los profesores logra que le cedan la palabra. En ese

\footnotetext{
${ }^{62}$ Disponible en http://pierreparlebas.blogspot.com.ar/
} 
momento les recuerda que la mitad del equipo había jugado dos partidos como mínimo y que el contrario, al finalizar el primer tiempo, cambió al plantel entero; inmediatamente pregunta si habían salido las asociaciones trabajadas en el entrenamiento. La discusión empieza nuevamente, algunos de los primeros comentarios fueron: ¡Si, es cierto!, ¡salieron pero pocas veces!, ¡jugamos mal!, ¡nos faltó correr!, ipero no fue penal!, jel 2 tenia barba!, ese fue el orden de los comentarios. Una vez más, el peso del resultado era más fuerte para los jugadores y también para los espectadores ocasionales.

La amenaza que atenta en contra de la enseñanza de un deporte en términos educativos la muestra vulnerable a una enseñanza posible en tanto contenido de la Educación Física funcional a un sistema que la domina. El problema es considerar que es así necesariamente. Se trata de un movimiento tan sutil que sucede en la profundidad del pensamiento y que impacta en el hacer, pero que no se cuestiona.

Que su carácter mimético motive expresiones descontroladas no implica que éstas necesariamente deban serlo en su totalidad. Parafraseando a Elias (Elias y Dunning 1992) debe conseguirse un descontrol controlado, lo cual no puede quedar desvinculado de la tolerancia a la violencia de un momento y lugar determinado, lo que recuerda una de las series conceptuales elaboradas: mimesis, tolerancia a la violencia y reglas.

Habría que preguntarse si lo que se conoce o se ha entendido como deporte en los momentos llamados de formación son efectivamente educativos. Si el deporte requiere gente civilizada habría que ver si en los espacios de formación se encuentran personas (niños, jóvenes y adultos) que posean estas características y se comporten en consecuencia. Si el deporte tiene reglas que hay que respetar y la situación coyuntural de un grupo aun no admite tales relaciones entonces lo que se puede llevar adelante serán juegos ${ }^{63}$ pero no deporte. Esto recuerda a otra serie elaborada: juego, deporte y gimnasia.

${ }^{63}$ La palabra juego refiere, en este caso, a juegos medievales. 
El control sobre las emociones es una cuestión intrínseca al deporte en la cual radica una de sus potencias educativas. La formación del control en momentos de alta tensión hace al disfrute, ese es el juego de la mímesis, que no es tanto una simulación como una buena actuación, similar a la de un actor al llorar con su personaje sin olvidar que es parte del guión y es precisamente porque conoce y se sujeta a este guión que se puede permitir emocionarse y recorrer zonas nuevas jugando con la interpretación del mismo.

El deporte es, precisamente, esta relación de compromiso e identificación con el personaje del jugador con quien efectivamente juega: juego al fútbol y soy un jugador, respeto las reglas, me paro en el límite, mi agresividad hace equilibrio en el borde que plantean las reglas y el objetivo que me proponen, el otro también interpreta el guión y en conjunto se lleva adelante la obra, que es el partido.

El deporte requiere de acción motriz para realizarse pero es mucho más que eso. Necesita de una interpretación de estas acciones que son más complejas y exceden el carácter motriz. Es esta complejidad la fuente de su potencia educativa. Si solo se piensa en acciones motrices el deporte difícilmente alcanzará objetivos de carácter educativo.

Además las acciones se ponen en juego con una disciplina que coacciona y que implica el respeto de normas y acuerdos que, en principio se encuentran en el reglamento $y$, en segunda instancia, en los acuerdos colectivos propios de un grupo de trabajo. Esto estructura y arma la red de interdependencia en la que se ponen en juego estas acciones. Se ponen en juego ambas dimensiones de la libertad y la tensión entre éstas varía según las circunstancias del juego. En este marco el jugador toma decisiones poniendo en juego la dimensión negativa.

En el fútbol actual (y por lo general en gran parte de los deportes colectivos) existe una tendencia a trabajar en conjunto las dimensiones de la práctica como la preparación física, la táctica y la técnica, algo de esto menciona De Marziani cuando plantea la lógica empirista en los espacios de formación de fútbol infantil donde se ven trabajos que emulan la realidad observable en el alto rendimiento. 
Respecto a las entrevistas realizadas a entrenadores, De Marziani (2014: 48) menciona que: "A la hora de consultárseles como enseñan su deporte, la mayoría responde que lo hacen teniendo en cuenta la técnica, la táctica o la estrategia; otros consideran al juego -entendido como el 7 vs. 7 - y a la participación como los aspectos fundamentales; mientras que un grupo menor considera la disciplina que el deporte puede engendrar, los principios que orientan su enseñanza. En este sentido, se considera la disciplina como una regulación de las conductas a partir de ciertas normas de comportamiento a través de la práctica del fútbol".

El deporte supone un juego asociado, aun con el oponente, sumamente complejo cuyas características no son (no todas) apreciables a la vista. Tal como plantea Marcelo Bielsa, en un fragmento de la ponencia que grabó para la Aspire Academy, en torno a los distintos tipos de desmarque y tareas de entrenamiento:

(...) esto tiene un sinfín de normas, yo tengo que hacer un movimiento previo para llevar al jugador defensa a un lugar donde a él le resulte más incómodo ir, hacia donde yo ya decidí que voy a ir. Por eso, el juego asociado que parece que no tiene normas, tiene infinidad de normas que uno debe enseñarle a un jugador $(\ldots)^{64}$.

La dificultad radica en que hoy se destacan goles, jugadas técnicamente espectaculares, un caño, una gambeta, una rabona, algún firulete, pero rara vez se festeja un desmarque y nunca un desmarque de desmarque, que Bielsa en la ponencia lo explica como: “(...) el que desmarca esta desmarcando, no para el que la tiene sino para el que la recibe, y eso el rival no lo puede leer".

Otro criterio es el que podemos encontrar en la entrevista realizada por los periodistas Sebastián Varela del Río y Ezequiel Scher al ex jugador de fútbol Pablo Aimar en el diario Página /12, publicada el día 15 de julio $2017^{65}$, donde,

\footnotetext{
${ }^{64}$ Disponible en https://www.youtube.com/watch?v=B6YINZO bGM

${ }^{65}$ Disponible en https://www.pagina12.com.ar/50137-somos-la-ultima-generacion-que-ve-partidos$\underline{\text { enteros }}$
} 
ante la pregunta en torno a cómo se aplica ese individualismo al juego, Aimar responde:

El equipo de fútbol que consigue evitar ese pensamiento individual, prevalece. Es que hay una pelota y veintidós tipos y cada uno la toca tres minutos sobre noventa. Es decir que cada uno juega ochentaisiete minutos sin la pelota. Entonces, si vos conseguís moverte para que el gol lo haga un compañero, sos un genio. Si vos conseguís darle una solución al compañero y que él salga en la tapa y vos ni pintes, bárbaro, jugás para el equipo. Al final, los mejores jugadores de fútbol son los que hacen jugar bien al otro.

Esta cita muestra el carácter relacional de las acciones del juego, en las que la comunicación, el sistema y los demás acuerdos previos son la diferencia entre jugar a la pelota y jugar al fútbol. Sin embargo la diferencia radica entre un modelo de formación deportiva cuyo objeto de enseñanza es la práctica deportiva como objeto de consumo y un modelo de formación que hace de la práctica deportiva su objeto de enseñanza, interpretado como contenido educativo.

La búsqueda de resultados en edades tempranas atenta contra el proceso formativo. Si lo que se pretende es ganar hoy, por ejemplo, lo mejor es enfocarse en el dominio acabado de un sistema, si se trabaja es probable que se pueda ganar el torneo sub 13 , el sub 14 , el sub 15 , pero qué pasa cuando un entrenador empieza a trabajar con uno de estos jugadores y resulta que éste solo conoce un sistema y se especializó tanto que no puede salir de ahí. En palabras del ex director técnico argentino, César Luis Menotti, entrevistado en el programa La llave de-I gol, emitido el día 26 de septiembre de 2016: “(...) yo dije un día que el $90 \%$ de los jugadores no sabe jugar al fútbol (...)"66.

Esto va en línea con la apreciación de Julio Velasco respecto a la diferencia entre jugar a la pelota y jugar al fútbol, sin embargo, si bien se puede utilizar para

${ }^{66}$ Disponible en https://www.youtube.com/watch?v=e3lqoCLeOZQ 
pensar en aquellos que se dedican al deporte también se aplica para quienes lo utilizan como actividad de ocio, como espectadores o practicantes amateurs.

Educar en el deporte y para el deporte resulta más significativo cuando se pone en juego no solo el saber jugar sino el saber participar o, en términos más generales, el saber desempeñarse en la práctica deportiva, así lo confirman las observaciones hechas en la escuela de futbol San José cuando muestran los comportamientos de algunos padres en los diferentes partidos donde protestan fallos arbitrales en gran cantidad pero rara vez reconocen un buen fallo, se lamentan efusivamente cuando un jugador comete un error y con la misma efusividad lo exaltan cuando lo hace bien, inducen a la agresividad, por ejemplo. Claramente significativo resulta esto si consideramos que en la actualidad la Asociación del Fútbol Argentino (AFA) no admite público visitante en el torneo local debido a los reiterados problemas relacionados a la violencia entre los espectadores.

No hay deporte sin disciplina, porque éste requiere gente educada no tanto porque sea lo correcto, que lo es, sino porque es lo mejor para la práctica. El deporte en tanto derecho del ciudadano debe ser devuelto a la sociedad no ya como un bien a consumir ni como un producto más en el mercado internacional sino como actividad lujosa. Una práctica que, en vez de estandarizar o de universalizar, de particularizar en pos del sostén de la dinámica de consumo, habilite el sentirse bien con la propia particularidad y una relación armónica con los otros.

De esta forma, el deporte en términos educativos no puede ser interpretado como un bien de consumo o como un servicio, sino como una práctica lujosa, como algo que -de hecho- no tiene mayores consecuencias, ya que no es más que un juego. Esto no implica que el deporte sea cualquier cosa, sino todo lo contrario. El deporte se practica porque si, porque se tiene tiempo, no es algo importante por su utilidad. No se puede suponer que sólo porque se practica deporte se incorporan valores, no hay un desarrollo natural que se produzca a partir de la práctica del mismo sino que la elaboración de valores éticos depende de cuál es el deporte que hacemos, pensamos y decimos. 
Esta práctica deportiva, que es también corporal ya que toma por objeto al cuerpo, supone la pregunta por el cuerpo y por la educación del cuerpo. Pensar la educación en el deporte implica reflexionar acerca de las tensiones entre la individualidad y el individualismo que caracterizan a las sociedades actuales.

El individualismo no puede confundirse con la individualidad que produce la disciplina, la racionalidad que sostiene cada una es drásticamente diferente. El individualismo empuja hacia y sostiene el olvido del otro. Desde la lógica del mercado el otro se constituye como el enemigo, aquel que hay que destruir, cuando en el deporte esperamos todo lo contrario. La espectacularidad de un clásico no es sino con la presencia de dos adversarios tradicionales y, en este sentido, el otro no solo es una opción, es fundamental y necesario. La lógica deportiva implica una individualidad, pero ésta no puede socavar los intereses colectivos.

La disciplina elabora la individualidad asignándole un rol que funciona en un equipo para el que es funcional $y$, de hecho, la disciplina opera articulando esta individualidad en lo que Foucault (2009) describe como una de las grandes operaciones de la disciplina, la constitución de cuadros vivos, los cuales ordenan las individualidades para sacar de ellas mucho más que la suma de las partes.

El individualismo opaca este último movimiento haciendo de un solo jugador un cuadro vivo. La formación de deportistas adquiere así un carácter productivo que funciona a los fines del mercado, el deportista como producto de la industria y como objeto de consumo, que es más que ejercicios de gustos, antojos y acciones irreflexivas, es el lugar donde ocurren los procesos socioculturales en que se realizan la apropiación y los usos de los productos. Importa fabricar o descubrir buenos jugadores y serán buenos en tanto y en cuanto muestren resultados individuales.

Estos desplazamientos del pensamiento muestran la dirección de procesos que hemos ido desnaturalizando. Tal como escribe Elías (1994: 52): 
Bien pudiera ser que, en el futuro consiguiéramos una comprensión más clara que nos ayudase a orientar estos procesos que hoy se desarrollan en nosotros y en torno a nosotros de un modo no muy distinto al de los fenómenos de la naturaleza y frente a los cuales nos encontramos en la misma situación que los hombres medievales frente a las fuerzas naturales.

En esta desnaturalización encontramos herramientas para orientar los procesos de enseñanza. El dispositivo disciplinario en el deporte que opera bajo la lógica que produce el mercado funciona como un dispositivo que aumenta las fuerzas productivas y anula las políticas. Una práctica deportiva que se vuelve lujosa trabaja con aspectos éticos que permiten, al hacer del dispositivo disciplinario una técnica de sí, una serie de técnicas que habilitan una práctica ascética, pero no en el sentido restringido de renuncia, sino en una práctica mesurada y controlada (Foucault, 1999). Aspectos que resultan fundamentales en todo proceso de enseñanza con fines formativos y educativos.

Reflexiones sobre la tecnología disciplinar en la práctica deportiva invita a tomar el asunto sobre la educación del deporte para comprender cuáles son los sentidos que atraviesan los procesos de enseñanza hoy e inextricablemente el estudio sobre la disciplina como condición de posibilidad a los fines de perseguir el cumplimiento de objetivos de formación y educación.

El deporte entendido como práctica supone un contenido que rompe el sentido llano del término y lo transforma en algo más cercano a la dinámica compleja de las relaciones con los otros. Es la disciplina como herramienta de la enseñanza la que garantiza el equilibrio de las tensiones que habilitan el deporte educativo y es ésta una característica central en la formación del deportista y, sobre todo, del ciudadano. 


\section{BIBLIOGRAFIA}

Agamben, G. (2004). Estado de excepción. Buenos Aires: Adriana Hidalgo.

Arendt, H. (1977). Entre el pasado y el futuro. Londres: Penguin Books.

Arendt, H. (1997). ¿Qué es la política? Buenos Aires: Ediciones Paidós.

Arendt, H. (2010). La condición humana. Buenos Aires: Ediciones Paidós.

Bachelard, G. (2000). La formación del espíritu científico. Buenos Aires: Siglo XXI.

Barbero González, J. I. (ed.) (1993). Materiales de sociología del deporte. Madrid: Ediciones de la Piqueta.

Barcia, R. (1945). Diccionario General Etimológico de la Lengua Española. Buenos Aires: Editorial Anaconda.

Berlín, I. (1998). Cuatro ensayos sobre la libertad. Madrid: Alianza Editorial.

Bielsa, M. (2015). Los 11 caminos al gol. Buenos Aires: Sudamericana.

Bobbio, N. (1992). Liberalismo y democracia. Buenos Aires: Fondo de Cultura Económica.

Bobbio, N. (1993). Igualdad y libertad. Barcelona: Ediciones Paidós.

Bobbio, N. (1998). La duda y la elección. Intelectuales y poder en la sociedad contemporánea. Barcelona: Ediciones Paidós.

Bobbio, N. (2006). Estado, gobierno y sociedad: por una teoría general de la política. México: Fondo de Cultura Económica.

Bourdieu, P. (1990). Sociología y Cultura. México: Editorial Grijalbo.

Cagigal, J.M. (1957). Hombres y deportes. Madrid: Taurus.

Cagigal, J.M. (1975). El deporte en la sociedad actual. Madrid: Editorial Prensa Española.

Cagigal, J.M. (1979). Cultura Intelectual y Cultura Física. Buenos Aires: Kapelusz.

Carballo, C. (2015). Diccionario Crítico de la Educación Física Académica: rastreo y análisis de los debates y tensiones del campo académico de la educación física en Argentina. Buenos Aires: Prometeo.

Castro, E. (2011). El vocabulario de Michael Foucault. Buenos Aires: Universidad Nacional de Quilmes.

Corominas, J. (1983). Breve diccionario etimológico. Madrid: Gredos. 
Crisorio, R. (2014). Formación inicial de educadores corporales: estudio para la elaboración del plan de estudios. Instituto de Investigaciones en Humanidades y Ciencias Sociales. Facultad de Humanidades y Ciencias de la Educación. Universidad Nacional de La Plata.

De Marziani, F.A. (2014). Fútbol infantil: Conflictos, tensiones e intereses de una práctica institucionalizada. El caso de la liga LISFI de la ciudad de La Plata (Tesis de Maestría). Facultad de Humanidades y Ciencias de la Educación. Universidad Nacional de La Plata. Disponible en http://www.memoria.fahce.unlp.edu.ar/tesis/te.1052/te.1052.pdf

Diem, C. (1966). Historia de los deportes. Barcelona: Luis de Caralt.

Durvan. (1965). Gran enciclopedia del mundo. Bilbao: Editorial Marín.

Elias, N. (1994). El proceso de la civilización. Investigaciones sociogenéticas y psicogenéticas. México: Fondo de Cultura Económica.

Elias, N. y Dunning, E. (1992). Deporte y Ocio en el proceso de la civilización. Buenos Aires: Fondo de Cultura Económica.

Enríquez, E. (2009). "Educación y Formación. Aportes de una teoría de la Institución y las organizaciones", en Serie Los documentos de la carrera de Formación de Formadores. Buenos Aires: Facultad de Filosofía y Letras de la Universidad de Buenos Aires.

Federación Internacional de Football Asociación (FIFA). (2015). Reglas del juego FIFA. Disponible en https://es.fifa.com/mm/document/footballdevelopment/refereeing/02/36/01/1 1/lawsofthegamewebes_spanish.pdf

Foucault, M. (1979). Microfísica del Poder. Madrid: Ediciones La Piqueta.

Foucault, M. (1991). El orden del discurso. Madrid: Ediciones La Piqueta.

Foucault, M. (1994). “¿Que es la ilustración?”, en Revista Actual (28). Ediciones La Piqueta.

Foucault, M. (1996). Genealogía del Racismo. La Plata: Editorial Altamira.

Foucault, M. (1999). Estética, ética y hermenéutica. Barcelona-Buenos Aires: Editorial Paidós. 
Foucault, M. (2006). Seguridad, territorio y población. Buenos Aires: Fondo de Cultura Económica.

Foucault, M. (2008a). Historia de la Sexualidad 3. Argentina: Siglo XXI.

Foucault, M. (2008b). Las palabras y las cosas. Una arqueología de las ciencias humanas. Buenos Aires: Siglo XXI

Foucault, M. (2009). Vigilar y Castigar. Madrid: Siglo XXI.

Foucault, M. (2013). La Inquietud por la verdad: Escritos sobre la sexualidad y el sujeto. Buenos Aires: Siglo XXI.

Freire, P. (2007). La educación en la ciudad. México: Siglo XXI.

Gallino, L. (1995). Diccionario de sociología. México: Siglo XXI.

García Canclini, N. (1995). Consumidores y ciudadanos: conflictos multiculturales de la globalización. México D.F: Grijalbo.

Giorgi, G. y Rodríguez, F. (comps.). (2007). Ensayos sobre política. Excesos de vida. Buenos Aires: Editorial Paidós.

Gramsci, A. (2011). Odio a los indiferentes. Barcelona: Editorial Planeta.

Gruschetsky, M. (sf). Apuntes para una definición del concepto deporte. Disponible en https://es.scribd.com/doc/52369548/Gruschetsky-Apuntessobre-el-concepto-de-deporte

Heidegger, M. (1994). Conferencias y artículos. Barcelona: Ediciones del Serbal.

Heinich, N. (1999). Norbert Elías. Historia y Cultura en Occidente. Buenos Aires: Nueva Visión.

Hernández Mendo, A. (1999). "Acerca del término deporte", en revista Educación $\begin{array}{llllll}\text { Física } \quad y \quad \text { Deportes, } 4 & \text { (17). Disponible en }\end{array}$ http://www.efdeportes.com/efd17/deporte.htm

Heisenberg, W. (1994). La imagen de la naturaleza en la física actual. Madrid: Proyectos Editoriales y Audiovisuales.

Hobbes, T. (1999). Tratado sobre el ciudadano. Madrid: Editorial Trotta.

Horkhaimer, M. y Adorno, T. (1998). Dialéctica de la Ilustración. Madrid: Editorial Trotta.

Kitto, H.D. F. (2007). Los griegos. Buenos Aires: Eudeba.

Koyre, A. (1987). Estudio de historia del pensamiento científico. México: Siglo XXI. 
Koyre, A. (1994). Pensar la Ciencia. Barcelona-Buenos Aires-México: Ediciones Paidós.

Lacan, J. (2005). El Triunfo de la Religión. Buenos Aires: Ediciones Paidós.

Lacan, J. (1971). Escritos 1. España: Siglo XXI.

Lacan, J. (2007). Mi enseñanza. Buenos Aires: Ediciones Paidós.

Lakatos, I. (1978). La metodología de los programas de investigación científica. Madrid: Alianza Editorial.

Márquez Guanipa, J.; Díaz Nava, J. y Cazzato Dávila, S. (2007). "La disciplina escolar: aportes de las teorías psicológicas", en Revista de Artes y Humanidades UNICA, 8 (18), pp. 126-148.

Mata, M.C. (2010). "De la cultura masiva a la cultura mediática", en Diálogos de la comunicación, pp. 80-91. Disponible en https://es.slideshare.net/guest062c6d/mara-cristina-mata

Míguez, H. (2008). "Alcohol y sociedad 'líquida'", en Crepúsculo, pp. 7-10 Disponible en $\quad$ http://www.fundaciontrespinos.org/wpcontent/uploads/2014/06/6.pdf.

Morgan, E.S. (2006). La invención de un pueblo. El surgimiento de la soberanía popular en Inglaterra y Estados Unidos. Buenos Aires: Siglo XXI.

Olivera Betrán, J. (2006). "Hacia una nueva comprensión del deporte. Factores endógenos y exógenos", en Revista Apunts, 86. Disponible en http://www.revista-apunts.com/es/hemeroteca?article=98

Olivera-Betrán, J. y Torrabadella-Flix, X. (2015). "Del sport al deporte. Una discusión etimológica, semántica y conceptual en la lengua castellana", en Revista Internacional de Medicina y Ciencias de la Actividad Física y Deporte, $\quad 15 \quad$ (57). $\quad$ Disponible en http://cdeporte.rediris.es/revista/revista57/artsport530.htm

Orwell, G. (2007). 1984. Barcelona: Ediciones Destino.

Parlebas, P. (2001). Juegos, Deportes y Sociedades. Léxico de praxiología motriz. Barcelona: Ed. Paidotribo.

Pascal, B. (2015). Pensamientos. Madrid: Editorial Alianza. 
Cuerpo y Mente Deportes. (1988). "Si existen límites, ¿dónde están?", en revista Cuerpo y Mente Deportes, 4 (33).

Robles Rodríguez, J., Abad Robles, M.T. y Giménez Fuentes-Guerra, F.J. (2009). "Concepto, características, orientaciones y clasificaciones del deporte actual", en revista Efdeportes, 14 (138). Disponible en http://www.efdeportes.com/efd138/concepto-y-clasificaciones-del-deporteactual.htm

Rosanvallon, P. (2007). La Contrademocracia: La política en la era de la desconfianza. Buenos Aires: Editorial Manantial.

Rousseau, J.J. (1993). El contrato social. Barcelona: Ediciones Altaya.

Sábato, E. (1998). Antes del fin. Buenos Aires: Seix Barral.

Taylor, S.J. y Bogdan, R. (1996). Introducción a los métodos cualitativos de investigación. Barcelona: Ediciones Paidós.

Toro, B. y Tallone, A. (coord.). (2011). Educación, valores y ciudadanía. Metas Educativas 2021: La educación que queremos para la generación de los bicentenarios. Madrid: Fundación SM y Organización de Estados Iberoamericanos para la Educación, la Ciencia y la Cultura.

Valles, M. (1999). Técnicas cualitativas de investigación social. Reflexión metodológica y práctica profesional. Madrid: Síntesis Sociológica.

Velázquez Buendía, R. (2001). "El deporte moderno. Consideraciones acerca de su génesis y de la evolución de su significado y funciones sociales", en $\begin{array}{lllll}\text { revista Efdeportes, } & 7 & \text { (36). Disponible en }\end{array}$ http://www.efdeportes.com/efd36/deporte.htm

Wacquant, L. (1999). "Un arma sagrada. Los boxeadores profesionales: capital corporal y trabajo corporal", en Auyero, J. Caja de herramientas. El lugar de la cultura en la sociología norteamericana. Buenos Aires: Universidad Nacional de Quilmes.

Weber, M. (1997). El político y el científico. Madrid: Alianza Editorial.

Wiegorek, E. (1978). Solidaridad Olímpica. Problemas en la organización y la dirección del deporte. Madrid: Instituto Nacional de Educación Física. 